\title{
A Bioorthogonal Near-infrared Fluorogenic Probe for mRNA Detection
}

Haoxing $\mathrm{Wu}^{\ddagger}$, Seth C. Alexander ${ }^{\ddagger}$, Shuaijiang Jin, and Neal K. Devaraj*

Department of Chemistry and Biochemistry, University of California, San Diego, La Jolla, California 92093, United States. 


\section{Supplementary Information}

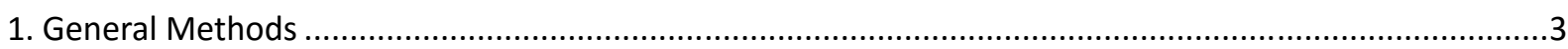

2. Probe synthesis

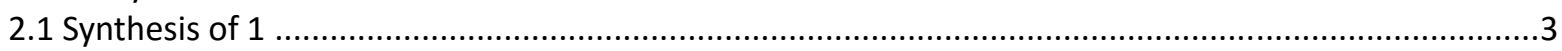

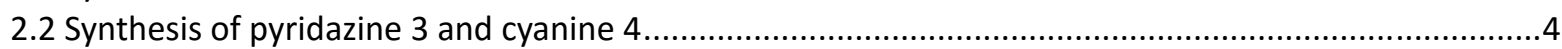

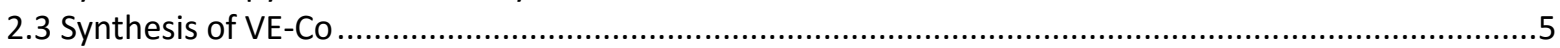

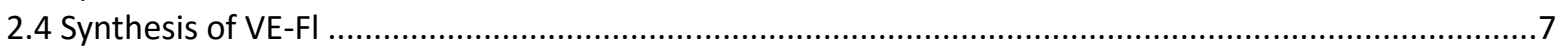

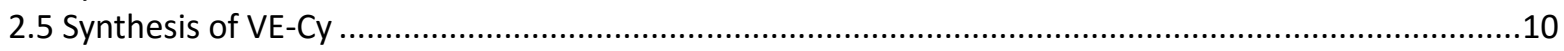

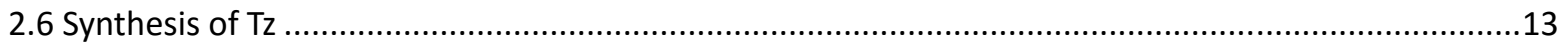

3. Oligonucleotide probe synthesis and characterization ..........................................................................

3.1 General procedure for oligonucleotide probe modification. .............................................................13

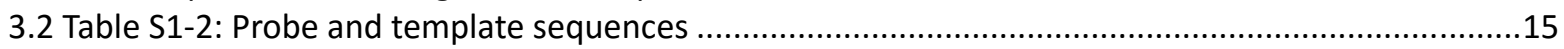

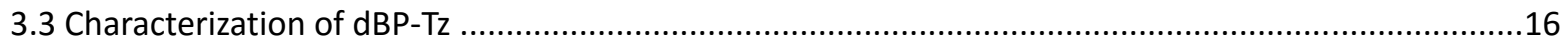

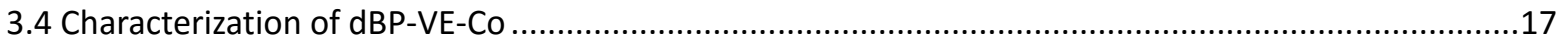

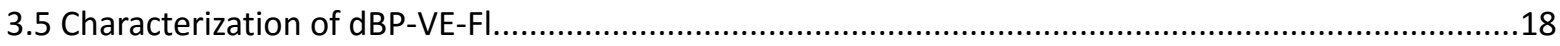

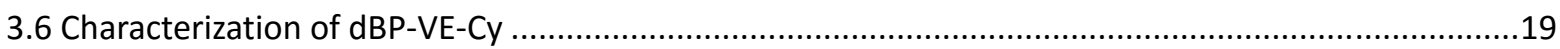

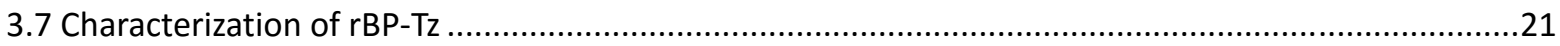

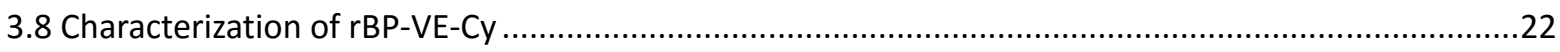

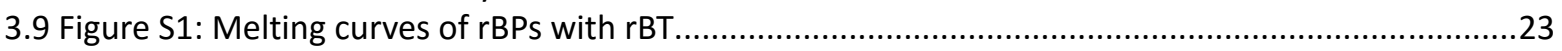

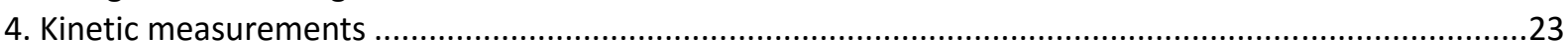

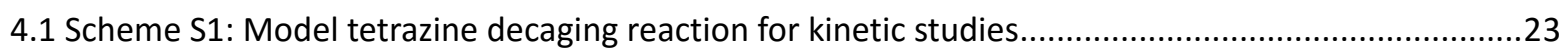

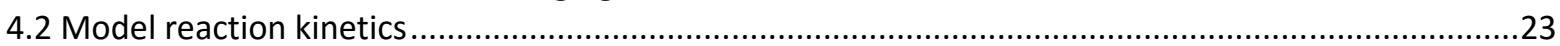

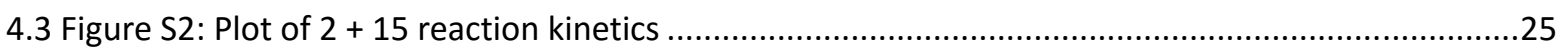

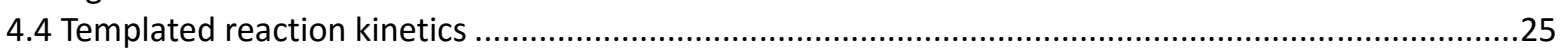

4.5 Figure S3: Plot of DNA templated reaction kinetics of dBP-Tz with dBP-VE-Co ................................26

5. Absorbance and fluorescence spectra of vinyl ether probes and their corresponding fluorophores .......26

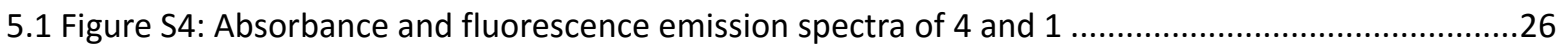

5.2 Figure S5: Absorbance and fluorescence emission spectrum of 5 and $6 \ldots \ldots \ldots \ldots \ldots \ldots \ldots \ldots \ldots \ldots \ldots \ldots \ldots . . .27$

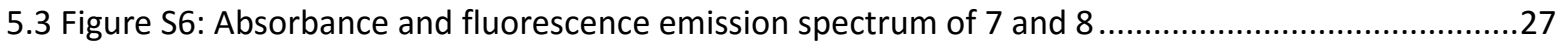

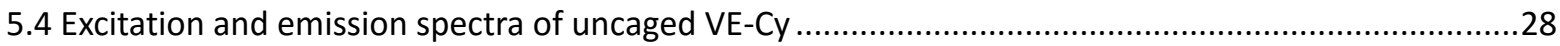

5.5 Figure S7: Expanded fluorescence turn on from DNA templated reactions .......................................29

6. DNA/RNA-templated VE-Tz bioorthogonal reactions and corresponding fluorescence turn-on................29

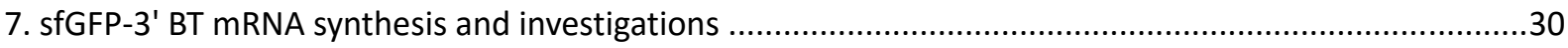

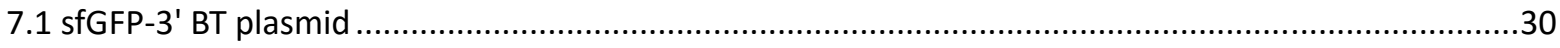

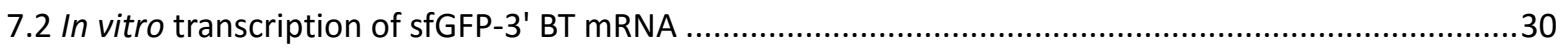

7.3 Fluorescent measurements of full length mRNA fluorogenic tetrazine decaging reactions ..................31

7.4 Figure S8: Fluorescence response of $\mathrm{rBP}-\mathrm{Tz}$ and $\mathrm{rBP}-\mathrm{VE}-\mathrm{Cy}$ in the presence of varying

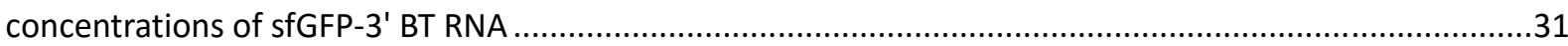

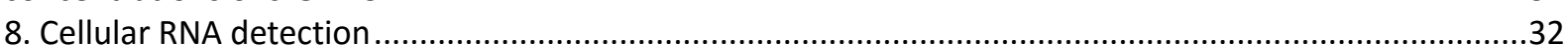

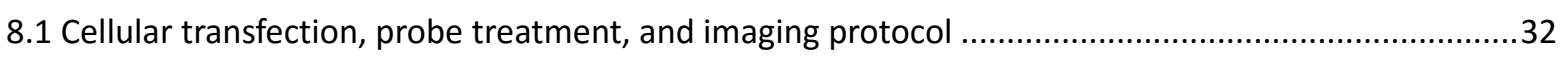

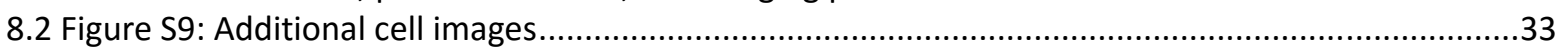

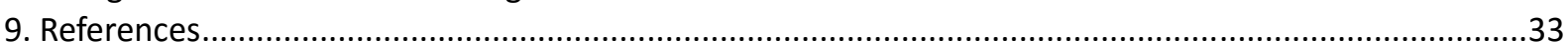

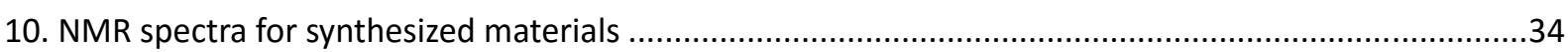




\section{General Methods}

All reagents were purchased from Sigma-Aldrich and used without further purification unless otherwise noted. All oligonucleotides were purchased from Integrated DNA Technologies. The TLC plates used for purification were purchased from Agela Technologies (silica $200 \times$ $200 \mathrm{~mm}, \mathrm{PH}=5, \mathrm{MF}=254$, glass back). Other chromatographic purifications were conducted using 40-63 $\mu \mathrm{m}$ silica gel. All mixtures of solvents are given in $v / v$ ratio. ${ }^{1} \mathrm{H}$ and ${ }^{13} \mathrm{C}$ NMR spectroscopy were performed on a Jeol NMR at $500\left({ }^{1} \mathrm{H}\right)$ or $125\left({ }^{13} \mathrm{C}\right) \mathrm{MHz}$. All ${ }^{13} \mathrm{C}$ NMR spectra were proton decoupled. Fluorescence measurements were performed on a HORIBA FluoroMax-P spectrophotometer equipped with a single cuvette reader. Oligonucleotide concentrations were measured on a ThermoScientific NanoDrop 2000c UV-Vis Spectrophotometer with absorption wavelength of $260 \mathrm{~nm}$. The control plasmid employed, pcDNA3-EGFP, was a gift from Doug Golenbock (Addgene plasmid \# 13031).

\section{Probe synthesis}

\subsection{Synthesis of 1}
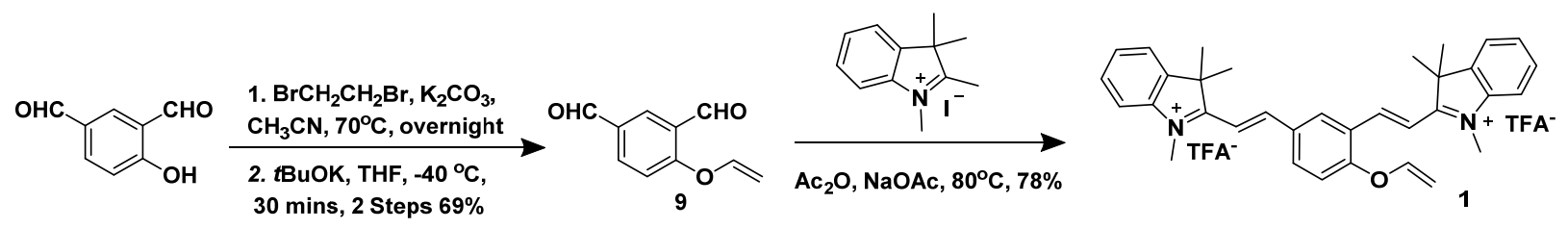

Synthesis of Compound 9:

4-Hydroxyisophthalaldehyde (150 mg, $1 \mathrm{mmol}$ ) was dissolved in anhydrous acetonitrile (5.0 $\mathrm{mL}$ ). 1,2-Dibromoethane (1.9 g, $10 \mathrm{mmol}$ ) was added followed by $\mathrm{K}_{2} \mathrm{CO}_{3}(276 \mathrm{mg}, 2 \mathrm{mmol}$ ) at room temperature. Then the reaction was stirred at $70{ }^{\circ} \mathrm{C}$ overnight. After the reaction was completed, the solution was filtered, and the solvent was removed in vacuo. The residue was dissolved in anhydrous THF $(10 \mathrm{~mL})$ at $-40{ }^{\circ} \mathrm{C}$. $t$-BuOK $(0.5 \mathrm{mmol})$ was slowly added over 10 minutes. Then the reaction was stirred at $-40{ }^{\circ} \mathrm{C}$ for 30 minutes. After the reaction was complete, the reaction was quenched by water, and the solution was extracted with EtOAc $(30 \mathrm{~mL} \times 3)$. The organic layer was dried over $\mathrm{Na}_{2} \mathrm{SO}_{4}$, filtered, and concentrated in vacuo. The residue was purified by silica column (Hexanes:EtOAc $=25: 1)$ to afford pure $9(138 \mathrm{mg}$, yield $78 \%, 2$ steps) as a white solid.

${ }^{1}$ H NMR: $\left(500 \mathrm{MHz}, \mathrm{CD}_{2} \mathrm{Cl}_{2}\right) \delta(\mathrm{ppm}): 10.46(\mathrm{~d}, J=0.9 \mathrm{~Hz}, 1 \mathrm{H}), 9.96(\mathrm{~s}, 1 \mathrm{H}), 8.37-8.28$ $(\mathrm{m}, 1 \mathrm{H}), 8.13-8.07(\mathrm{~m}, 1 \mathrm{H}), 7.25(\mathrm{~d}, J=8.6 \mathrm{~Hz}, 1 \mathrm{H}), 6.85-6.76(\mathrm{~m}, 1 \mathrm{H}), 5.10-5.05(\mathrm{~m}$, $1 \mathrm{H}), 4.82-4.78(\mathrm{~m}, 1 \mathrm{H})$. 
${ }^{13}$ C NMR: (126 MHz, $\left.\mathrm{CD}_{2} \mathrm{Cl}_{2}\right) \delta$ (ppm): 190.52, 188.42, 163.28, 146.39, 135.99, 132.02, 131.64, 126.07, 116.81, 100.43.

HRMS: $[\mathrm{M}+\mathrm{H}]^{+} \mathrm{m} / \mathrm{z}$ calcd. for $\left[\mathrm{C}_{10} \mathrm{H}_{9} \mathrm{O}_{3}\right]^{+} 177.0546$, found $177.0545(\Delta=0.56 \mathrm{ppm})$

Synthesis of Compound 1:

A mixture of compound 9 (88 $\mathrm{mg}, 0.5 \mathrm{mmol}), \mathrm{NaOAc}$ (99 $\mathrm{mg}, 1.2 \mathrm{mmol}$ ), and 1,2,3,3,-tetramethyl-3H-indolium iodide $\left(345 \mathrm{mg}, 1.15 \mathrm{mmol}\right.$ ) was dissolved in $2 \mathrm{~mL} \mathrm{Ac}_{2} \mathrm{O}$. The reaction mixture was stirred for $30 \mathrm{~min}$ at $80{ }^{\circ} \mathrm{C}$ under an $\mathrm{Ar}$ atmosphere and monitored by HPLC-MS. After the reaction completed, the solvent was removed in vacuo. The resulting crude product was dissolved in $\mathrm{MeOH}$, and purified by preparative RP-HPLC (grad. $15 \%-100 \% \mathrm{MeOH}$ in water with $0.1 \% \mathrm{TFA}, 30 \mathrm{~min})$ to give compound $\mathbf{1}(190 \mathrm{mg}, 78 \%)$ as a yellow solid.

${ }^{1}$ H NMR: (500 MHz, $\mathrm{CD}_{2} \mathrm{Cl}_{2}$ ) $\delta$ (ppm): 9.09 (s, 1H), 8.63 (d, $\left.J=14.6 \mathrm{~Hz}, 1 \mathrm{H}\right), 8.40-8.29$ $(\mathrm{m}, 1 \mathrm{H}), 8.16-8.00(\mathrm{~m}, 2 \mathrm{H}), 7.84(\mathrm{~d}, J=10.3 \mathrm{~Hz}, 1 \mathrm{H}), 7.65(\mathrm{~d}, J=10.3 \mathrm{~Hz}, 8 \mathrm{H}), 7.29$ (t, $J=$ $8.4 \mathrm{~Hz}, 1 \mathrm{H}), 6.87$ (dd, $J=13.5,5.9 \mathrm{~Hz}, 1 \mathrm{H}), 5.16$ (dd, $J=13.4,2.1 \mathrm{~Hz}, 1 \mathrm{H}), 4.90$ (dd, $J=5.7$, $2.1 \mathrm{~Hz}, 1 \mathrm{H}), 4.26(\mathrm{~d}, J=20.1 \mathrm{~Hz}, 6 \mathrm{H}), 1.85(\mathrm{~s}, 12 \mathrm{H})$.

${ }^{13}$ C NMR: (126 MHz, $\left.\mathrm{CD}_{2} \mathrm{Cl}_{2}\right) \delta$ (ppm): 182.89, 182.78, 160.00, 153.15, 147.08, 145.70, 143.32 , 143.30, 141.31, 141.29, 137.44, 131.52, 130.56, 130.30, 129.74, 129.65, 129.58, $124.68,122.79,122.77,116.09,114.79,114.68,114.54,112.71,100.41,52.87,52.84,34.86$, 34.74, 26.51, 26.51, 26.08, 26.08.

HRMS: $[\mathrm{M}]^{2+} \mathrm{m} / \mathrm{z}$ calcd. for $\left[\mathrm{C}_{34} \mathrm{H}_{36} \mathrm{~N}_{2} \mathrm{O}\right]^{2+} 244.1408$, found $244.1411(\Delta=1.23 \mathrm{ppm})$

\subsection{Synthesis of pyridazine 3 and cyanine 4}

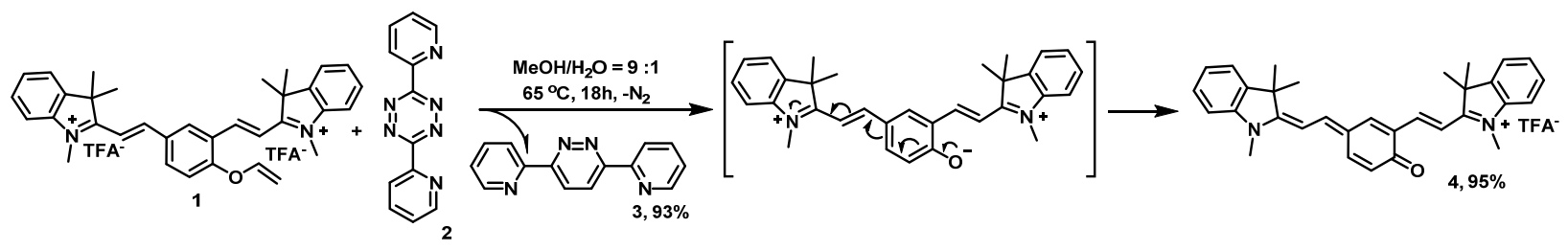

3,6-di-(2-pyridyl)-s-tetrazine 2 (4.7 $\mathrm{mg}, 0.02 \mathrm{mmol}$ ) and compound 1 (9.8 $\mathrm{mg}, 0.02 \mathrm{mmol})$ were dissolved in $0.5 \mathrm{~mL}$ solution of $9: 1 \mathrm{MeOH}: \mathrm{H}_{2} \mathrm{O}$ in a $5 \mathrm{~mL}$ reaction vessel equipped with a stirring bar. The reaction was heated in an oil bath at $65^{\circ} \mathrm{C}$ for $18 \mathrm{~h}$, at which point TLC indicated that the reaction had completed. The reaction was concentrated in vacuo and the residue was purified by preparative TLC $\left(50: 1 \mathrm{CH}_{2} \mathrm{Cl}_{2}: \mathrm{MeOH}\right)$, to give compound 3 as a white solid (4.4 mg, 93\%), and further purified by semi-preparative HPLC (grad. 15\%-100\% $\mathrm{MeOH}$ in water with $0.1 \% \mathrm{TFA}, 30 \mathrm{~min})$, to give cyanine compound 4 ( $8.5 \mathrm{mg}, 95 \%)$.

${ }^{1} \mathbf{H}$ NMR of Pz-0: $\left(500 \mathrm{MHz}, \mathrm{CD}_{2} \mathrm{Cl}_{2}\right) \delta$ (ppm): $8.76-8.70(\mathrm{~m}, 4 \mathrm{H}), 8.67(\mathrm{~d}, J=0.7 \mathrm{~Hz}, 2 \mathrm{H})$, $7.95-7.89(\mathrm{~m}, 2 \mathrm{H}), 7.45-7.39(\mathrm{~m}, 2 \mathrm{H})$. 
${ }^{1} \mathbf{H}$ NMR of Cy-2: $\left(500 \mathrm{MHz}, \mathrm{CD}_{2} \mathrm{Cl}_{2}\right) \delta(\mathrm{ppm}): 8.82(\mathrm{~s}, 1 \mathrm{H}), 8.71(\mathrm{~d}, J=16.3 \mathrm{~Hz}, 1 \mathrm{H}), 8.29$ $(\mathrm{d}, J=15.9 \mathrm{~Hz}, 1 \mathrm{H}), 8.08$ (d, $J=16.0 \mathrm{~Hz}, 1 \mathrm{H}), 7.82$ (d, $J=8.6 \mathrm{~Hz}, 1 \mathrm{H}), 7.63-7.49$ (m, 9H), $7.46(\mathrm{~d}, J=15.9 \mathrm{~Hz}, 1 \mathrm{H}), 4.14(\mathrm{~s}, 3 \mathrm{H}), 4.09$ (s, 3H), 1.85 (s, 6H), $1.82(\mathrm{~s}, 6 \mathrm{H})$.

\subsection{Synthesis of VE-Co}

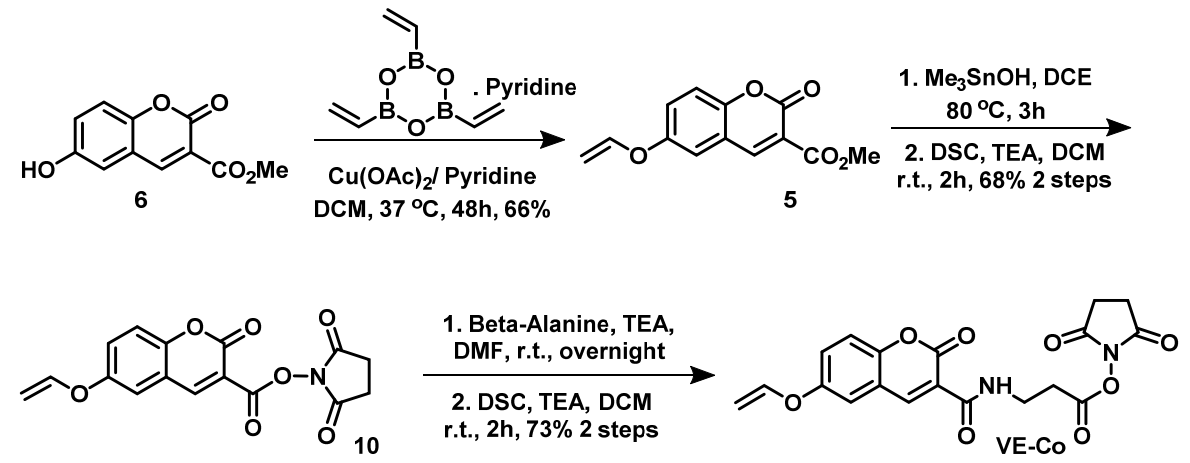

Synthesis of Compound 5:
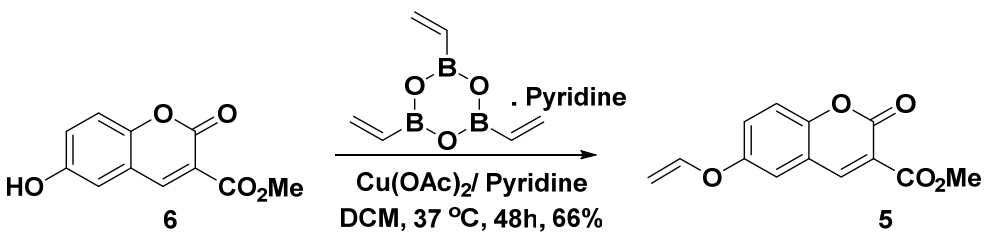

In a $25 \mathrm{~mL}$ round bottom flask, $\mathrm{Cu}(\mathrm{OAc})_{2}(36 \mathrm{mg}, 0.2 \mathrm{mmol})$ was stirred at room temperature in anhydrous $\mathrm{CH}_{2} \mathrm{Cl}_{2}(5 \mathrm{~mL})$ for 10 minutes. 2,4,6-Trivinylcyclotriboroxane-pyridine complex (30 mg, $0.2 \mathrm{mmol}$ ), Methyl 6-hydroxycoumarin-3-carboxylate $6^{(1)}$ (44 mg, 0.2 $\mathrm{mmol}$ ), and pyridine (160 $\mathrm{mg}, 2 \mathrm{mmol})$ were added and the reaction stirred at room temperature for 48 hours. The reaction solution was concentrated in vacuo. The residue was purified by silica column (10:1 Hexane:EtOAc) to afford 5 as an off-white solid (33 $\mathrm{mg}$, $66 \%)$.

${ }^{1}$ H NMR: $\left(500 \mathrm{MHz} \mathrm{CDCl}_{3}\right) \delta(\mathrm{ppm}): 8.55(\mathrm{~s}, 1 \mathrm{H}), 7.59-7.54(\mathrm{~m}, 1 \mathrm{H}), 6.98(\mathrm{dd}, J=8.6$, $2.4 \mathrm{~Hz}, 1 \mathrm{H}), 6.93$ (d, $J=2.3 \mathrm{~Hz}, 1 \mathrm{H}), 6.67$ (dd, $J=13.5,6.0 \mathrm{~Hz}, 1 \mathrm{H}), 5.02$ (dd, $J=13.5,2.0$ $\mathrm{Hz}, 1 \mathrm{H}), 4.72(\mathrm{dd}, J=5.9,2.0 \mathrm{~Hz}, 1 \mathrm{H}), 3.94(\mathrm{~s}, 3 \mathrm{H})$.

${ }^{13}$ C NMR: (126 MHz, $\left.\mathrm{CDCl}_{3}\right) \delta$ (ppm): 164.05, 162.06, 157.23, 156.92, 149.26, 145.69, $131.23,115.14,114.52,113.27,103.54,99.78,53.00$.

HRMS: $[\mathrm{M}+\mathrm{Na}]^{+} \mathrm{m} / \mathrm{z}$ calcd. for $\left[\mathrm{C}_{13} \mathrm{H}_{10} \mathrm{O}_{5} \mathrm{Na}\right]^{-} 269.0420$, found $269.0422(\Delta=0.74 \mathrm{ppm})$

Synthesis of Compound 10:

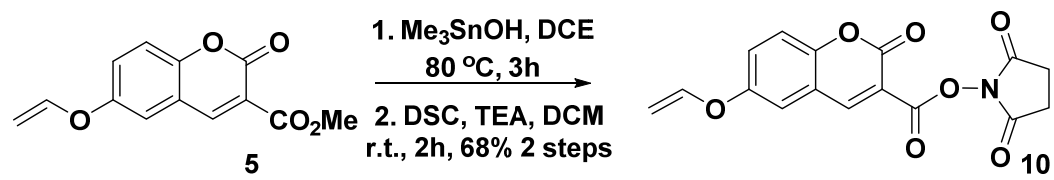


In a $10 \mathrm{~mL}$ reaction vessel equipped with a stir bar, compound 5 (10.6 $\mathrm{mg}, 0.04 \mathrm{mmol})$ was dissolved in 1,2-dichloroethane to which $\mathrm{Me}_{3} \mathrm{SnOH}(20 \mathrm{mg}, 0.12 \mathrm{mmol}$ ) was added. The solution was heated to $80{ }^{\circ} \mathrm{C}$ and stirred for 3 hours. The reaction solution was evaporated and purified by flash column chromatography $\left(50: 1 \mathrm{CH}_{2} \mathrm{Cl}_{2}: \mathrm{MeOH}\right)$ to afford the carboxylic acid intermediate. The intermediate was dissolved in anhydrous $\mathrm{CH}_{2} \mathrm{Cl}_{2}$ followed by addition of $\mathrm{Et}_{3} \mathrm{~N}(6 \mathrm{uL}, 0.044 \mathrm{mmol})$ and $N, N^{\prime}$-disuccinimidyl carbonate $(11 \mathrm{mg}, 0.044 \mathrm{mmol})$. This solution was stirred at room temperature for 1 hour. The reaction solution was evaporated and purified by preparative TLC (1:1 Hexane:EtOAc) to afford compound $\mathbf{1 0}(9 \mathrm{mg}, 68 \%$ in 2 steps).

${ }^{1}$ H NMR: $\left(500 \mathrm{MHz}, \mathrm{CDCl}_{3}\right) \delta(\mathrm{ppm}): 8.89(\mathrm{~s}, 1 \mathrm{H}), 7.71(\mathrm{~d}, J=8.7 \mathrm{~Hz}, 1 \mathrm{H}), 7.12(\mathrm{dd}, J=$ 8.7, $2.3 \mathrm{~Hz}, 1 \mathrm{H}), 7.05(\mathrm{~d}, J=2.3 \mathrm{~Hz}, 1 \mathrm{H}), 6.71$ (dd, $J=13.5,5.9 \mathrm{~Hz}, 1 \mathrm{H}), 5.09$ (dd, $J=13.5$, $2.1 \mathrm{~Hz}, 1 \mathrm{H}), 4.81(\mathrm{dd}, J=5.9,2.1 \mathrm{~Hz}, 1 \mathrm{H}), 3.20(\mathrm{~d}, J=2.1 \mathrm{~Hz}, 4 \mathrm{H})$.

${ }^{13}$ C NMR: (126 MHz, $\left.\mathrm{CDCl}_{3}\right) \delta$ (ppm): 169.01, 169.01, 163.22, 158.06, 157.83, 155.44, 151.70, 145.16, 131.91, 114.90, 112.58, 109.93, 103.39, 100.51, 25.66, 25.66.

HRMS: $[\mathrm{M}+\mathrm{Na}]^{+} \mathrm{m} / \mathrm{z}$ calcd. for $\left[\mathrm{C}_{16} \mathrm{H}_{11} \mathrm{NO}_{7} \mathrm{Na}\right]^{+} 352.0428$, found $352.0425 .(\Delta=0.85 \mathrm{ppm})$

Synthesis of VE-Co
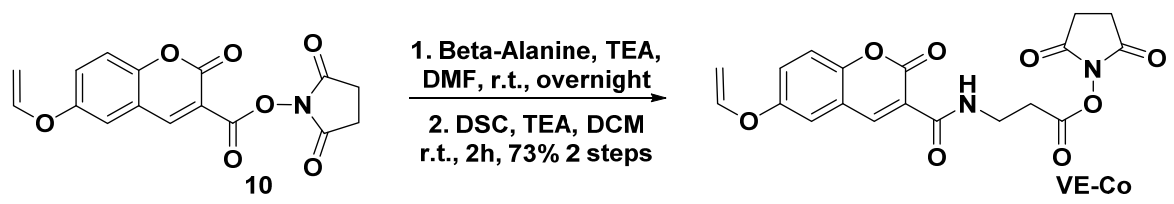

In a $10-\mathrm{mL}$ reaction vessel equipped with a stir bar, compound $\mathbf{1 0}(9.9 \mathrm{mg}, 0.03 \mathrm{mmol})$ was dissolved in anhydrous DMF, to which $\beta$-Alanine ( $3 \mathrm{mg}, 0.036 \mathrm{mmol}$ ) and TEA (14 $\mu \mathrm{L}, 0.11$ mmol) was added sequentially. The solution was stirred at room temperature overnight. The reaction solution was evaporated and purified by flash column chromatography (40:1 $\mathrm{CH}_{2} \mathrm{Cl}_{2}: \mathrm{MeOH}$ ) to afford the carboxylic acid intermediate. The intermediate was dissolved in anhydrous $\mathrm{CH}_{2} \mathrm{Cl}_{2}$ followed by addition of $\mathrm{Et}_{3} \mathrm{~N}(4.4 \mu \mathrm{L}, 0.032 \mathrm{mmol})$ and $N, N$ '-disuccinimidyl carbonate $(8.2 \mathrm{mg}, 0.032 \mathrm{mmol})$. This solution was stirred at room temperature for 2 hours. The reaction solution was evaporated and purified by preparative TLC (1:2 Hexane:EtOAc) to afford VE-Co ( $8.7 \mathrm{mg}, 73 \%$ in 2 steps).

${ }^{1}$ H NMR: $\left(500 \mathrm{MHz}, \mathrm{CDCl}_{3}\right) \delta$ (ppm): $9.12(\mathrm{~s}, 1 \mathrm{H}), 8.87-8.81(\mathrm{~m}, 1 \mathrm{H}), 7.64(\mathrm{~d}, J=8.7 \mathrm{~Hz}$, 1H), 7.02 (dd, $J=8.6,2.3 \mathrm{~Hz}, 1 \mathrm{H}), 6.97$ (d, $J=2.5 \mathrm{~Hz}, 1 \mathrm{H}), 6.68(\mathrm{dd}, J=13.5,6.0 \mathrm{~Hz}, 1 \mathrm{H})$, $5.02(\mathrm{dd}, J=13.5,2.0 \mathrm{~Hz}, 1 \mathrm{H}), 4.72(\mathrm{dd}, J=5.9,2.0 \mathrm{~Hz}, 1 \mathrm{H}), 3.84$ (q, $J=6.3 \mathrm{~Hz}, 2 \mathrm{H}), 3.00$ (t, $J=6.4 \mathrm{~Hz}, 2 \mathrm{H}), 2.84(\mathrm{~s}, 4 \mathrm{H})$.

${ }^{13}$ C NMR: $\left(126 \mathrm{MHz}, \mathrm{CDCl}_{3}\right) \delta$ (ppm): 169.05, 167.31, 162.40, 161.75, 161.44, 156.34, 148.39 , 145.74, 131.47, 115.67, 114.96, 114.91, 113.96, 103.47, 99.75, 35.26, 31.36, 25.71, 25.71 .

HRMS: $[\mathrm{M}+\mathrm{Na}]^{+} \mathrm{m} / \mathrm{z}$ calcd. for $\left[\mathrm{C}_{19} \mathrm{H}_{16} \mathrm{~N}_{2} \mathrm{O}_{8} \mathrm{Na}\right]^{+}$423.0799, found 423.0797. $(\Delta=0.47$ ppm) 


\subsection{Synthesis of VE-Fl}

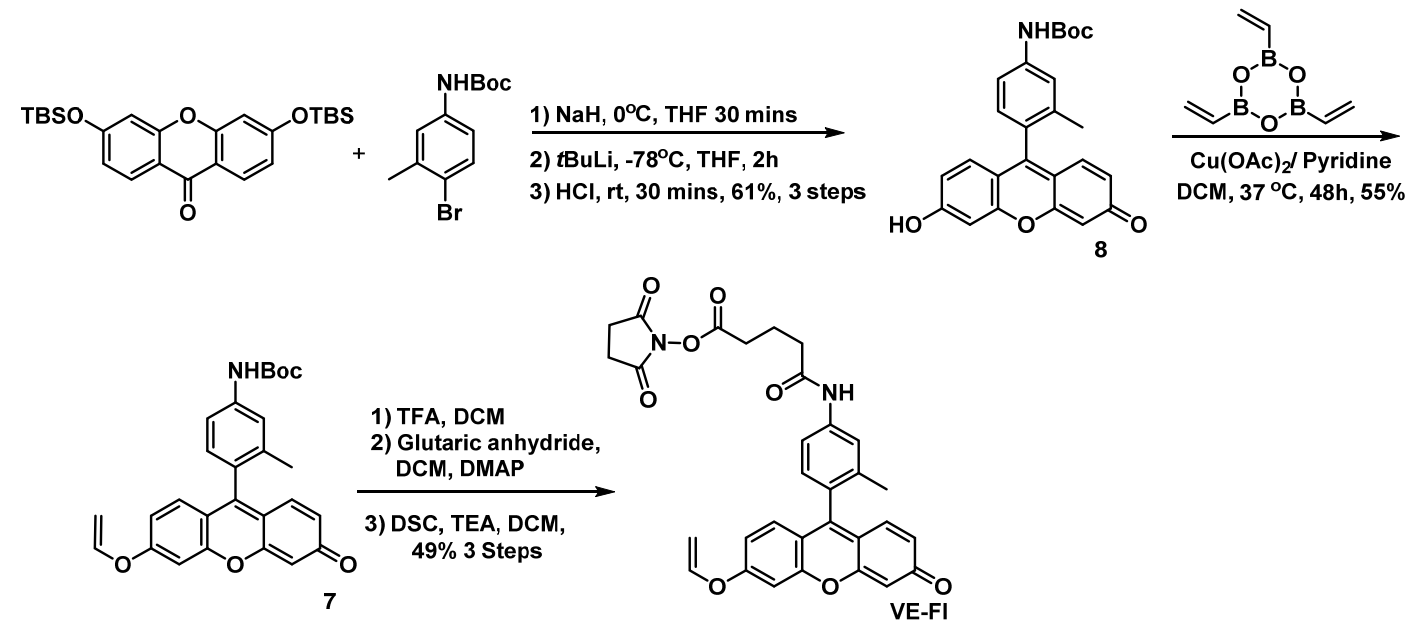

Synthesis of Compound 8:
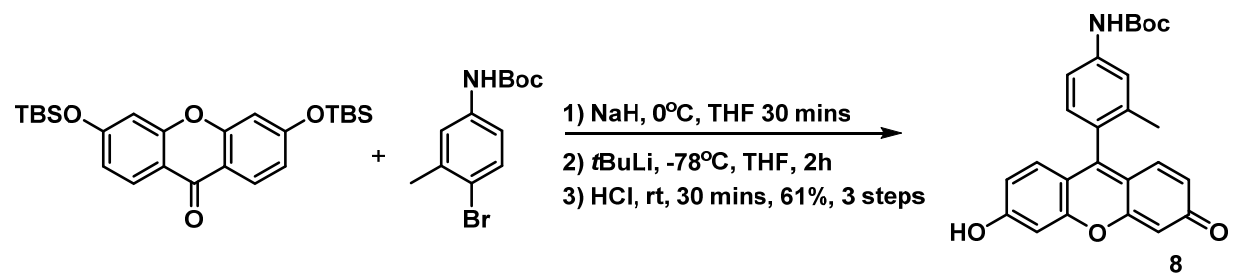

The synthesis of compound $\mathbf{8}$ was adapted from a previous report. ${ }^{(2)}$ (4-Bromo-3-methylphenyl) carbamic acid tert-butyl ester (140 mg, $0.5 \mathrm{mmol}$ ) (Combi-Blocks, San Diego, CA) was dissolved in $20 \mathrm{~mL}$ anhydrous THF and cooled to $0{ }^{\circ} \mathrm{C}$. Next, sodium hydride (14 mg, $0.6 \mathrm{mmol}$ ) was added. After stirring for 15 minutes, the solution was cooled to $-78{ }^{\circ} \mathrm{C}$. Then, tert-butyllithium $(1.7 \mathrm{M}, 0.59 \mathrm{~mL}, 1.00 \mathrm{mmol})$ was added dropwise to the flask. After stirring for 30 minutes, a solution of 3,6-bis(tert-butyldimethylsilyloxy)-9H-xanthen-9-one (160 $\mathrm{mg}, 0.35 \mathrm{mmol}$ ) in $3 \mathrm{~mL}$ anhydrous THF was slowly added into the flask. After stirring for 2 hours at $-78{ }^{\circ} \mathrm{C}$, the reaction was allowed to warm to room temperature over 15 minutes. The reaction was quenched with the careful addition of $2 \mathrm{M} \mathrm{HCl}$. After stirring for another 15 minutes, the solvent was removed in vacuo and the remaining residue was purified by silica flash column (1:1 Hexane:EtOAc), yielding compound $\mathbf{8}(90 \mathrm{mg}, 61 \%)$ as a yellow solid.

${ }^{1}$ H NMR: $\left(500 \mathrm{MHz}, \mathrm{CD}_{3} \mathrm{OD}\right) \delta$ (ppm): 7.53 (s, 1H), $7.50(\mathrm{dd}, J=8.3,2.0 \mathrm{~Hz}, 1 \mathrm{H}), 7.13$ (m, $7.5 \mathrm{~Hz}, 3 \mathrm{H}), 6.77-6.69(\mathrm{~m}, 4 \mathrm{H}), 2.02(\mathrm{~s}, 3 \mathrm{H}), 1.56(\mathrm{~s}, 9 \mathrm{H})$.

${ }^{13}$ C NMR: (126 MHz, $\left.\mathrm{CD}_{3} \mathrm{OD}\right) \delta$ (ppm): 159.73, 159.28, 156.12, 155.11, 155.11, 142.32, $138.00,132.47,132.47,130.78,130.78,129.01,127.35,121.17,117.11,116.67,114.81$, $104.35,104.35,103.19,81.17,28.68,28.68,28.68,19.97$.

HRMS: $[\mathrm{M}+\mathrm{H}]^{+} \mathrm{m} / \mathrm{z}$ calcd. for $\left[\mathrm{C}_{25} \mathrm{H}_{24} \mathrm{NO}_{5}\right]^{+} 418.1649$, found 418.1648. $(\Delta=0.24 \mathrm{ppm})$ 
Synthesis of Compound 7:
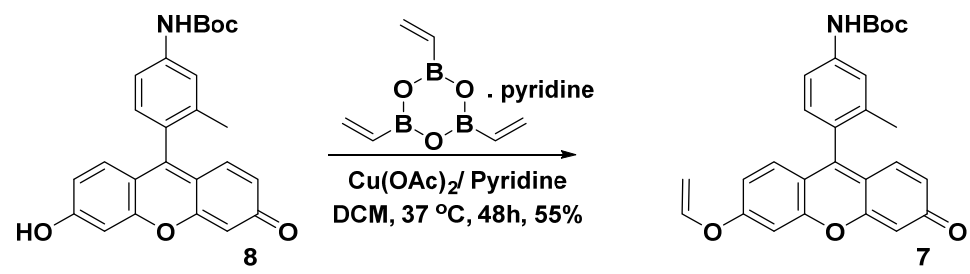

In a $25 \mathrm{~mL}$ round bottom flask, $\mathrm{Cu}(\mathrm{OAc})_{2}(18 \mathrm{mg}, 0.1 \mathrm{mmol})$ was stirred at room temperature in $5 \mathrm{~mL}$ anhydrous $\mathrm{CH}_{2} \mathrm{Cl}_{2}$ for 10 minutes. 2,4,6-trivinylcyclotriboroxane-pyridine complex (16 mg, $0.07 \mathrm{mmol})$, compound 8 (42 $\mathrm{mg}, 0.1 \mathrm{mmol})$, and pyridine ( $80 \mathrm{mg}, 1 \mathrm{mmol}$ ) were added and the reaction and stirred at room temperature for 48 hours. The reaction solution was concentrated in vacuo and the residue was purified by silica column (2:1 Hexane:EtOAc) to afford 7 as a pure off-white solid (25 $\mathrm{mg}, 55 \%)$.

${ }^{1}$ H NMR: $\left(500 \mathrm{MHz}, \mathrm{CDCl}_{3}\right) \delta(\mathrm{ppm}): 7.51(\mathrm{~s}, 1 \mathrm{H}), 7.33(\mathrm{dd}, J=8.2,2.1 \mathrm{~Hz}, 1 \mathrm{H}), 7.07$ (dd, $J=10.7,7.3 \mathrm{~Hz}, 2 \mathrm{H}), 7.05$ (s, 1H), $7.00-6.97(\mathrm{~m}, 1 \mathrm{H}), 6.84(\mathrm{dd}, J=8.8,2.4 \mathrm{~Hz}, 1 \mathrm{H}), 6.70$ $(\mathrm{dd}, J=13.6,6.0 \mathrm{~Hz}, 1 \mathrm{H}), 6.66(\mathrm{~s}, 1 \mathrm{H}), 6.57(\mathrm{dd}, J=9.7,1.9 \mathrm{~Hz}, 1 \mathrm{H}), 6.45-6.43(\mathrm{~m}, 1 \mathrm{H})$, $5.01(\mathrm{dd}, J=13.5,2.0 \mathrm{~Hz}, 1 \mathrm{H}), 4.70(\mathrm{dd}, J=6.0,2.0 \mathrm{~Hz}, 1 \mathrm{H}), 2.05(\mathrm{~s}, 3 \mathrm{H}), 1.56(\mathrm{~s}, 9 \mathrm{H})$.

${ }^{13}$ C NMR: (126 MHz, $\left.\mathrm{CDCl}_{3}\right) \delta$ (ppm): 186.06, 161.05, 158.90, 154.24, 152.81, 148.88, $145.96,139.73,137.51,130.83,130.51,130.03,129.93,126.79,120.21,119.50,116.25$, 116.16, 114.12, 106.10, 103.59, 99.32, 81.26, 28.46, 28.46, 28.46, 20.07.

HRMS: $[\mathrm{M}+\mathrm{H}]^{+} \mathrm{m} / \mathrm{z}$ calcd. for $\left[\mathrm{C}_{27} \mathrm{H}_{26} \mathrm{NO}_{5}\right]^{+} 444.1805$, found 444.1806. $(\Delta=0.23 \mathrm{ppm})$ 
Synthesis of VE-FI:
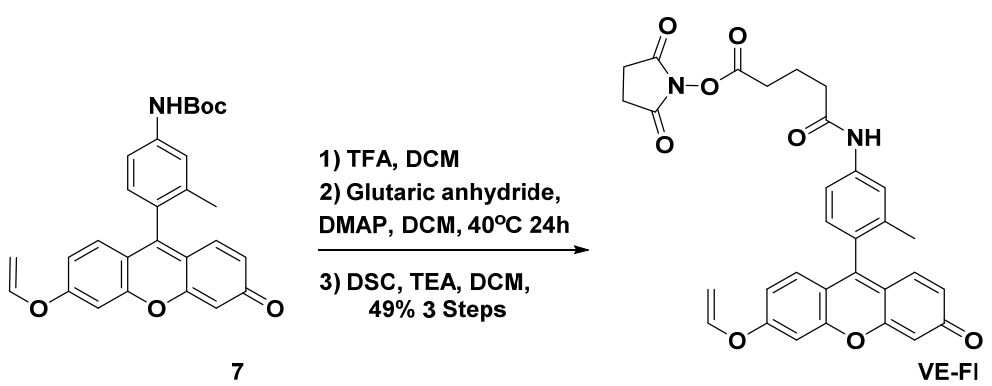

In a $10 \mathrm{~mL}$ round bottom flask, Compound $7(14.5 \mathrm{mg}, 0.033 \mathrm{mmol})$ was stirred at $0{ }^{\circ} \mathrm{C}$ in a $15 \%$ TFA in anhydrous $\mathrm{CH}_{2} \mathrm{Cl}_{2}$ solution $(3 \mathrm{~mL})$ for 20 minutes. After the reaction was completed, the solvent was removed in vacuo, and the residue was directly carried on to the next step without purification. The residue was dissolved in $5 \mathrm{~mL}$ anhydrous $\mathrm{CH}_{2} \mathrm{Cl}_{2}$, and glutaric anhydride $(7.6 \mathrm{mg}, 0.066 \mathrm{mmol})$ and DMAP $(8.2 \mathrm{mg}, 0.066 \mathrm{mmol})$ were added into the reaction solution sequentially. The reaction solution was kept at $40{ }^{\circ} \mathrm{C}$ for 24 hours. After the reaction was completed, the reaction solution was evaporated and purified by flash column chromatography to afford the carboxylic acid intermediate. The intermediate was dissolved in anhydrous $\mathrm{CH}_{2} \mathrm{Cl}_{2}$ followed by addition of $\mathrm{Et}_{3} \mathrm{~N}(5.0 \mu \mathrm{L}, 0.036 \mathrm{mmol})$ and $N, N$ '-disuccinimidyl carbonate $(10 \mathrm{mg}, 0.036 \mathrm{mmol})$. This solution was stirred at room temperature for 3 hours. The reaction solution was evaporated and purified by preparative TLC (1:1 EtOAc: $\mathrm{CH}_{2} \mathrm{Cl}_{2}$ ) to afford VE-FI ( $8.4 \mathrm{mg}, 49 \%$ in 3 steps).

${ }^{1}$ H NMR: (500 MHz, CD $\left.{ }_{3} \mathrm{OD}\right) \delta$ (ppm): 7.69 (s, 1H), 7.63 (d, $\left.J=8.2 \mathrm{~Hz}, 1 \mathrm{H}\right), 7.28$ (d, $J=$ $2.4 \mathrm{~Hz}, 1 \mathrm{H}), 7.23-7.11(\mathrm{~m}, 3 \mathrm{H}), 7.03(\mathrm{dd}, J=9.0,2.4 \mathrm{~Hz}, 1 \mathrm{H}), 6.95(\mathrm{dd}, J=13.4,6.0 \mathrm{~Hz}$, $1 \mathrm{H}), 6.59$ (dd, $J=9.7,2.0 \mathrm{~Hz}, 1 \mathrm{H}), 6.45(\mathrm{~d}, J=2.0 \mathrm{~Hz}, 1 \mathrm{H}), 5.00-4.95(\mathrm{~m}, 1 \mathrm{H}), 4.72-4.68$ $(\mathrm{m}, 1 \mathrm{H}), 4.60(\mathrm{~s}, 1 \mathrm{H}), 2.82(\mathrm{~d}, J=1.7 \mathrm{~Hz}, 4 \mathrm{H}), 2.76(\mathrm{t}, J=7.2 \mathrm{~Hz}, 2 \mathrm{H}), 2.55(\mathrm{t}, J=7.3 \mathrm{~Hz}$, $2 \mathrm{H}), 2.14-2.06(\mathrm{~m}, 2 \mathrm{H}), 2.02(\mathrm{~s}, 3 \mathrm{H})$.

${ }^{13}$ C NMR: (126 MHz, $\left.\mathrm{CD}_{3} \mathrm{OD}\right) \quad \delta$ (ppm): 187.65, 173.40, 171.90, 171.90, 169.96, 163.46, $161.41,156.11,154.19,147.30,141.51,138.24,132.98,131.69,130.89,130.06,128.66$, $122.80,119.82$, 118.76, 117.28, 115.96, 105.79, 104.25, 99.36, 36.21, 30.86, 26.51, 26.51, 21.57, 19.96.

HRMS: $[\mathrm{M}+\mathrm{H}]^{+} \mathrm{m} / \mathrm{z}$ calcd. for $\left[\mathrm{C}_{31} \mathrm{H}_{27} \mathrm{~N}_{2} \mathrm{O}_{8}\right]^{+}$555.1762, found 555.1761. ( $\left.\Delta=0.18 \mathrm{ppm}\right)$ 


\subsection{Synthesis of VE-Cy}
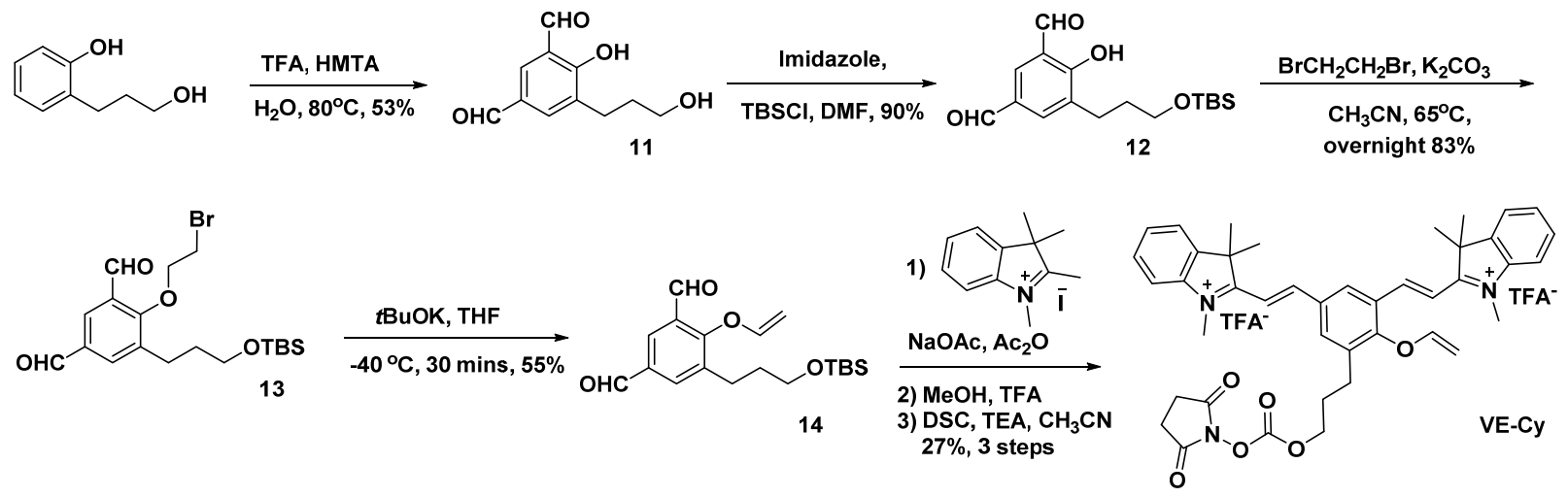

Synthesis of compound $\mathbf{1 1}$

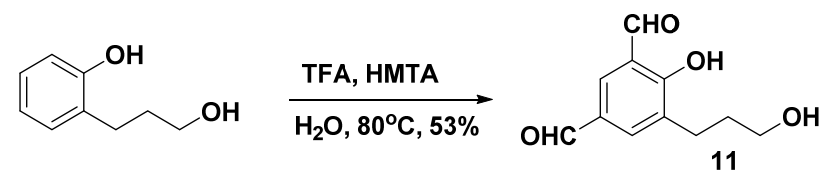

A mixture of 2-(3-hydroxypropyl)-phenol $(910 \mathrm{mg}, 6 \mathrm{mmol})$ and hexamethylenetetramine $(3.5 \mathrm{~g}, 24.8 \mathrm{mmol})$ were dissolved in TFA $(7 \mathrm{~mL})$. The reaction was refluxed overnight, and cooled to room temperature. $40 \mathrm{~mL}$ of water was then added and the reaction was heated to $80{ }^{\circ} \mathrm{C}$ for 2 hours. After cooling to room temperature, the product was extracted with EtOAc $(50 \mathrm{~mL} \times 5)$. The organic layer was dried over $\mathrm{Na}_{2} \mathrm{SO}_{4}$, filtered, and concentrated in vacuo. The crude product was purified by silica column (2:1 Hexane:EtOAc) to afford compound 11 (678 $\mathrm{mg}, 53 \%)$ as a colorless liquid.

${ }^{1}$ H NMR: $\left(500 \mathrm{MHz}, \mathrm{CDCl}_{3}\right) \delta$ (ppm): 11.92 (s, 1H), 9.99 (s, 1H), 9.92 (s, 1H), 8.00 (d, $J=$ $2.1 \mathrm{~Hz}, 1 \mathrm{H}), 7.97(\mathrm{~d}, J=2.0 \mathrm{~Hz}, 1 \mathrm{H}), 3.68$ (t, $J=6.2 \mathrm{~Hz}, 2 \mathrm{H}), 2.88-2.81(\mathrm{~m}, 2 \mathrm{H}), 1.97-$ $1.88(\mathrm{~m}, 2 \mathrm{H})$.

${ }^{13}$ C NMR: $\left(126 \mathrm{MHz}, \mathrm{CDCl}_{3}\right) \delta$ (ppm): 196.37, 189.58, 164.56, 136.75, 134.83, 132.10, 128.97, 119.88, 61.79, 31.96, 25.21 .

HRMS: [M-H] $]^{-} \mathrm{m} / \mathrm{z}$ calcd. for $\left[\mathrm{C}_{11} \mathrm{H}_{11} \mathrm{O}_{4}\right]^{-} 207.0663$, found 207.0664. $(\Delta=0.48 \mathrm{ppm})$

Synthesis of compound $\mathbf{1 2}$

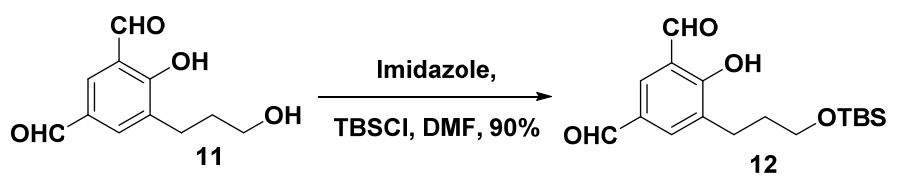

Compound 11 (208 mg, $1 \mathrm{mmol})$ was dissolved in anhydrous DMF $(15.0 \mathrm{~mL})$ at $0{ }^{\circ} \mathrm{C}$. Imidazole (75 mg, $1.1 \mathrm{mmol}$ ) was added followed by TBSCl $(165 \mathrm{mg}, 1.1 \mathrm{mmol})$ at $0{ }^{\circ} \mathrm{C}$ and stirred at room temperature for 30 minutes. After the reaction was completed, $50 \mathrm{~mL}$ of EtOAc was added into the reaction solution, and washed by water $(50 \mathrm{~mL} \times 3)$. The organic 
layer was dried over $\mathrm{Na}_{2} \mathrm{SO}_{4}$, filtered, and concentrated in vacuo. The crude residue was purified by silica column (30:1 Hexane: EtOAc) to afford 12 (298 mg, 90\%) as a colorless liquid.

${ }^{1}$ H NMR: (500 MHz, $\left.\mathrm{CDCl}_{3}\right) \delta$ (ppm): $11.82(\mathrm{~s}, 1 \mathrm{H}), 9.98(\mathrm{~s}, 1 \mathrm{H}), 9.90$ (s, 1H), 7.98 (d, $J=$ $2.1 \mathrm{~Hz}, 1 \mathrm{H}), 7.94(\mathrm{~d}, J=1.9 \mathrm{~Hz}, 1 \mathrm{H}), 3.65$ (t, $J=6.2 \mathrm{~Hz}, 2 \mathrm{H}), 2.82-2.77(\mathrm{~m}, 2 \mathrm{H}), 1.89-$ $1.82(\mathrm{~m}, 2 \mathrm{H}), 0.90(\mathrm{~s}, 9 \mathrm{H}), 0.04(\mathrm{~s}, 6 \mathrm{H})$.

${ }^{13}$ C NMR: (126 MHz, $\left.\mathrm{CDCl}_{3}\right) \delta$ (ppm): 196.49, 189.82, 164.87, 136.81, 134.83, 132.65, $128.91,120.00,62.40,31.92,26.06,26.06,26.06,25.74,18.43,-5.19,-5.19$.

HRMS: $[\mathrm{M}+\mathrm{Na}]^{+} \mathrm{m} / \mathrm{z}$ calcd. for $\left[\mathrm{C}_{17} \mathrm{H}_{26} \mathrm{O}_{4} \mathrm{SiNa}\right]^{+} 345.1493$, found 345.1499. $(\Delta=1.74$ ppm)

Synthesis of Compound $\mathbf{1 3}$

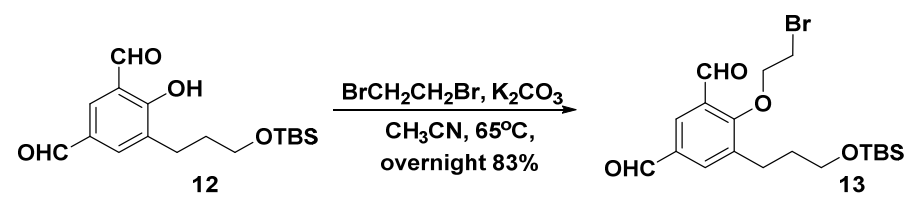

Compound 12 (161 mg, $0.5 \mathrm{mmol})$ was dissolved in anhydrous acetonitrile $(10.0 \mathrm{~mL})$. 1,2-Dibromoethane $(0.94 \mathrm{~g}, 5 \mathrm{mmol})$ was added followed by $\mathrm{K}_{2} \mathrm{CO}_{3}(138 \mathrm{mg}, 1 \mathrm{mmol})$ at room temperature. Then the reaction was stirred at $65{ }^{\circ} \mathrm{C}$ overnight. After the reaction was completed, the reaction solution was filtered, and concentrated in vacuo. The residue was purified by silica column (30:1 Hexane: EtOAc) to afford $\mathbf{1 3}(178 \mathrm{mg}, 83 \%)$ as a light yellow oil.

${ }^{1}$ H NMR: $\left(500 \mathrm{MHz}, \mathrm{CDCl}_{3}\right) \delta(\mathrm{ppm}): 10.42(\mathrm{~s}, 1 \mathrm{H}), 10.00(\mathrm{~s}, 1 \mathrm{H}), 8.20(\mathrm{~d}, J=2.2 \mathrm{~Hz}, 1 \mathrm{H})$, $8.04(\mathrm{~d}, J=2.2 \mathrm{~Hz}, 1 \mathrm{H}), 4.40-4.32(\mathrm{~m}, 2 \mathrm{H}), 3.76-3.71(\mathrm{~m}, 2 \mathrm{H}), 3.69(\mathrm{t}, J=6.0 \mathrm{~Hz}, 2 \mathrm{H})$, $2.90-2.83(\mathrm{~m}, 2 \mathrm{H}), 1.93-1.85(\mathrm{~m}, 2 \mathrm{H}), 0.91(\mathrm{~s}, 9 \mathrm{H}), 0.06(\mathrm{~s}, 6 \mathrm{H})$.

${ }^{13}$ C NMR: (126 MHz, $\left.\mathrm{CDCl}_{3}\right) \delta$ (ppm): 190.51, 189.21, 163.62, 138.35, 135.88, 132.99, $130.97,129.81,75.95,62.34,33.13,29.49,26.39,26.11,26.11,26.11,18.50,-5.15,-5.15$.

HRMS: $[\mathrm{M}+\mathrm{H}]^{+} \mathrm{m} / \mathrm{z}$ calcd. for $\left[\mathrm{C}_{19} \mathrm{H}_{30} \mathrm{BrO}_{4} \mathrm{Si}\right]^{+} 429.1091$, found $429.1092 .(\Delta=0.23 \mathrm{ppm})$

Synthesis of Compound 14
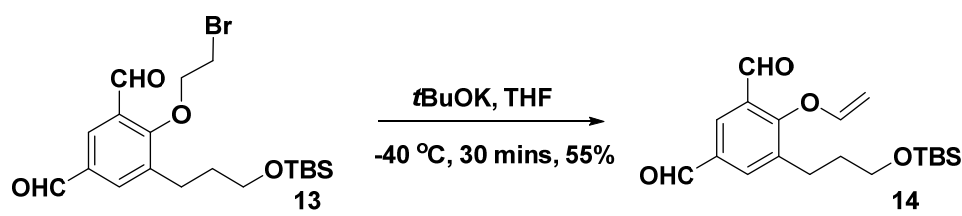

Compound 13 (108 mg, $0.25 \mathrm{mmol})$ was dissolved in anhydrous THF $(5 \mathrm{~mL})$ at $-40{ }^{\circ} \mathrm{C}$, at which point a $1 \mathrm{M}$ solution in THF of $t$ - BuOK $(0.5 \mathrm{mmol})$ was slowly added over 10 minutes, and the reaction was stirred at $-40{ }^{\circ} \mathrm{C}$ for 30 minutes. After the reaction was completed, the reaction was quenched by water, and the reaction solution was extracted with EtOAc $(30 \mathrm{~mL}$ 
$\times 3$ ). The organic layer was dried over $\mathrm{Na}_{2} \mathrm{SO}_{4}$, filtered, and concentrated in vacuo. The residue was purified by silica column (50:1 Hexanes: EtOAc) to afford 14 (47 $\mathrm{mg}, 55 \%)$ as a light yellow oil.

${ }^{1}$ H NMR: (500 MHz, $\left.\mathrm{CD}_{2} \mathrm{Cl}_{2}\right) \delta(\mathrm{ppm}): 10.25(\mathrm{~s}, 1 \mathrm{H}), 10.02(\mathrm{~s}, 1 \mathrm{H}), 8.23(\mathrm{~s}, 1 \mathrm{H}), 8.08$ (s, $1 \mathrm{H}), 6.89-6.75(\mathrm{~m}, 1 \mathrm{H}), 4.38(\mathrm{dd}, J=6.3,2.8 \mathrm{~Hz}, 1 \mathrm{H}), 4.16$ (dd, $J=14.1,2.8 \mathrm{~Hz}, 1 \mathrm{H}), 3.66$ $(\mathrm{dd}, J=8.2,3.8 \mathrm{~Hz}, 2 \mathrm{H}), 2.84-2.73(\mathrm{~m}, 2 \mathrm{H}), 1.86(\mathrm{dd}, J=7.5,6.0 \mathrm{~Hz}, 2 \mathrm{H}), 0.91(\mathrm{~s}, 9 \mathrm{H})$, $0.05(\mathrm{~s}, 6 \mathrm{H})$.

${ }^{13}$ C NMR: (126 MHz, $\left.\mathrm{CD}_{2} \mathrm{Cl}_{2}\right) \delta$ (ppm): 191.03, 189.07, 160.12, 152.37, 138.72, 136.32, $134.33,130.19,129.36,92.85,62.73,33.28,26.51,26.24,26.24,26.24,18.67,-5.09,-5.09$.

HRMS: $[\mathrm{M}+\mathrm{H}]^{+} \mathrm{m} / \mathrm{z}$ calcd. for $\left[\mathrm{C}_{19} \mathrm{H}_{29} \mathrm{O}_{4} \mathrm{Si}\right]^{+} 349.1830$, found 349.1830. ( $\left.\Delta=0.00 \mathrm{ppm}\right)$

Synthesis of VE-Cy
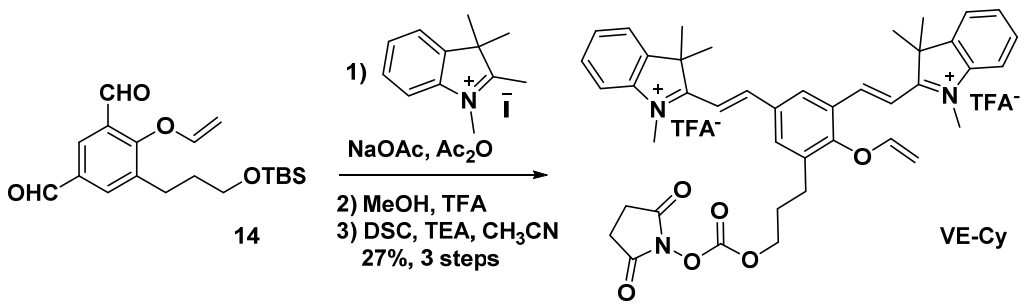

A mixture of compound 14 (7 mg, $0.02 \mathrm{mmol}), \mathrm{NaOAc}(4 \mathrm{mg}, 0.048 \mathrm{mmol}$ ), and 1,2,3,3-tetramethyl-3H-indolium iodide $(14.5 \mathrm{mg}, 0.048 \mathrm{mmol})$ was dissolved in $1 \mathrm{~mL} \mathrm{Ac}_{2} \mathrm{O}$. The reaction mixture was stirred for 30 minutes at $80{ }^{\circ} \mathrm{C}$ under an $\mathrm{Ar}$ atmosphere and monitored by HPLC-MS. After the reaction was completed, the solvent was removed in vacuo, the crude product was purified by semi-preparative HLPC, then the resulting product was dissolved in $2 \mathrm{~mL}$ of a 5\% TFA in methanol solution. The reaction mixture was stirred for 1 hour at room temperature and monitored by HPLC-MS. After the reaction was completed, the solvent was removed in vacuo and the crude intermediate was dissolved in 1 $\mathrm{mL}$ anhydrous $\mathrm{CH}_{3} \mathrm{CN}$ followed by addition of triethylamine $(28 \mu \mathrm{L}, 0.2 \mathrm{mmol})$ then subsequently $N, N^{\prime}$-disuccinimidyl carbonate $(51.2 \mathrm{mg}, 0.2 \mathrm{mmol})$ in portions over 3 hours monitoring the reaction by HPLC. This solution was stirred at room temperature for a total of 3 hours until the reaction had completed. The reaction solvent was removed in vacuo, the residue was dissolved in $\mathrm{MeOH}$, and purified by preparative RP-HPLC (grad. 15\%-100\% $\mathrm{MeOH}$ in water with $0.1 \% \mathrm{TFA}, 30 \mathrm{~min}$ ) to give VE-Cy (4 mg, 27\% in 3 steps) as a yellow solid.

${ }^{1}$ H NMR: $\left(500 \mathrm{MHz}, \mathrm{CD}_{2} \mathrm{Cl}_{2}\right) \delta$ (ppm): $8.88(\mathrm{~s}, 1 \mathrm{H}), 8.35(\mathrm{~m}, 2 \mathrm{H}), 8.00(\mathrm{~m}, 2 \mathrm{H}), 7.80$ (s, $1 \mathrm{H}), 7.63(\mathrm{~m}, 9 \mathrm{H}), 6.90(\mathrm{dd}, J=14.0,6.3 \mathrm{~Hz}, 1 \mathrm{H}), 4.48(\mathrm{dd}, J=6.1,2.7 \mathrm{~Hz}, 1 \mathrm{H}), 4.39$ (t, $J=$ $5.8 \mathrm{~Hz}, 2 \mathrm{H}), 4.32-4.21(\mathrm{~m}, 7 \mathrm{H}), 2.88(\mathrm{t}, J=7.4 \mathrm{~Hz}, 2 \mathrm{H}), 2.83(\mathrm{~s}, 4 \mathrm{H}), 2.17(\mathrm{~d}, J=6.8 \mathrm{~Hz}$, 2H), $1.86(\mathrm{~s}, 6 \mathrm{H}), 1.82$ (s, 6H). 
${ }^{13}$ C NMR: (126 MHz, $\left.\mathrm{CD}_{2} \mathrm{Cl}_{2}\right) \delta$ (ppm): 181.23, 181.07, 167.31, 167.31, 158.62, 154.96, $151.14,149.88,149.33,149.11,145.78,141.78,139.65,139.59,135.83,135.67,134.91$, $130.77,129.29,128.89,128.32,128.09,127.46,121.31,121.12,121.09,113.20,112.28$, $91.53,68.78,51.46,51.35,33.55,33.26,33.14,26.79,24.78,24.66,24.58,24.30,24.28$, 23.95 .

HRMS: $[\mathrm{M}]^{2+} \mathrm{m} / \mathrm{z}$ calcd. for $\left[\mathrm{C}_{42} \mathrm{H}_{45} \mathrm{~N}_{3} \mathrm{O}_{6}\right]^{2+}$ 343.6649, found 343.6647. $(\Delta=0.58 \mathrm{ppm})$

\subsection{Synthesis of $\mathrm{Tz}$}

The synthesis of the 3,6-Di(2-pyridinyl)-1,2,4,5-tetrazine dervatitive $\mathbf{T z}$ is identical to that of a previous report ${ }^{(3)}$.

\section{Oligonucleotide probe synthesis and characterization}

3.1 General procedure for oligonucleotide probe modification.

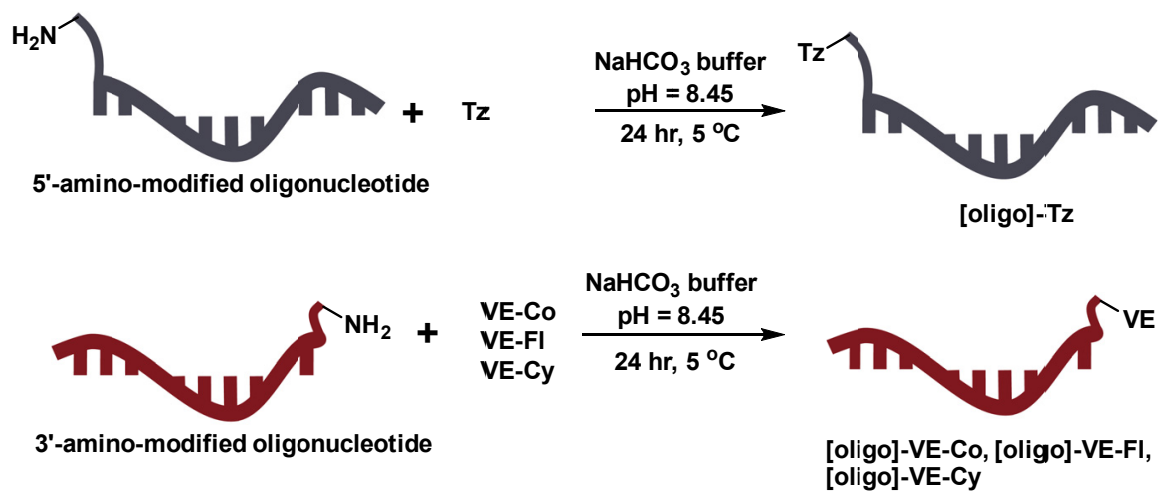

\section{Chemical Conjugation to Oligonucleotides}
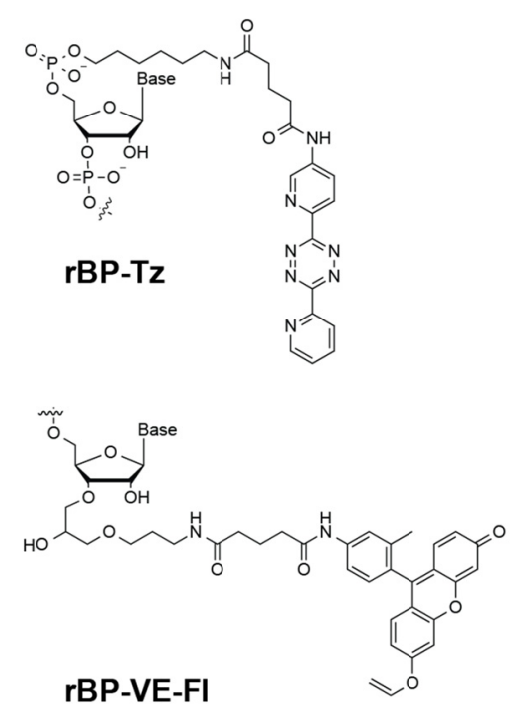
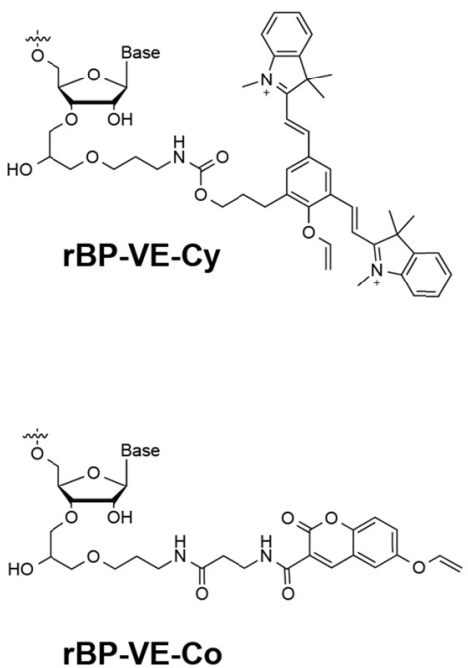

Amine-modified oligonucleotide sequences at selected terminus (1 eq) were dissolved in a $0.1 \mathrm{mM}$ sodium bicarbonate buffer $(\mathrm{pH}=8.45)$ (oligonucleotide final concentration $1 \mathrm{mM}$ ). A $30 \mathrm{mM}$ solution of the appropriate label (typically vinyl ether-NHS (VE-Co, VE-FI and 
VE-Cy) or tetrazine-NHS (Tz)) (30 eq) in DMSO was added in one portion. The reaction was left at $5{ }^{\circ} \mathrm{C}$ for $12-24$ hours while monitoring reaction progress by HPLC. The main product formed without significant side reactions. It was important to carefully purify the oligonucleotide after modification and to lyophilize the sample to remove solvent immediately after HPLC. The purified products were stored immediately as dry lyophilized solids at $-80{ }^{\circ} \mathrm{C}$ and care was taken not to subject the compounds to freeze thaw cycles. The purity of all compounds was verified by LC-MS prior to activation experiments.

LC-MS conditions: An Agilent 1260 HPLC system coupled with an Agilent 6230 time of flight mass spectrometer (TOFMS) was employed for LC-TOFMS analysis. The instrument was operated under negative ion mode use Jetstream electrospray ionization (ESI) as the ion source. A Phenomenex Clarity Oligo-MS column $(2.1 \mathrm{~mm}$ x $150 \mathrm{~mm}, 2.6 \mu \mathrm{m})$ was used for separation by using TEA : HFIP : $\mathrm{H}_{2} \mathrm{O}(0.4: 30: 1000 \mathrm{v} / \mathrm{v})$ as mobile phase A and $\mathrm{MeOH}$ as mobile phase B. LC gradient is as follows: Initial conditions $95 \% \mathrm{~A}, 5 \% \mathrm{~B}$, hold 1 min then a linear gradient starting at $1 \mathrm{~min}$ and ending at 16 min with $50 \% \mathrm{~A}, 50 \% \mathrm{~B}$. 
3.2 Table S1-2: Probe and template sequences

\begin{tabular}{|c|c|c|c|}
\hline \multicolumn{3}{|c|}{ Probe Sequences } & \\
\hline Name & Type & 5'-Sequence & Modification \\
\hline dBP-Tz & DNA & /5AmMC6/ GAT CTA TGG CGT CAA & $\mathbf{T z}$ \\
\hline dBP-VE & DNA & CGA TTG AAC ACT CCA/3AmMO/ & VE-Co,VE-F, VE-Cy \\
\hline rBP-Tz & $\begin{array}{l}\text { 2'-O-Methyl RNA } \\
\text { with }\end{array}$ & $\begin{array}{c}/ 5 \mathrm{AmMC} / \mathrm{U} * \mathrm{GA} * \mathrm{UU} * \mathrm{UA} * \mathrm{GA}^{*} \mathrm{UA} * \mathrm{CA} \\
* \mathrm{UG}\end{array}$ & $\mathbf{T z}$ \\
\hline rBP-VE & $\begin{array}{l}\text { Phosphorothioate } \\
\text { Bond }\end{array}$ & $\begin{array}{c}\mathrm{G}^{*} \mathrm{AA} * \mathrm{AA}^{*} \mathrm{UG}^{*} \mathrm{AU} \mathrm{UGG}^{*} \mathrm{GU} * \mathrm{G} \\
/ 3 \mathrm{AmO} /\end{array}$ & VE-Cy \\
\hline
\end{tabular}

Table S1: Table of probe sequences. /5AmMC6 /: 5' Amino Modifier C6. /3AmMO/: 3' Amino Modifier. *: Phosphorothioated RNA

\begin{tabular}{|c|c|c|}
\hline \multicolumn{2}{|c|}{ Template Sequences } \\
\hline Name & Type & 5'-Sequence \\
\hline dBT & DNA & 5'-TTG ACG CCA TAG ATC A TGG AGT GTT CAA TCG \\
\hline dBT-mis & DNA & 5'-TTG ACG CCA TAG ATC A TGG AGC GTT CAA TCG \\
\hline & & \\
\hline rBT & RNA & 5'-CAU GUA UCU AAA UCA G CAC CCA UCA UUU UC \\
\hline
\end{tabular}

Table S2: Table of Template Sequences 


\subsection{Characterization of dBP-Tz}

I5AmMC6/GTA CTA TGG CGT CAA -3' + Tz

Molecular Weight: 4771.2

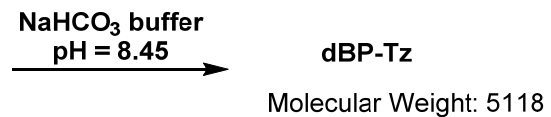

ESI-TOF MS of modified oligonucleotides. The original ESI-TOFMS spectrum and deconvoluted mass are shown, respectively.

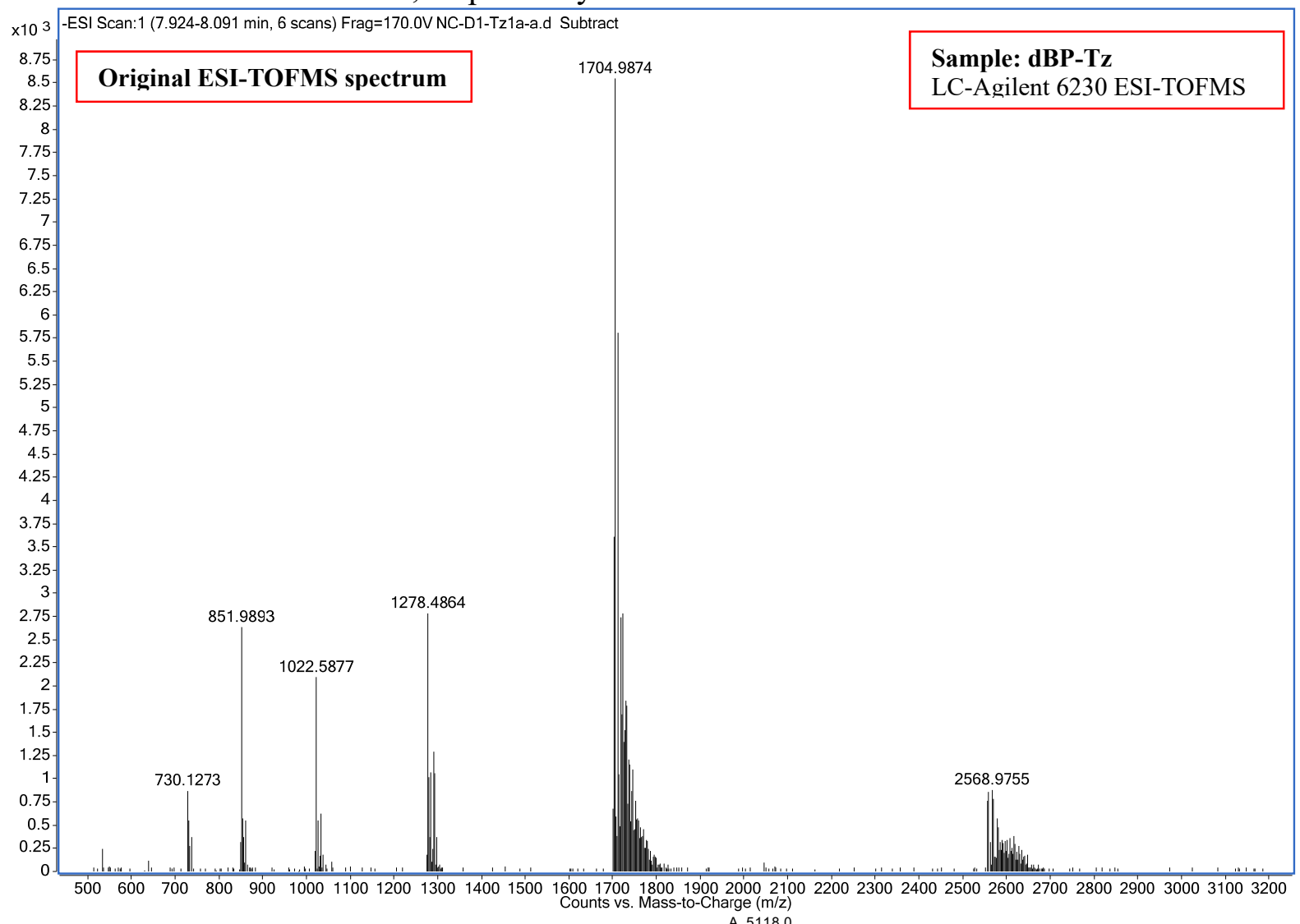

Deconvoluted mass spectrum

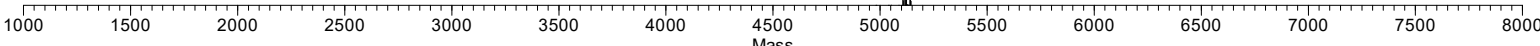




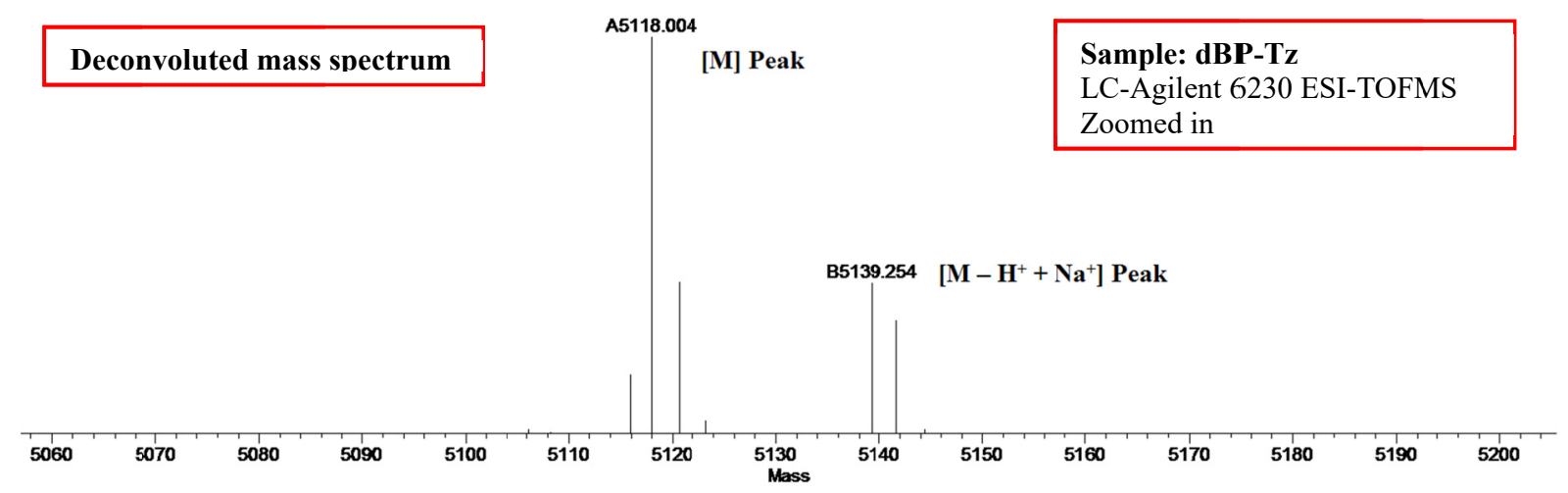

\subsection{Characterization of dBP-VE-Co}
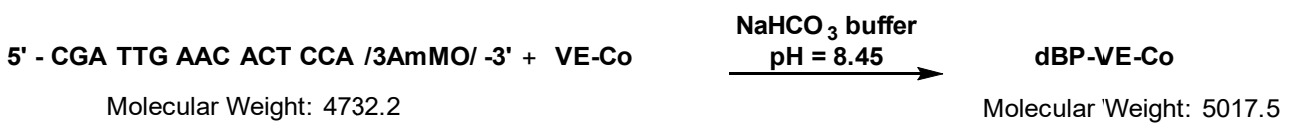

ESI-TOF MS of modified oligonucleotides. The original ESI-TOFMS spectrum and deconvoluted mass are shown, respectively.

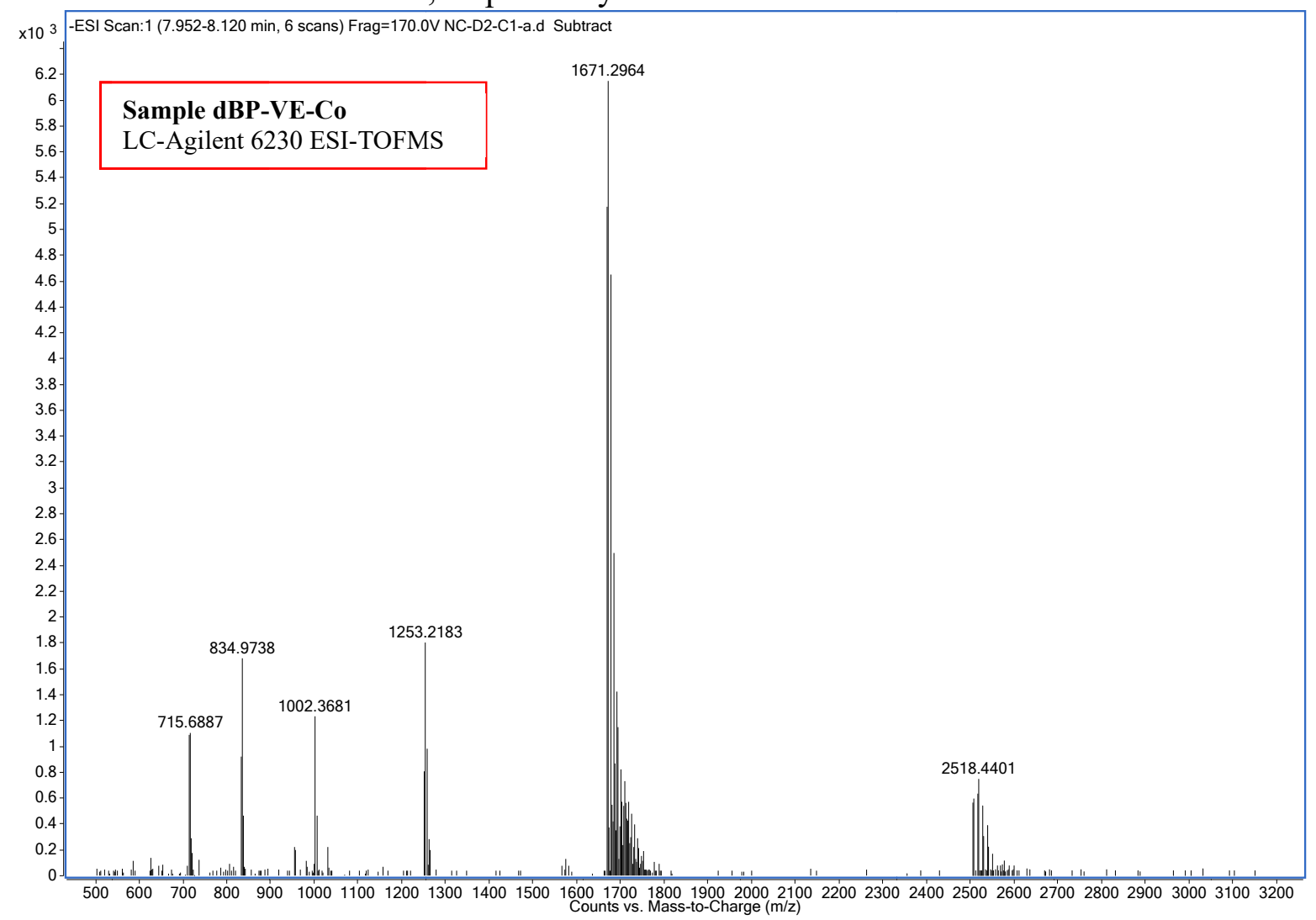




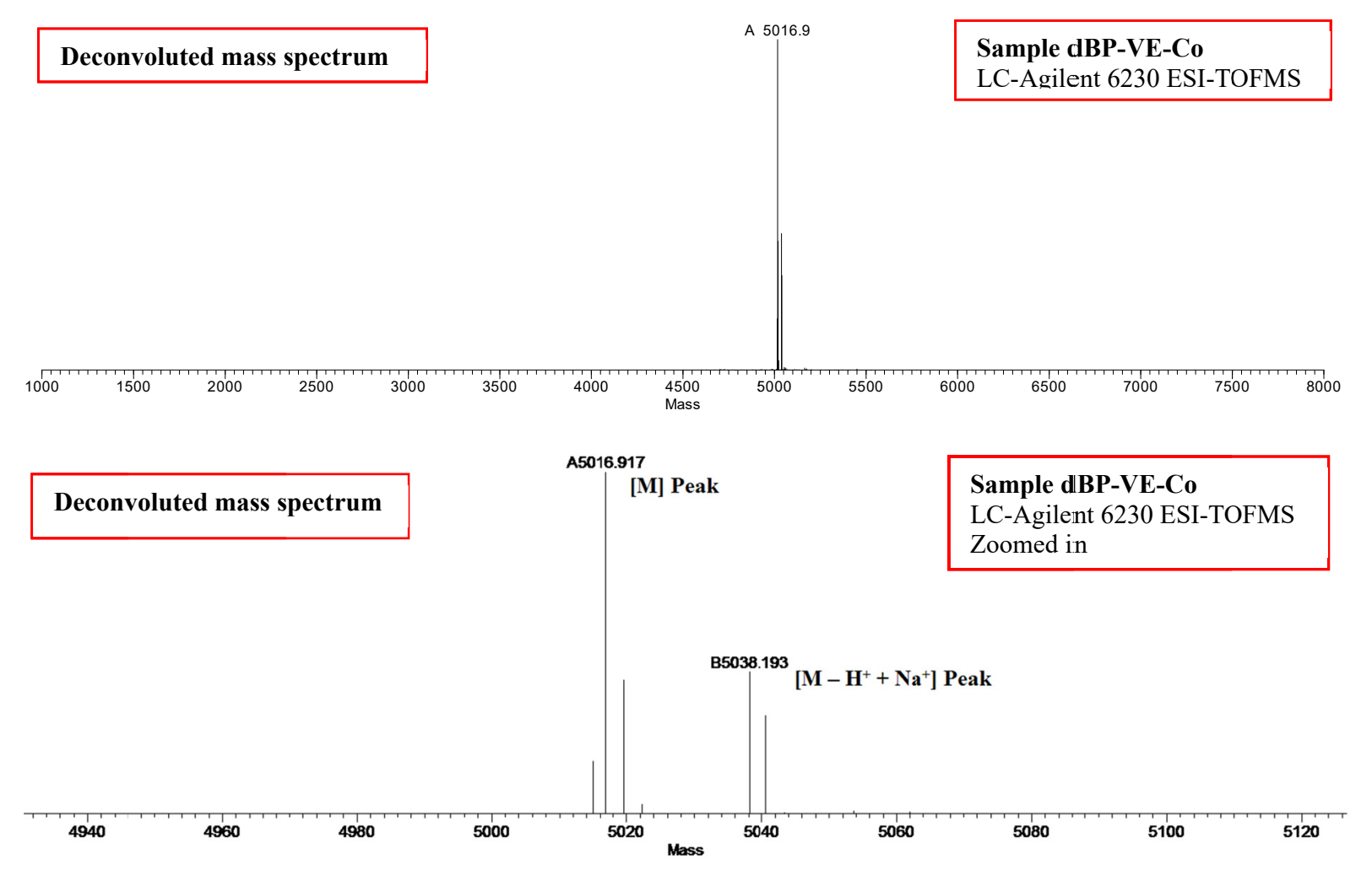

\subsection{Characterization of dBP-VE-FI}

5' - CGA TTG AAC ACT CCA /3AmMO/ -3' + VE-FI

Molecular Weight: 4732.2
$\mathrm{NaHCO}_{3}$ buffer $\mathrm{pH}=\mathbf{8 . 4 5}$

Molecular Weight: 5171.2

ESI-TOF MS of modified oligonucleotides. The original ESI-TOFMS spectrum and deconvoluted mass are shown, respectively.

\section{Original ESI-TOFMS spectrum}

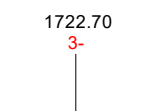

Sample dBP-VE-F

LC-Agilient 6230 ESI-TOFMS

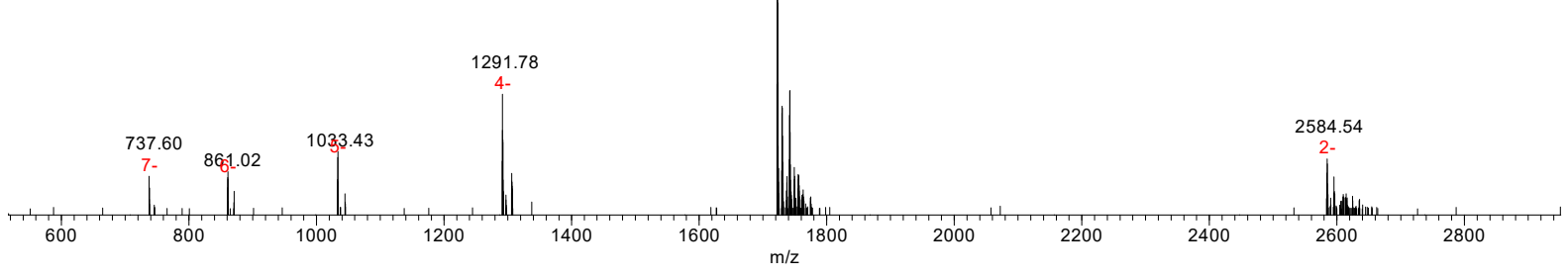




$3500 \quad 4000$

$\begin{array}{llll}4500 & 5000 & 5500 & 6000 \\ \text { Mass } & & \end{array}$

$\begin{array}{lllll}6000 & 6500 & 7000 & 7500 & 8000\end{array}$

\subsection{Characterization of dBP-VE-Cy}

5' - CGA TTG AAC ACT CCA /3AmMO/ -3' + VE-Cy
Molecular Weight: 4732.2 $\stackrel{\begin{array}{c}\mathrm{NaHCO}_{3} \text { buffer } \\ \mathrm{pH}=8.45\end{array}}{\longrightarrow} \begin{gathered}\text { dBP-VE-Cy } \\ \text { Molecular Weight: } 5305.0\end{gathered}$

ESI-TOF MS of modified oligonucleotides. The original ESI-TOFMS spectrum and deconvoluted mass are shown, respectively.

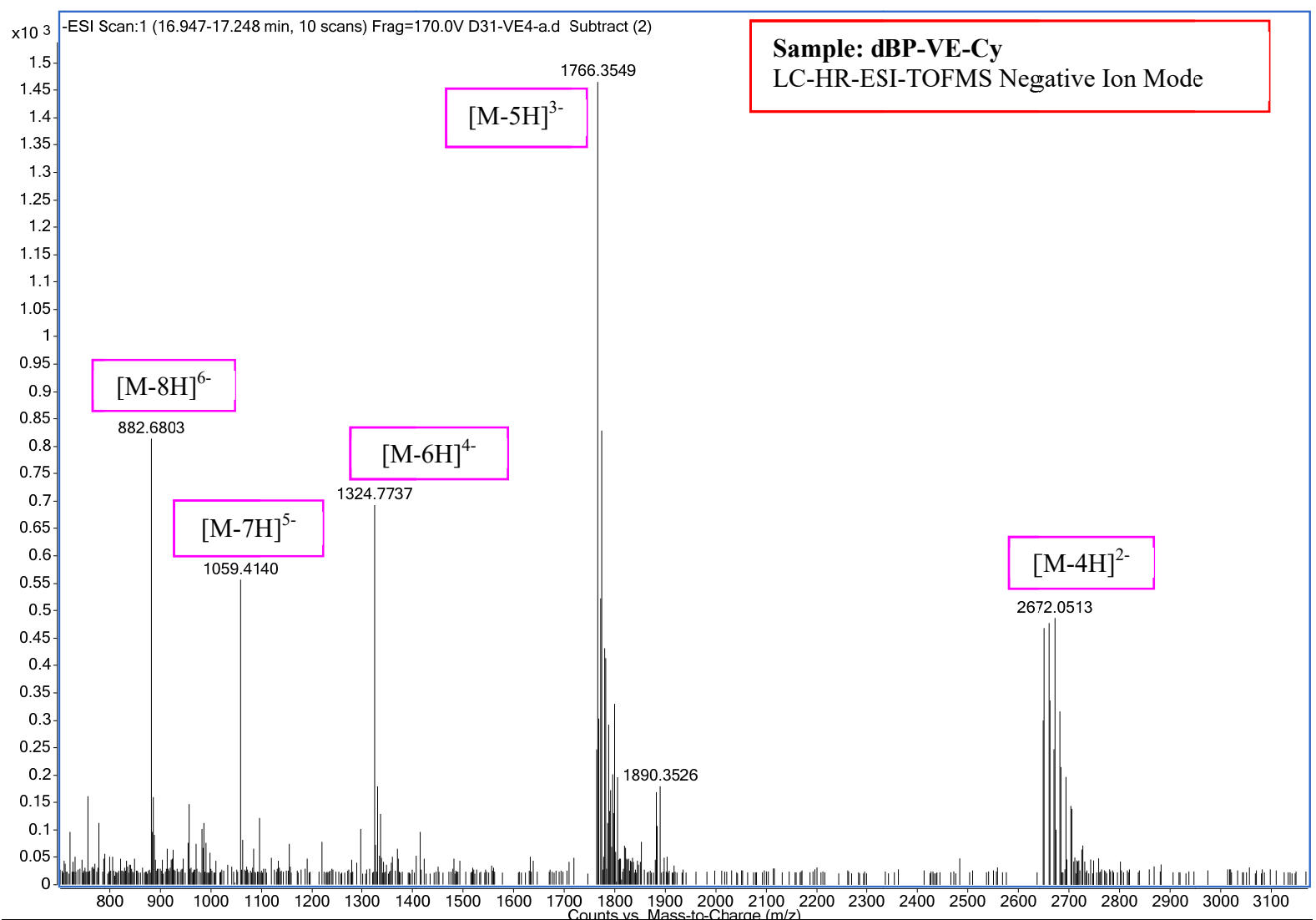



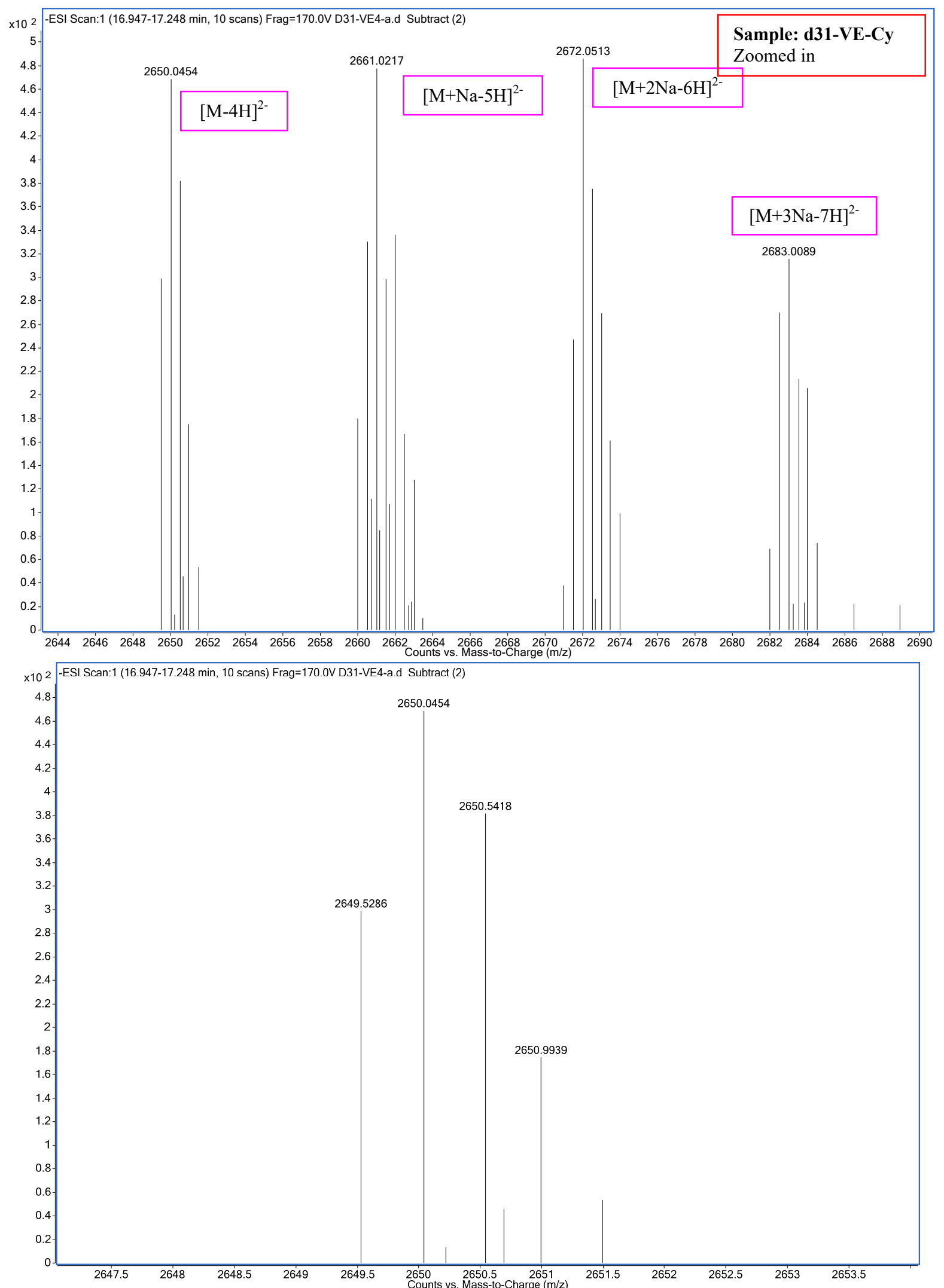


$500 \quad 2000 \quad 2500 \quad 3000$

\subsection{Characterization of rBP-Tz}
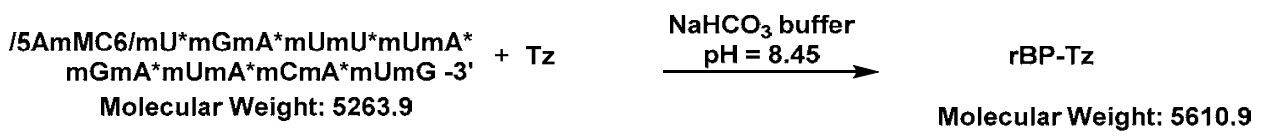

ESI-TOF MS of modified oligonucleotides. The original ESI-TOFMS spectrum and deconvoluted mass are shown, respectively.

\section{Original ESI-TOFMS spectrum}

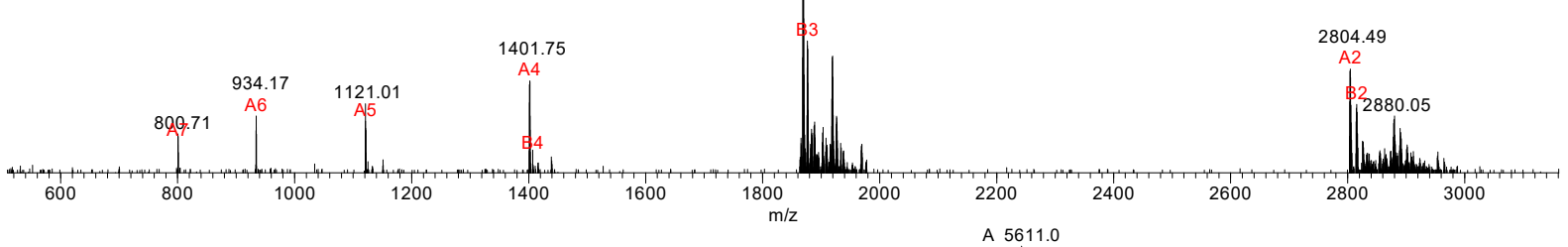

Deconvoluted mass spectrum

M Peak

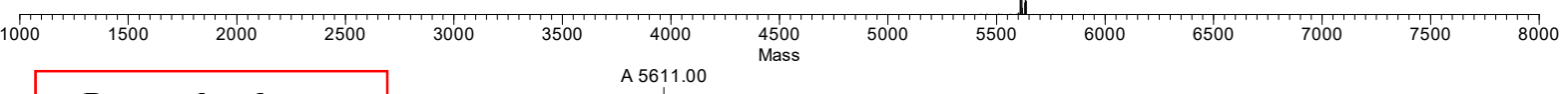

Deconvoluted mass spectrum Zoomed in

$5500 \quad 5520 \quad 5540 \quad 5560 \quad 5580 \quad 5600$

$[\mathrm{M}-\mathrm{H}+\mathrm{Na}]$

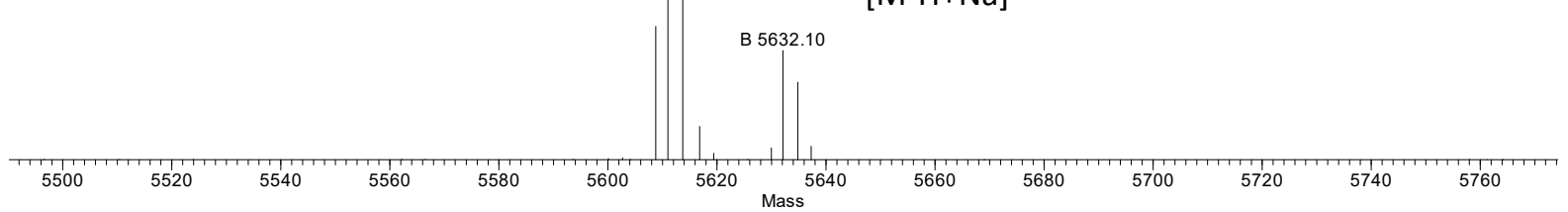




\subsection{Characterization of rBP-VE-Cy}
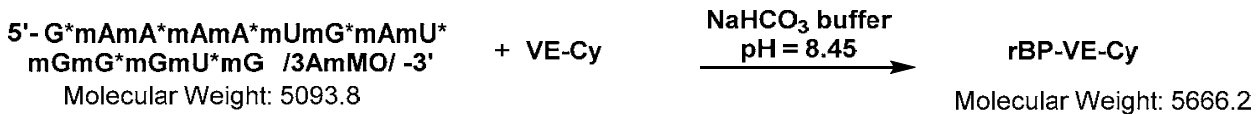

ESI-TOF MS of modified oligonucleotides. The original ESI-TOFMS spectrum and deconvoluted mass are shown, respectively.

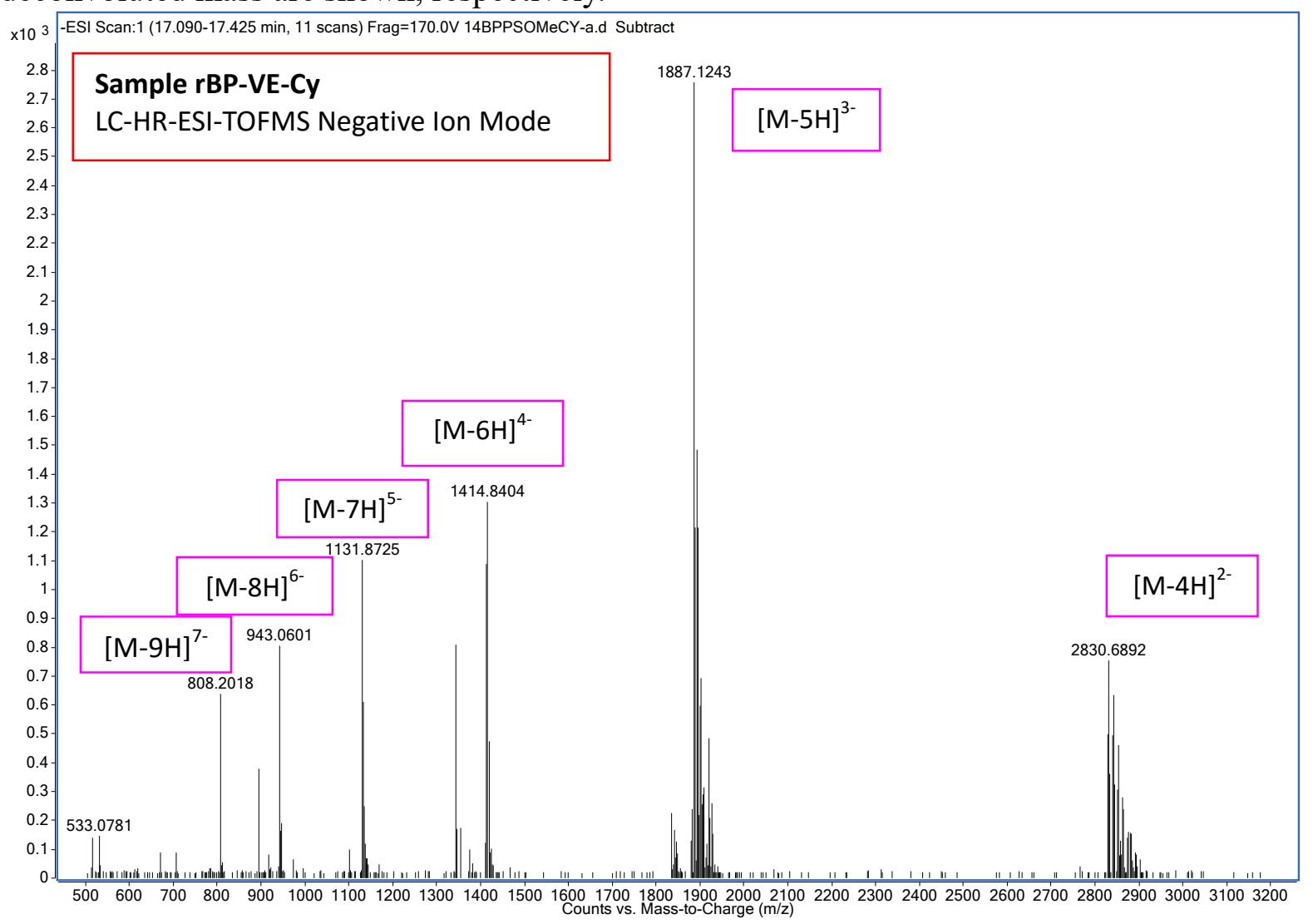

Original ESI-TOFMS spectrum

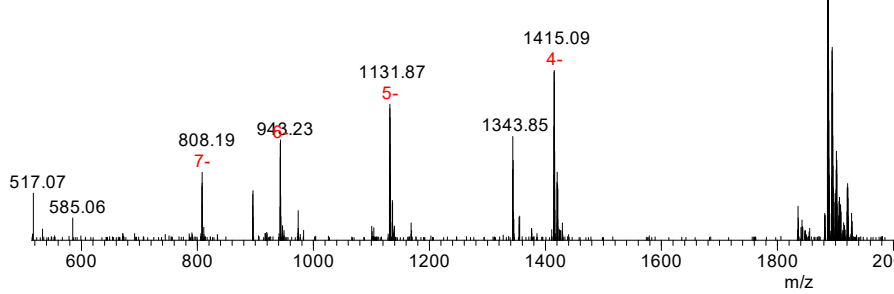

Deconvoluted mass spectrum

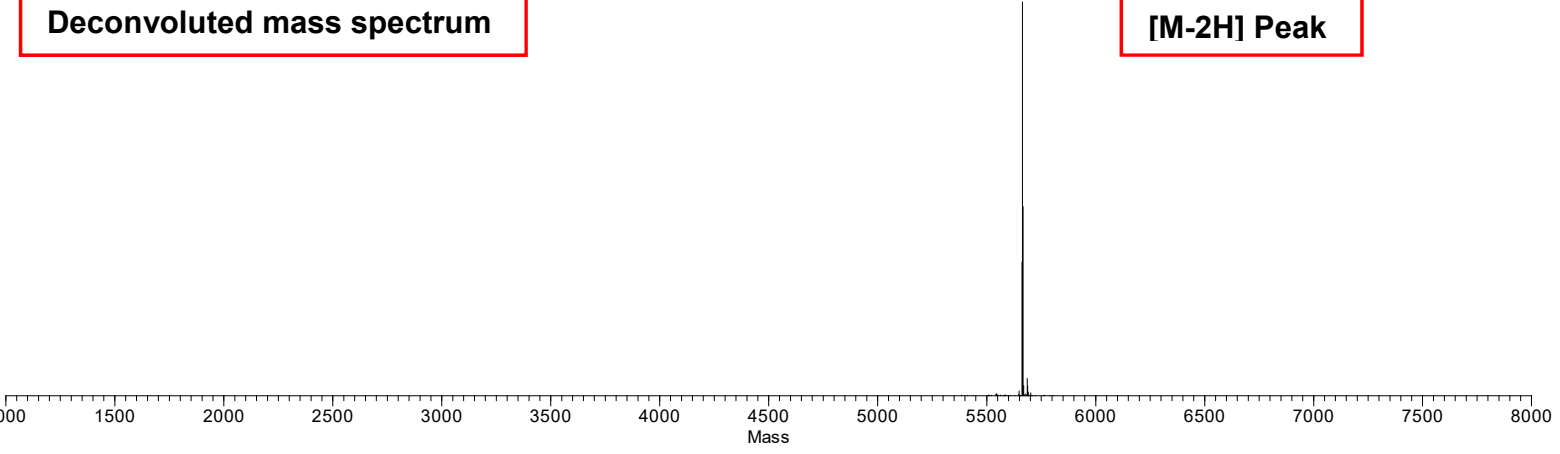




\subsection{Figure S1: Melting curves of rBPs with rBT}

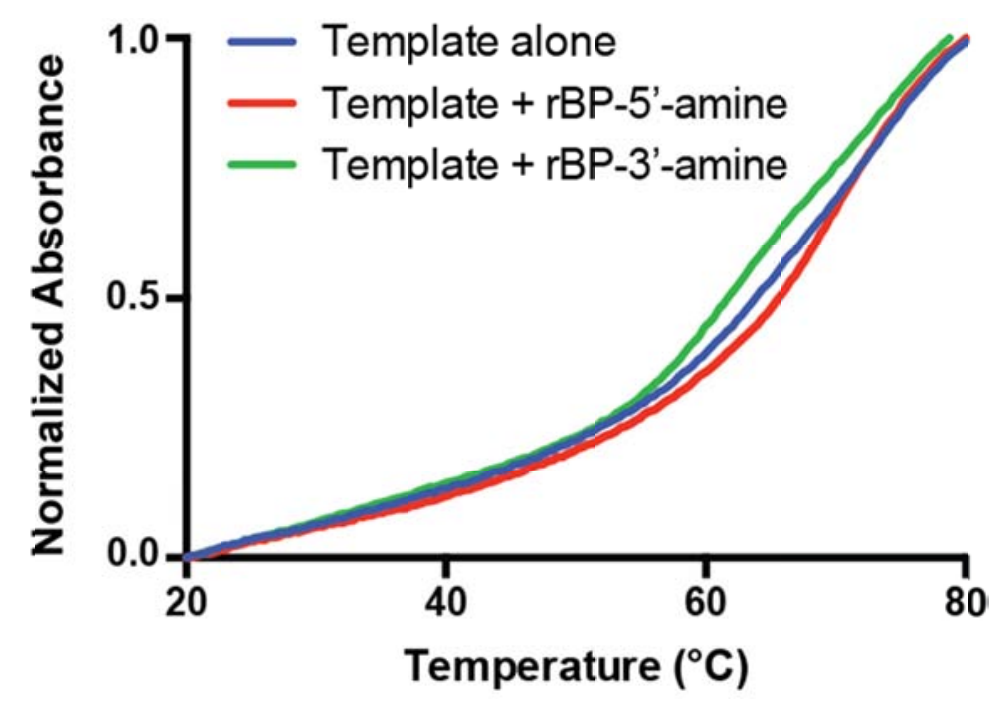

Figure S1: Melting curves were generated by incubating $1 \mu \mathrm{M}$ of RNA binding template either alone (blue), with $1 \mu \mathrm{M}$ of the free amine modified precursor of oligo rBP-Tz (red), or rBP-VE (green) in phosphate buffered saline solution. The absorbance was then monitored as a function of temperature to determine the melting curve. After an initial 5 minute $80{ }^{\circ} \mathrm{C}$ melt followed by cooling over 5 minutes, measurements were collected between $20-80{ }^{\circ} \mathrm{C}$ with a ramp rate of 1 degree per minute. Three cycles were averaged and plotted to generate the curves shown above. Minimal deviation from the three collected samples below $\sim 50{ }^{\circ} \mathrm{C}$ suggests the probes do not dissociate from the template to any significant extent at $37{ }^{\circ} \mathrm{C}$. This confirms the melting temperatures are high enough to prevent probe turnover in agreement with predicted melting temperatures from IDT.

\section{Kinetic measurements}

\subsection{Scheme S1: Model tetrazine decaging reaction for kinetic studies}

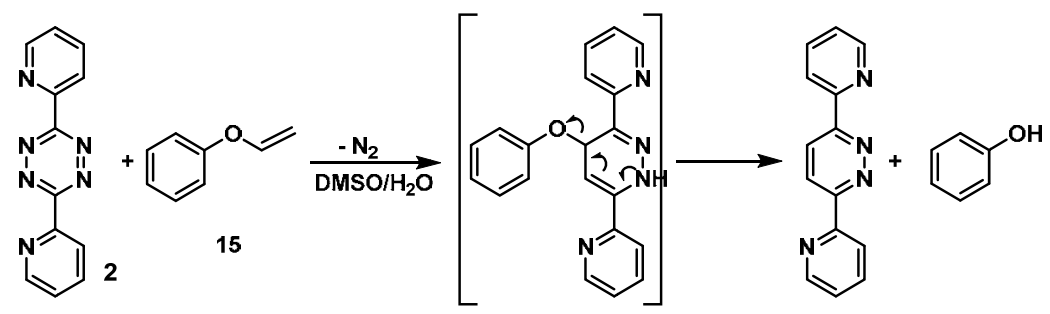

\subsection{Model reaction kinetics}

The kinetic experiment was conducted under pseudo-first order conditions.. Phenyl vinyl ether (15) at three separate concentrations was reacted with 3,6-di-(2-pyridyl)-s-tetrazine (2, $5 \mathrm{mM})$ in a $1 \mathrm{~mL}$ solution of 9:1 DMSO: $\mathrm{H}_{2} \mathrm{O}$. The absorption at $520 \mathrm{~nm}$ was measured every 30 
seconds monitoring the decrease in intensity over time (Figure S2, colored lines). The reaction was carried out at $37^{\circ} \mathrm{C}\left( \pm 0.5{ }^{\circ} \mathrm{C}\right)$ in a $1 \mathrm{~mL} \mathrm{UV}$ cuvette. The data was fit by one-phase exponential decay curves (Figure S2 dotted lines) to yield observed first-order rate constants from which the second order rate constant of $k=7.21( \pm 0.60) \times 10^{-4} \mathrm{M}^{-1} \mathrm{~s}^{-1}$ could be derived from the slope of the fit of observed rate versus concentration. 


\subsection{Figure S2: Plot of $2+15$ reaction kinetics}

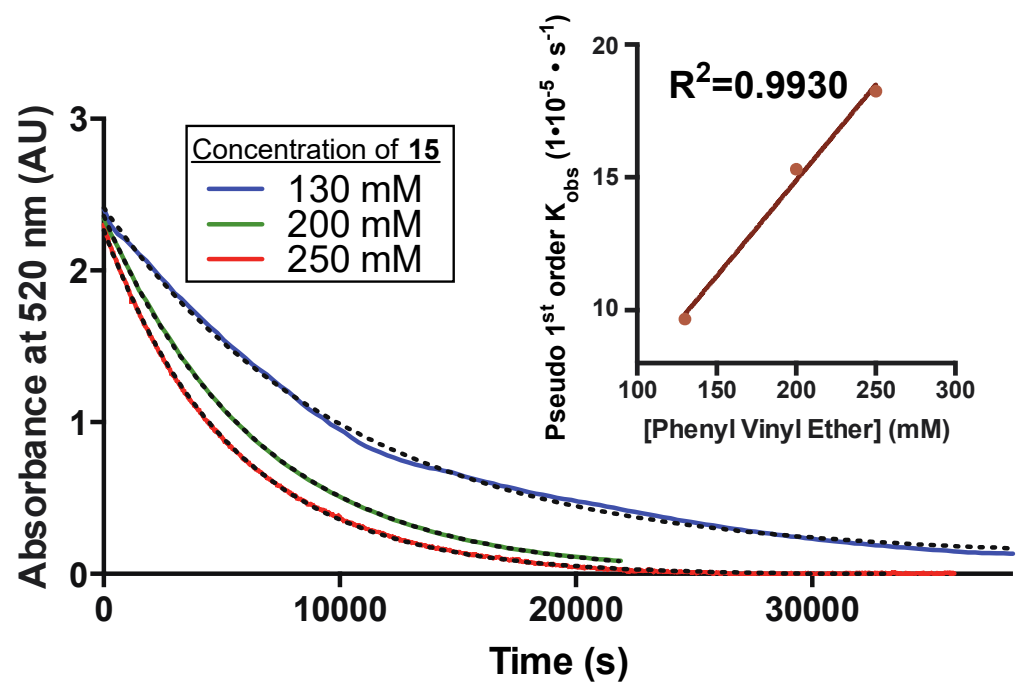

Figure S2: Reaction kinetics measurement of $2(5 \mathrm{mM})$ with 15 at three separate concentrations in $\mathrm{DMSO} / \mathrm{H}_{2} \mathrm{O}=9: 1$ at $37^{\circ} \mathrm{C}$. Inset graph illustrates linear plot of the pseudo $1^{\text {st }}$ order kinetics to calculate the $2^{\text {nd }}$ order rate constant.

\subsection{Templated reaction kinetics}

A TECAN Genios Pro/384-well multifunction microplate reader was used in the kinetic measurements, and the increase of the fluorescence intensity (excitation at $420 \mathrm{~nm}$ ) was measured over time. A solution of $\mathbf{~ d B P - T z}$ and $\mathbf{~ d B P - V E - C o}$ at $1 \mu \mathrm{M}$ was reacted with $1 \mu \mathrm{M}$ of $\mathbf{d B T}$ in a $100 \mathrm{mM}$ Tris- $\mathrm{HCl}(\mathrm{pH}=7.4)$ buffer containing $200 \mathrm{mM} \mathrm{MgCl}_{2}$, consistent with previous studies. Measurement commenced immediately upon the addition of dBP. All measurements were done at $37^{\circ} \mathrm{C}$.

The increase in fluorescence intensity over time is shown in Figure S3 (black dots). The fluorescence data was fitted with a one-phase exponential association curve (Figure S3, red line) and the observed first order rate constant was determined to be $0.00021 \pm 0.000003 \mathrm{~s}^{-1}$ with a $\mathrm{t}_{1 / 2}=54.9$ minutes. 
4.5 Figure S3: Plot of DNA templated reaction kinetics of dBP-Tz with dBP-VE-Co

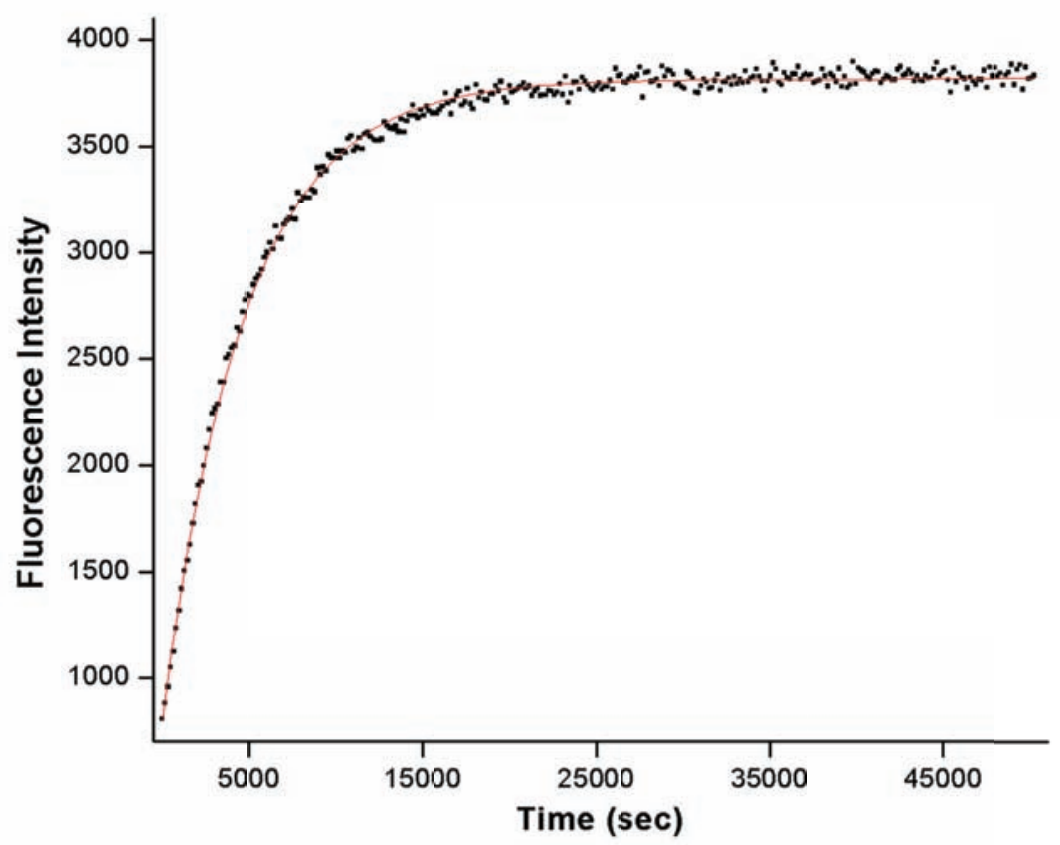

Figure S3: Reaction kinetics measurement of $1 \mu \mathrm{M}$ dBP-Tz with dBP-VE-Co and dBP in Tris- $\mathrm{HCl}$ buffer $(\mathrm{pH}=7.4)$ at $37^{\circ} \mathrm{C}$.

\section{Absorbance and fluorescence spectra of vinyl ether probes and their corresponding fluorophores}

\subsection{Figure S4: Absorbance and fluorescence emission spectra of 4 and 1}
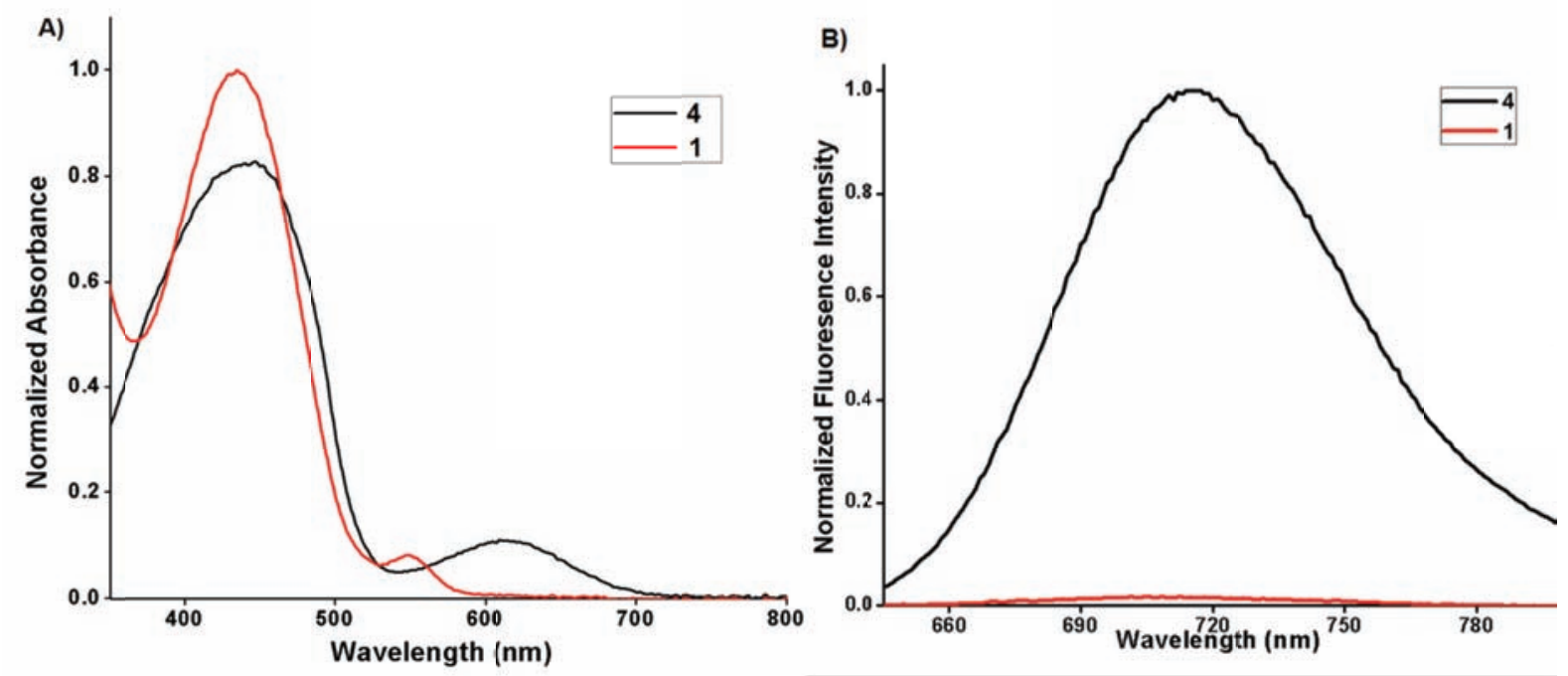

Figure S4. A). Normalized UV-Vis absorption spectrums of 4 (black) and 1 (red), both compounds were dissolved in $100 \mu \mathrm{M}$ EtOH solution. B) Normalized fluorescence emission spectrum of 4 (black) and 1 (red), in $1 \mu \mathrm{M}$ phosphate-buffered saline (PBS) at $\mathrm{pH} 7.4$, with an excitation wavelength of $620 \mathrm{~nm}(\mathrm{ex} \pm 3 \mathrm{~nm}$, em $\pm 3 \mathrm{~nm})$. A solution of compound 1 was obtained by directly diluting the stock solution with PBS to a final concentration of $1 \mu \mathrm{M}$. A 
solution of compound $\mathbf{4}$ was obtained after completion of the reaction between compounds $\mathbf{1}$ and 2 as indicated by TLC. This solution was directly diluted into PBS to a final concentration of $1 \mu \mathrm{M}$.

\subsection{Figure S5: Absorbance and fluorescence emission spectrum of 5 and 6}
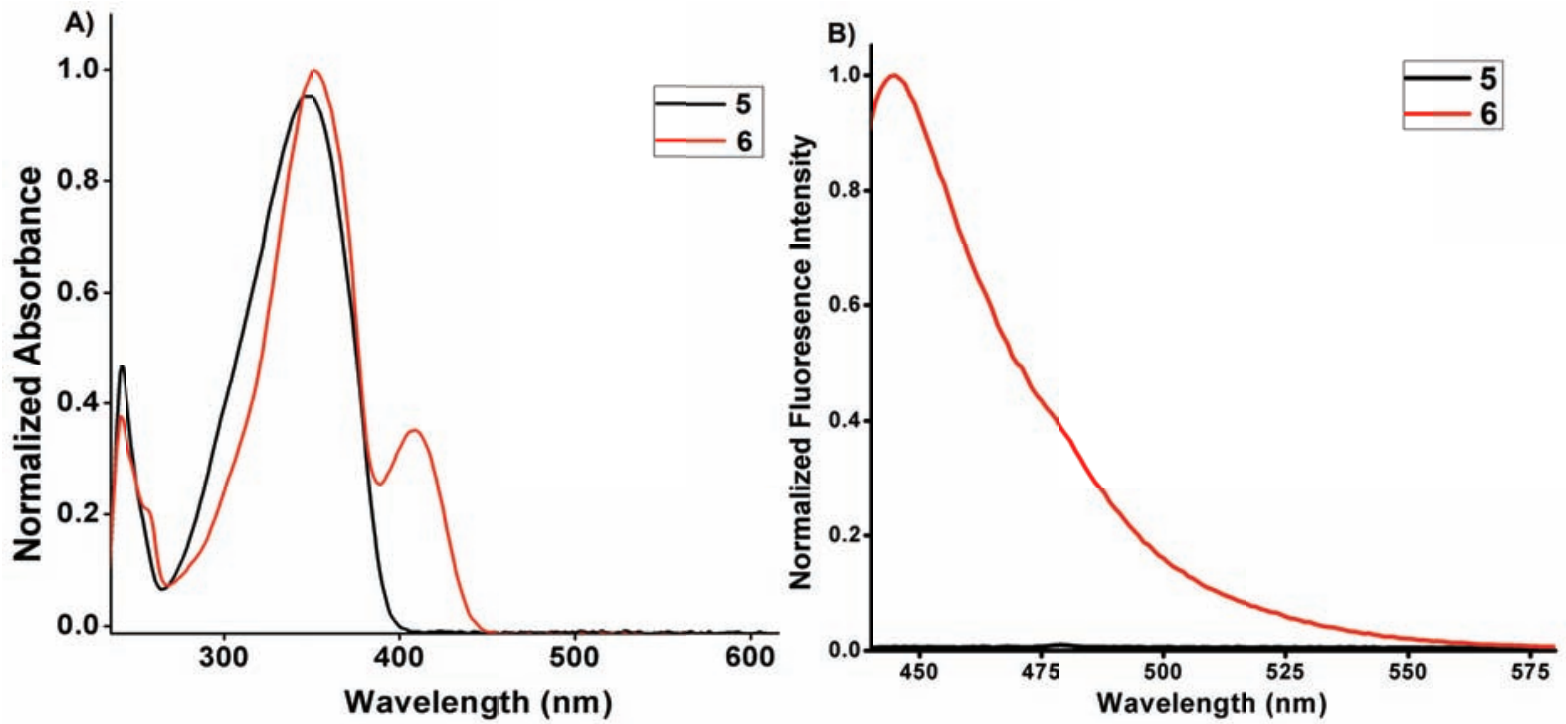

Figure S5. A). Normalized UV-Vis absorption spectrums of 5 (black) and 6 (red), both compounds were dissolved in $100 \mu \mathrm{M}$ EtOH solution. B) Normalized fluorescence emission spectrum of 5 (black) and 6 (red), in $1 \mu \mathrm{M} 20 \%$ DMF in phosphate-buffered saline (PBS) at

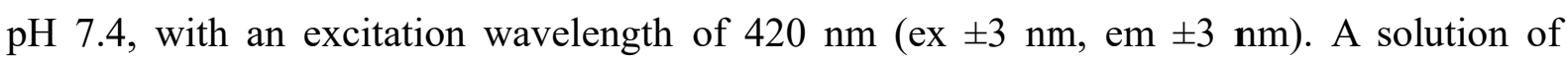
compound 5 was obtained by directly diluting the stock solution with PBS to a final concentration of $1 \mu \mathrm{M}$. A solution of compound 6 was obtained after completion of the reaction between compounds $\mathbf{5}$ and $\mathbf{2}$ as indicated by TLC. This solution was directly diluted into PBS to a final concentration of $1 \mu \mathrm{M}$.

\subsection{Figure S6: Absorbance and fluorescence emission spectrum of 7 and 8}
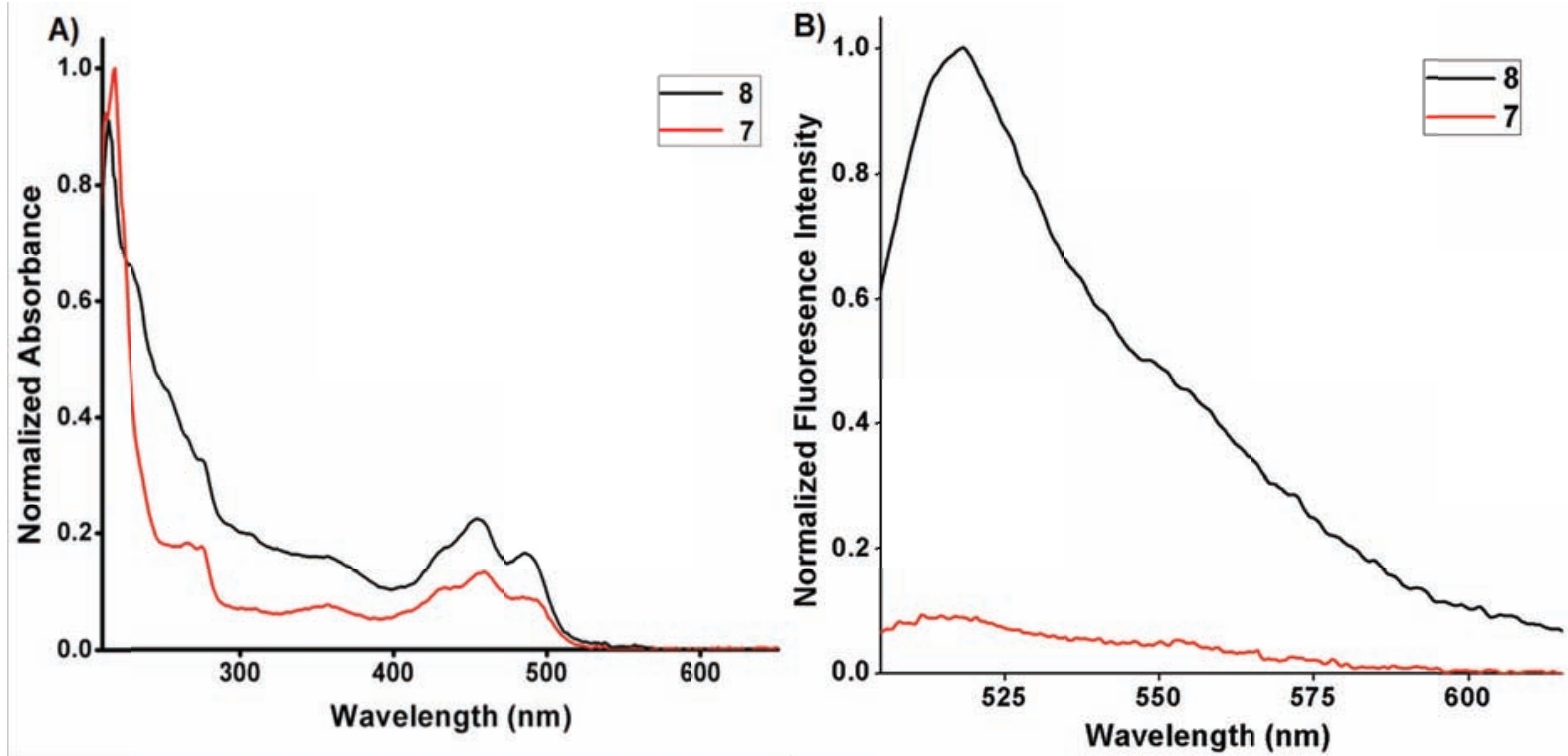
Figure S6. A). Normalized UV-Vis absorption spectrums of 8 (black) and 7 (red), both compounds were dissolved in $100 \mu \mathrm{M}$ EtOH solution. B) Normalized fluorescence emission spectrum of 8 (black) and 7 (red), in $1 \mu \mathrm{M} 20 \%$ DMF in phosphate-buffered saline (PBS) at $\mathrm{pH} 7.4$, with an excitation wavelength of $485 \mathrm{~nm}(\mathrm{ex} \pm 2 \mathrm{~nm}$, em $\pm 2 \mathrm{~nm})$. A solution of compound 7 was obtained by directly diluting the stock solution with PBS to a final concentration of $1 \mu \mathrm{M}$. A solution of compound $\mathbf{8}$ was obtained after completion of the reaction between compounds $\mathbf{7}$ and $\mathbf{2}$ as indicated by TLC. This solution was directly diluted into PBS to a final concentration of $1 \mu \mathrm{M}$.

\subsection{Excitation and emission spectra of uncaged VE-Cy}

The NHS deprotected, uncaged VE-Cy was dissolved into $150 \mu \mathrm{L}$ of phosphate buffered
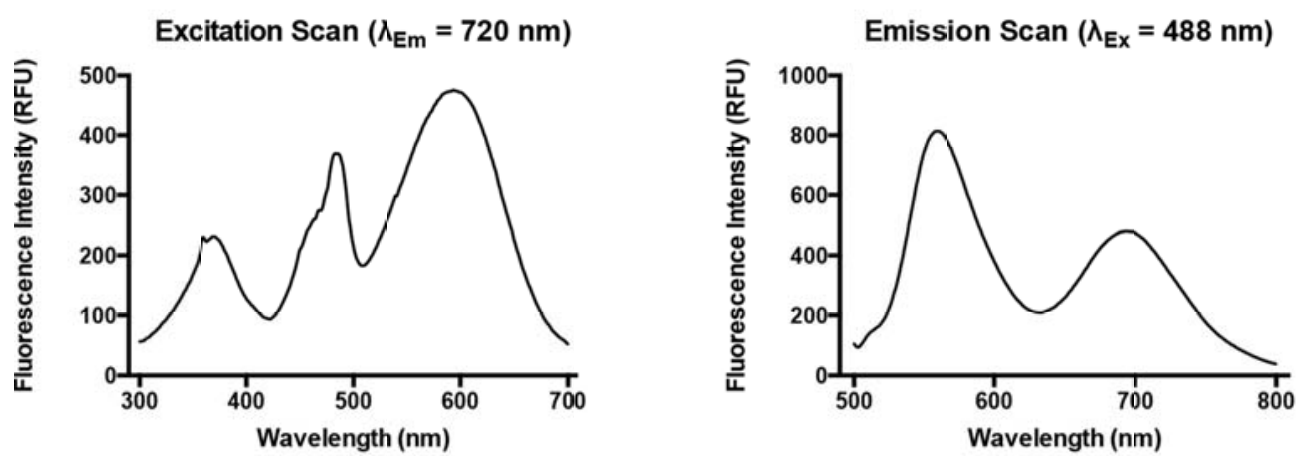

saline solution at $\mathrm{pH} 7.4$ containing $10 \% \mathrm{MeOH}$ to a final concentration of $5 \mu \mathrm{M}$. Excitation spectra (left) was collected with a fixed emission wavelength of $720 \pm 2 \mathrm{~nm}$ scanning excitation wavelengths between $300 \mathrm{~nm}$ and $700 \mathrm{~nm}$. Emission spectra (right) was collected in a similar fashion by holding the excitation wavelength constant at $488 \pm 2 \mathrm{~nm}$ and scanning emission wavelengths from $505-800 \mathrm{~nm}$ in a similar fashion to Figure S4. 


\subsection{Figure S7: Expanded fluorescence turn on from DNA templated reactions}

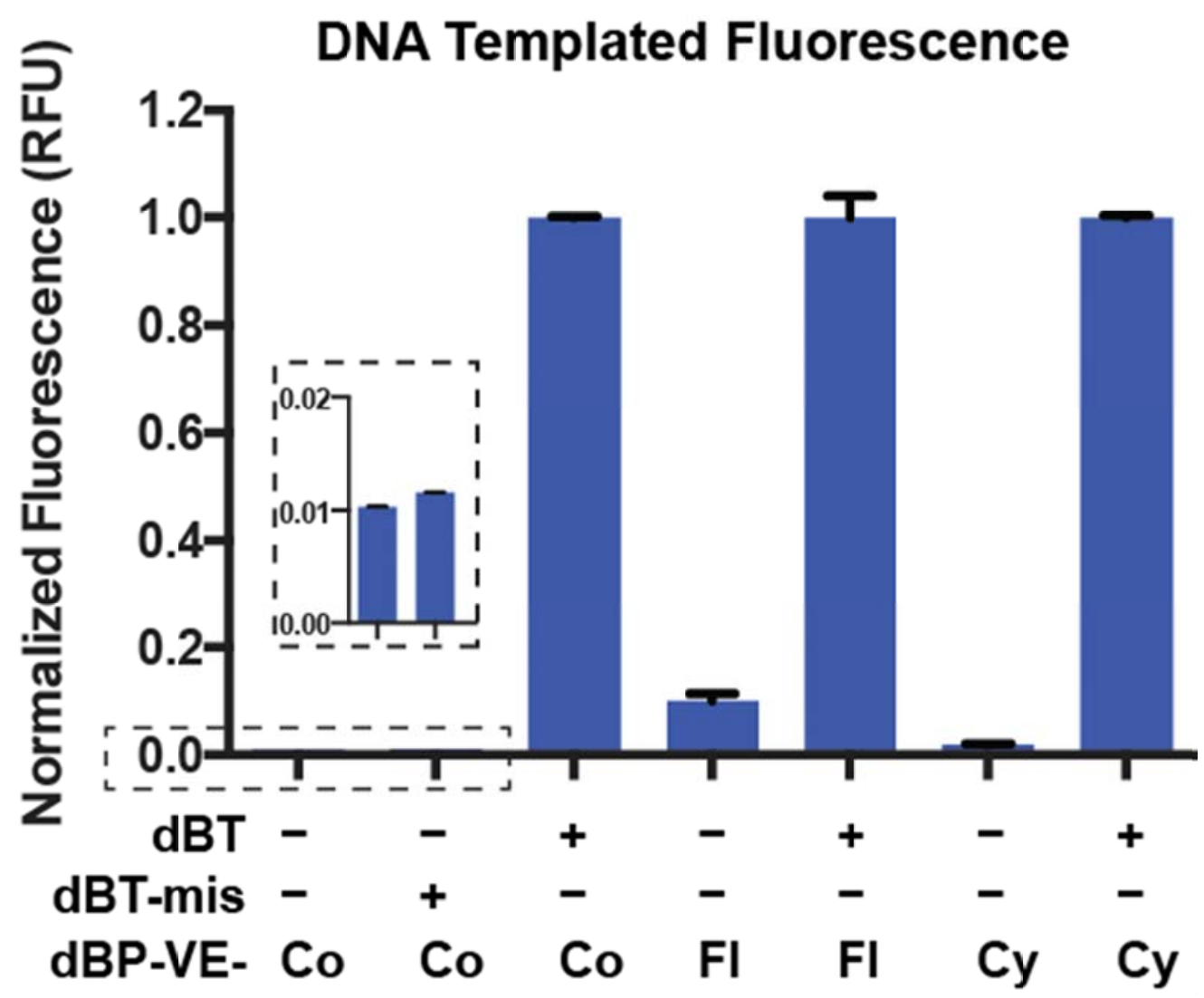

Figure S7: Expansion from Figure 2C highlighting the fluorescence levels from dBP-VE-Co and $\mathbf{d B P}-\mathbf{T z}$ in the absence of $\mathbf{d B T}$ and presence of $\mathbf{d B T}-\mathbf{m i s}$. All reactions were carried out in $100 \mathrm{mM}$ Tris $\mathrm{pH} 7.4$ containing $200 \mathrm{mM} \mathrm{MgCl}_{2}$ in the presence of $100 \mathrm{nM} \mathrm{dBP-Tz}$ and dBT or dBT-mis as well as dBT-VE-fluorophore as indicated above.

\section{DNA/RNA-templated VE-Tz bioorthogonal reactions and corresponding fluorescence turn-on}

General reaction conditions: In a $500-\mu 1$ microcentrifuge tube, DNA probes $\mathbf{d B P}-\mathbf{T z}$ and dBP-VE or RNA probes rBP-Tz and rBP-VE-Cy were added to a $100 \mathrm{mM}$ Tris-HCl buffer ( $\mathrm{pH}=7.4$ ) containing $200 \mathrm{mM} \mathrm{MgCl}$ (DNA) or $100 \mathrm{mM} \mathrm{NaCl}$ (RNA). To this mixture, the appropriate amount of perfect match template $\mathbf{~ d B T , ~} \mathbf{r B T}$, or mismatch template dBT-mis was added. Volumes and concentrations of solutions were chosen such that the final solution had a volume of $200 \mu \mathrm{l}$ and the concentrations of the individual components were: [Tris] $=100 \mathrm{mM}$, $\left[\mathrm{MgCl}_{2}\right]=200 \mathrm{mM}$ (DNA templated reaction only), $[\mathrm{NaCl}]=100 \mathrm{mM}$ (RNA templated reaction only), $[\mathrm{dBP}-\mathrm{Tz}]=100 \mathrm{nM},[\mathrm{dBP}-\mathrm{VE}]=100 \mathrm{nM}$, and $[\mathrm{dBT}]=100 \mathrm{nM}$. The solution was vortexed for $30 \mathrm{~s}$, incubated at $37^{\circ} \mathrm{C}$ for 8 hours, and subsequently measured in the fluorimeter. For the control samples, the reaction solution was prepared as described above but in the absence of template.

Next, fluorimetry measurements were performed using a spectrophotometer equipped with a single cuvette reader. For the reactions involving VE-Co, the excitation wavelength was set 
to $420 \mathrm{~nm}$, with a $3 \mathrm{~nm}$ slit width. For the reactions involving VE-FI, the excitation wavelength was set to $485 \mathrm{~nm}$, with a $3 \mathrm{~nm}$ slit width. For the reactions involving VE-Cy, the excitation wavelength was set to $620 \mathrm{~nm}$, with a $3 \mathrm{~nm}$ slit width. The fluorescence emission spectra were reported as an average of three independent replicate trials. Activation ratios were calculated from the background corrected peak emission intensity of the reaction product and their corresponding baseline intensity.

\section{7. sfGFP-3' BT mRNA synthesis and investigations}

\section{1 sfGFP-3' BT plasmid}

The sfGFP-3' BT plasmid was constructed by standard cloning methods by replacing the mCherry coding region of the previously reported vector mCherry-TAG ${ }^{(4)}$ (which already contained two binding template regions in the $3^{\prime}$ UTR) with the coding sequence for sfGFP. The assembled product was sequence verified to confirm the correct assembled product.

Sequence of sfGFP-3' BT DNA insert:

TAATACGACTCACTATAGGGAGACCCAAGCTTGGTACCGAGCTCGGATCGTCGCTA GCGATATCTAATACGACTCACTATAGGGAATAATTTTGTTTAACTTTAAGAAGGAGA TATAATGGTGAGCAAGGGCAGCAAAGGAGAAGAACTTTTCACTGGAGTTGTCCCA ATTCTTGTTGAATTAGATGGTGATGTTAATGGGCACAAATTTTCTGTCCGTGGAGA GGGTGAAGGTGATGCTACAAACGGAAAACTCACCCTTAAATTTATTTGCACTACTG GAAAACTACCTGTTCCGTGGCCAACACTTGTCACTACTCTGACCTATGGTGTTCAA TGCTTTTCCCGTTATCCGGATCACATGAAACGGCATGACTTTTTCAAGAGTGCCAT GCCCGAAGGTTATGTACAGGAACGCACTATATCTTTCAAAGATGACGGGACCTACA AGACGCGTGCTGAAGTCAAGTTTGAAGGTGATACCCTTGTTAATCGTATCGAGTTA AAGGGTATTGATTTTAAAGAAGATGGAAACATTCTTGGACACAAACTCGAGTACA ACTTTAACTCACACAATGTATACATCACGGCAGACAAACAAAAGAATGGAATCAA AGCTAACTTCAAAATTCGCCACAACGTTGAAGATGGTTCCGTTCAACTAGCAGAC CATTATCAACAAAATACTCCAATTGGCGATGGCCCTGTCCTTTTACCAGACAACCA TTACCTGTCGACACAATCTGTCCTTTCGAAAGATCCCAACGAAAAGCGTGACCAC ATGGTCCTTCTTGAGTTTGTAACTGCTGCTGGGATTACACATGGCATGGATGAGCT CTACAAAGCAGCGAACGACGAAAATTACGCCCTTGCAGCGTAAGGCGGCATGGA CGAGCTGTACAAGTAACCCCATGTATCTAAATCAGCACCCATCATTTTCATATCCCC GCAGACTGTAAATCTGCCCCCATGTATCTAAATCAGCACCCATCATTTTCATATCCC CCGAAAGGCGGGCTTTTCTGTGTCTCGAGGTTAATTAA

\subsection{In vitro transcription of SfGFP-3' BT mRNA}

DNA plasmid template was first cut to ensure uniform length transcriptions. sfGFP-3' BT plasmid was digested by PacI, isolated, and in vitro transcribed with T7 RNA polymerase according to previously reported procedures. ${ }^{(4)}$ 


\subsection{Fluorescent measurements of full length mRNA fluorogenic tetrazine decaging reactions}

Reaction conditions: In a 500- $\mu \mathrm{L}$ microcentrifuge tube, rBP-Tz and rBP-VE-Cy were dissolved into Ham's F-12K media with 10\% FBS added (Life Technologies, Carlsbad, CA). Then the appropriate amount of sfGFP-3' BT mRNA was subsequently added. Volumes and concentrations of solutions were chosen such that the final solution had a volume of $200 \mu \mathrm{L}$ and the concentrations of the individual components were: $[\mathbf{r B P}-\mathbf{T z}]=200 \mathrm{nM},[\mathbf{r B P}-\mathbf{V E}]=$ $200 \mathrm{nM}$, and [sfGFP-3' BT] $=100 \mathrm{nM}$. Control experiments lacking sfGFP-3' BT were also investigated. For the competitive experiment 50 competitive eq $(5 \mu \mathrm{M})$ of unmodified probe dBPTz and dBP-VE were added before the addition of SfGFP-3' BT. The solution was vortexed for $30 \mathrm{~s}$, incubated at $37{ }^{\circ} \mathrm{C}$ for 8 hours, and subsequently measured in the fluorimeter.

Fluorimetry measurements were performed using a spectrophotometer equipped with a single cuvette reader, with an excitation wavelength of $620 \mathrm{~nm}$ and a $3 \mathrm{~nm}$ slit width. The fluorescence emission signals were reported as average of values from three independent replicates. Activation ratios were calculated from the background corrected peak emission intensity of the reaction product and the corresponding baseline intensity.

7.4 Figure S8: Fluorescence response of $\mathrm{rBP}-\mathrm{Tz}$ and $\mathrm{rBP}-\mathrm{VE}-\mathrm{Cy}$ in the presence of varying concentrations of sfGFP-3' BT RNA

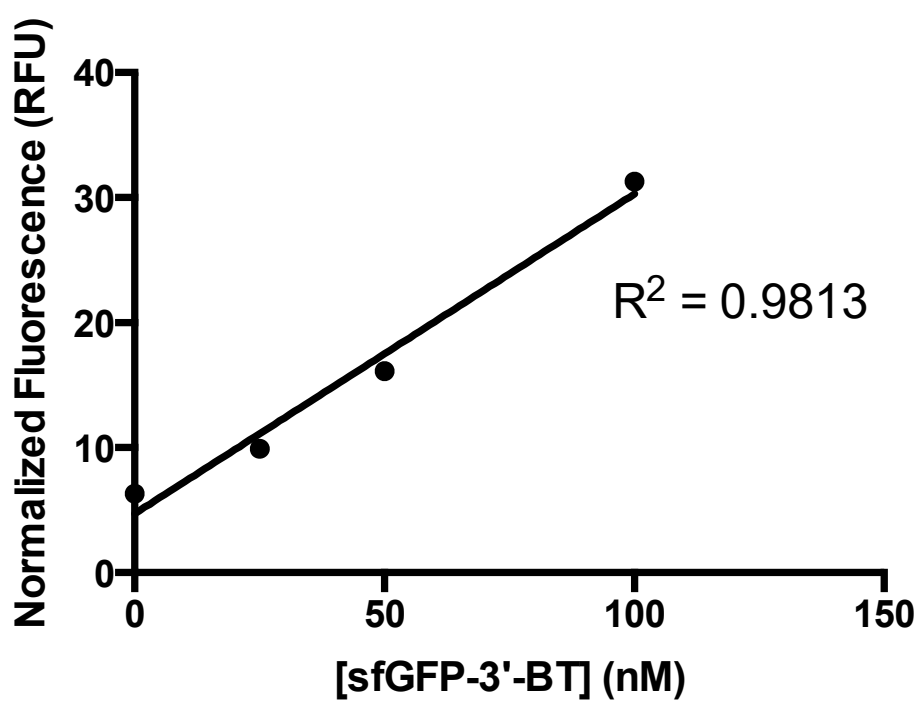

Figure S8: Fluorescence response of $\mathrm{rBP}-\mathrm{Tz}$ and $\mathrm{rBP}-\mathrm{VE}-\mathrm{Cy}$ in the presence of varying concentrations of RNA template. Samples were prepared in a similar fashion as above whereby $200 \mathrm{nM}$ each of $\mathbf{r B P}-\mathbf{T z}$ and $\mathbf{r B P}-\mathbf{V E}-\mathbf{C y}$ was incubated with varying concentrations of sfGFP-3' BT $(0,25,50$ or $100 \mathrm{nM})$ for 8 hours at $37^{\circ} \mathrm{C}$ in $100 \mathrm{mM}$ Tris pH 7.4 with $100 \mathrm{mM} \mathrm{NaCl}$ added. Fluorescence measurements were then acquired from each sample and normalized to buffer background signal. The relative fluorescence was then 
plotted as a function of $\mathbf{~ s f G F P - 3 ' ~ B T ~ c o n c e n t r a t i o n ~ a n d ~ a ~ l i n e a r ~ r e l a t i o n s h i p ~ w a s ~ o b s e r v e d ~ a s ~}$ shown above.

\section{Cellular RNA detection}

\subsection{Cellular transfection, probe treatment, and imaging protocol}

Chinese Hamster Ovary (CHO) cells (CRL-9606, ATCC, Manassas, VA) were cultured in Ham's F-12K media containing 10\% FBS (Life Technologies, Carlsbad, CA) and kept under 20 passages from the ATCC standard line. CHO cells were plated at an initial density of 10,000 cells per well in a Nunc Lab-Tek 8 well chamber slide (Thermo Scientific, Waltham, MA). Cells were allowed to adhere overnight and washed with Opti-MEM media (Life Technologies, Carlsbad, CA) and subsequently transfected with $0.5 \mathrm{ng}$ of sfGFP-3' BT (or pcDNA3-EGFP control) plasmid per well with $1.5 \mu \mathrm{L}$ of Lipofectamine ${ }^{\circledR} 2000$ (Life Technologies, Carlsbad, CA) in Opti-MEM as per manufacturer's protocol. Control wells lacking transfection were treated and washed with Opti-MEM in the absence of DNA and Lipofectamine ${ }^{\circledR}$. After overnight incubation, the cells were washed with Opti-MEM and subsequently treated with $25 \mathrm{nM}$ of each of $\mathbf{r B P}-\mathbf{T z}$ and $\mathbf{r B P}-\mathrm{VE}-\mathrm{Cy}$ with $1 \mu \mathrm{L}$ of Lipofectamine 2000 in Opti-MEM for 4 hours under $37{ }^{\circ} \mathrm{C}$ incubation. Cells were then taken directly to the confocal microscope for imaging. Images were acquired on a confocal laser scanner FV1000 (Olympus, Japan) built around an Olympus IX81 inverted microscope (Olympus, Japan) with a 60x, 1.42 NA oil immersion objective using the FLUOVIEW software package (Olympus, Japan). The cyanine near infrared fluorescent probe was excited with a $633 \mathrm{~nm}$ HeNe laser, and the sfGFP fluorescent protein was excited with a $488 \mathrm{~nm}$ Argon laser. Images were subsequently analyzed and processed using ImageJ (NIH, rsbweb.nih.gov). 


\subsection{Figure S9: Additional cell images}
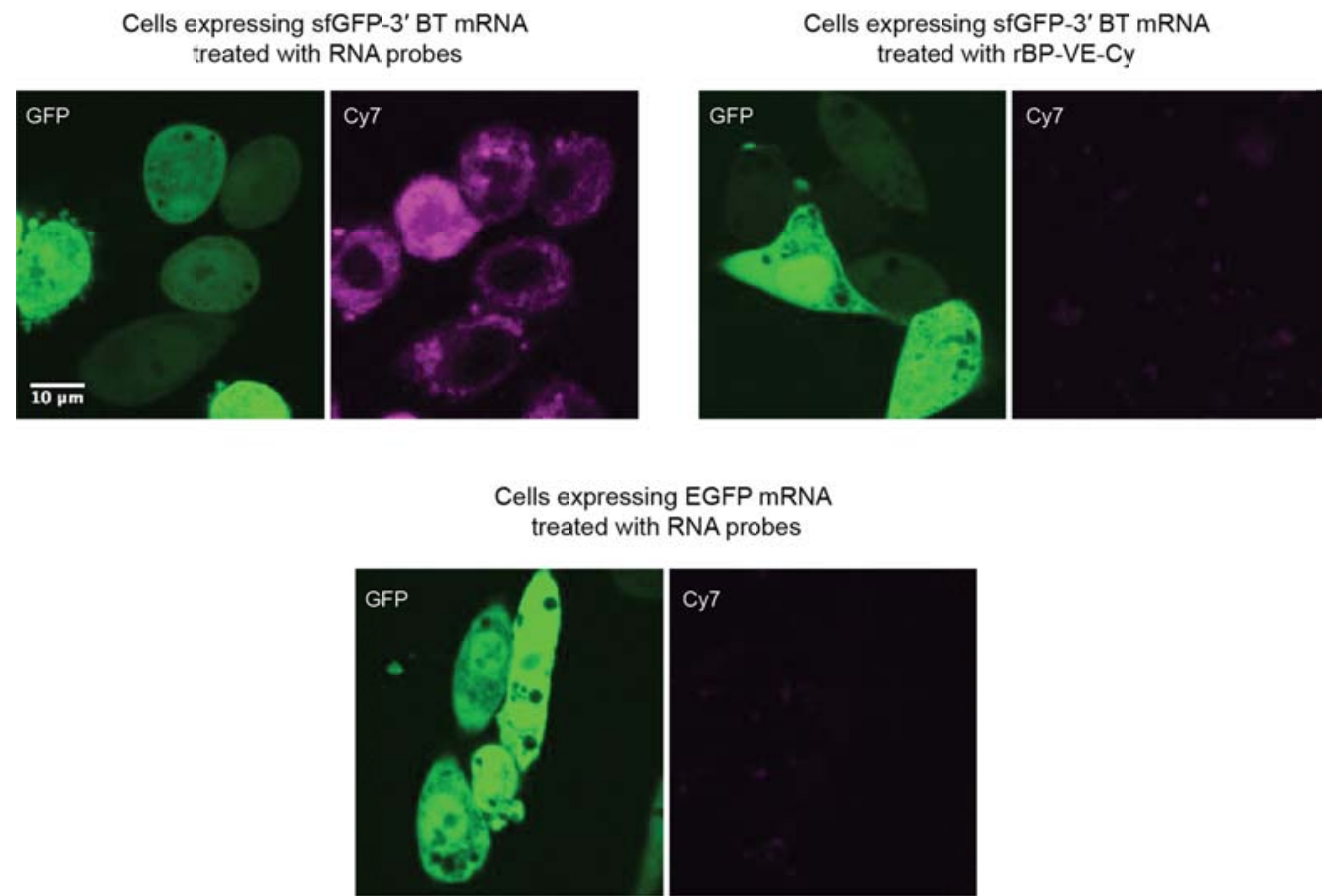

Figure S9: Additional cellular imaging. $\mathrm{CHO}$ cells were treated and imaged according to the outlined protocol. Control cells expressing sfGFP-3' BT that were subsequently treated with $25 \mathrm{nM}$ rBP-VE-Cy in the absence of rBP-Tz, as well as cells expressing EGFP without the recognition binding element $\left(-3^{\prime}\right.$ rBT), but treated with rBP-VE-Cy and rBP-Tz, both show less NIR signal.

\section{References}

1. Mertens MD, Hinz S, Müller CE, Gütschow M. Bioorg. Med. Chem. 2014, 22, 1916-1928.

2. Teeuwen R.L.M., van Berkel, SS, van Dulmen THH, Schoffelen S, Meeuwissen SA, Zuilhof H, de Wolf FA, van Hest JCM, Chem. Comm. 2009, 27, 4022-4024.

3. Kawamoto K, Grindy, SC, Liu J, Niels HA, Johnson JA. ACS macro lett.2015, 4, 458-461.

4. S. C. Alexander, K. N. Busby, C. M. Cole, C. Y. Zhou, N. K. Devaraj, J Am Chem Soc 2015, 137, 12756-12759. 
10. NMR spectra for synthesized materials

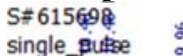

켜ำ

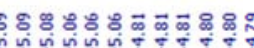

single
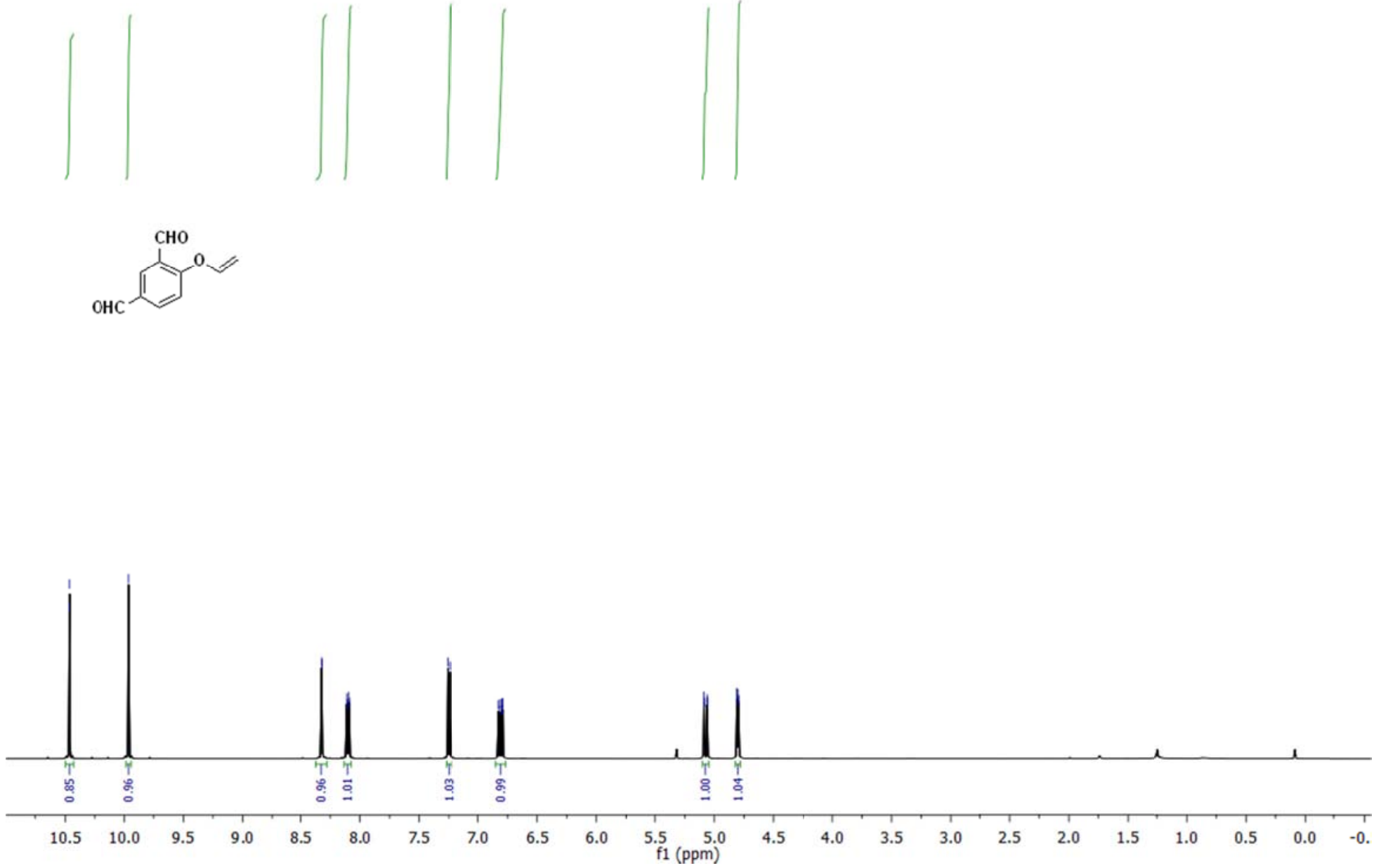


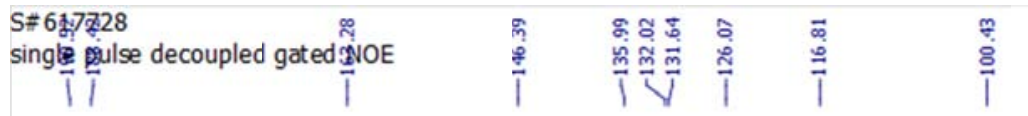

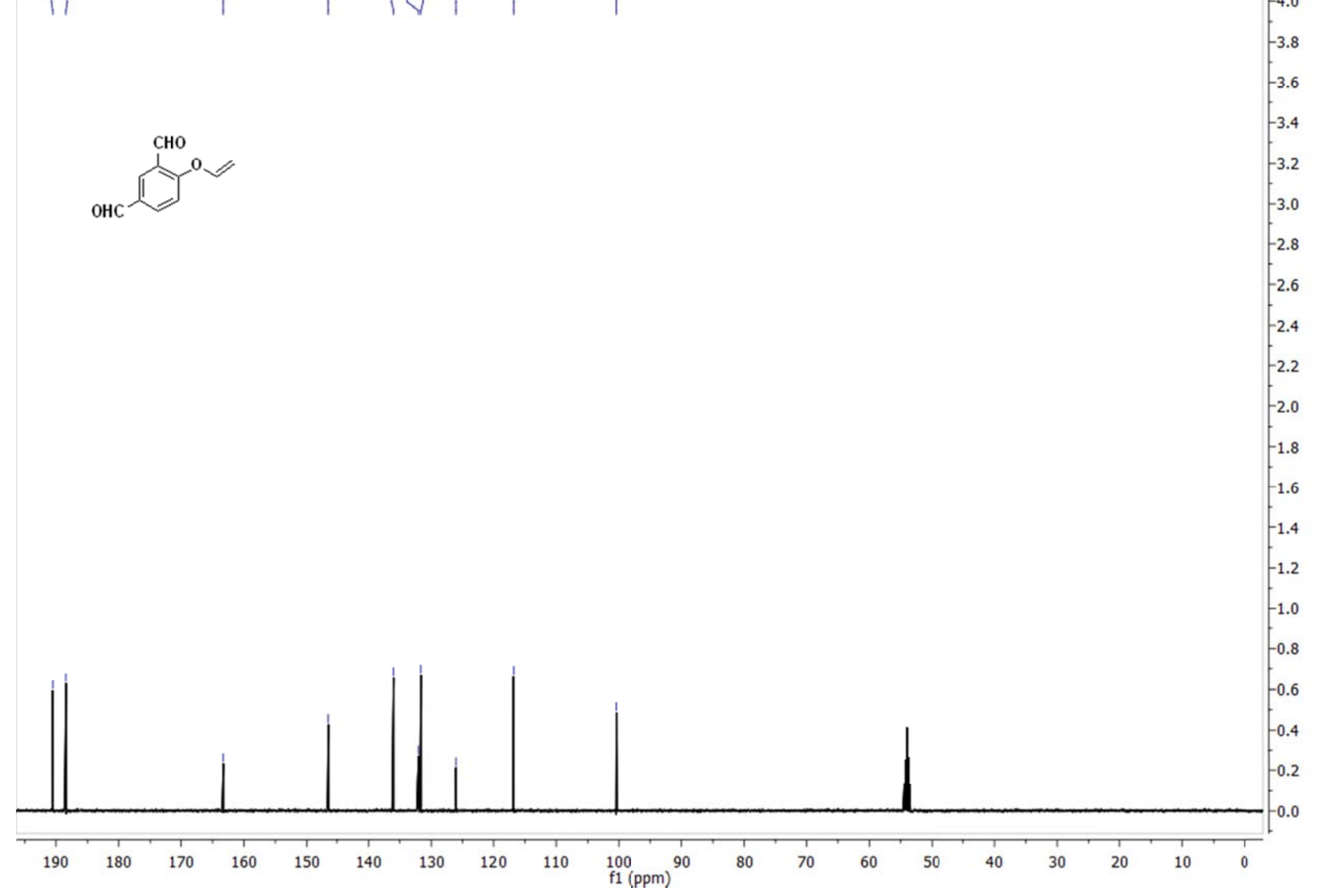




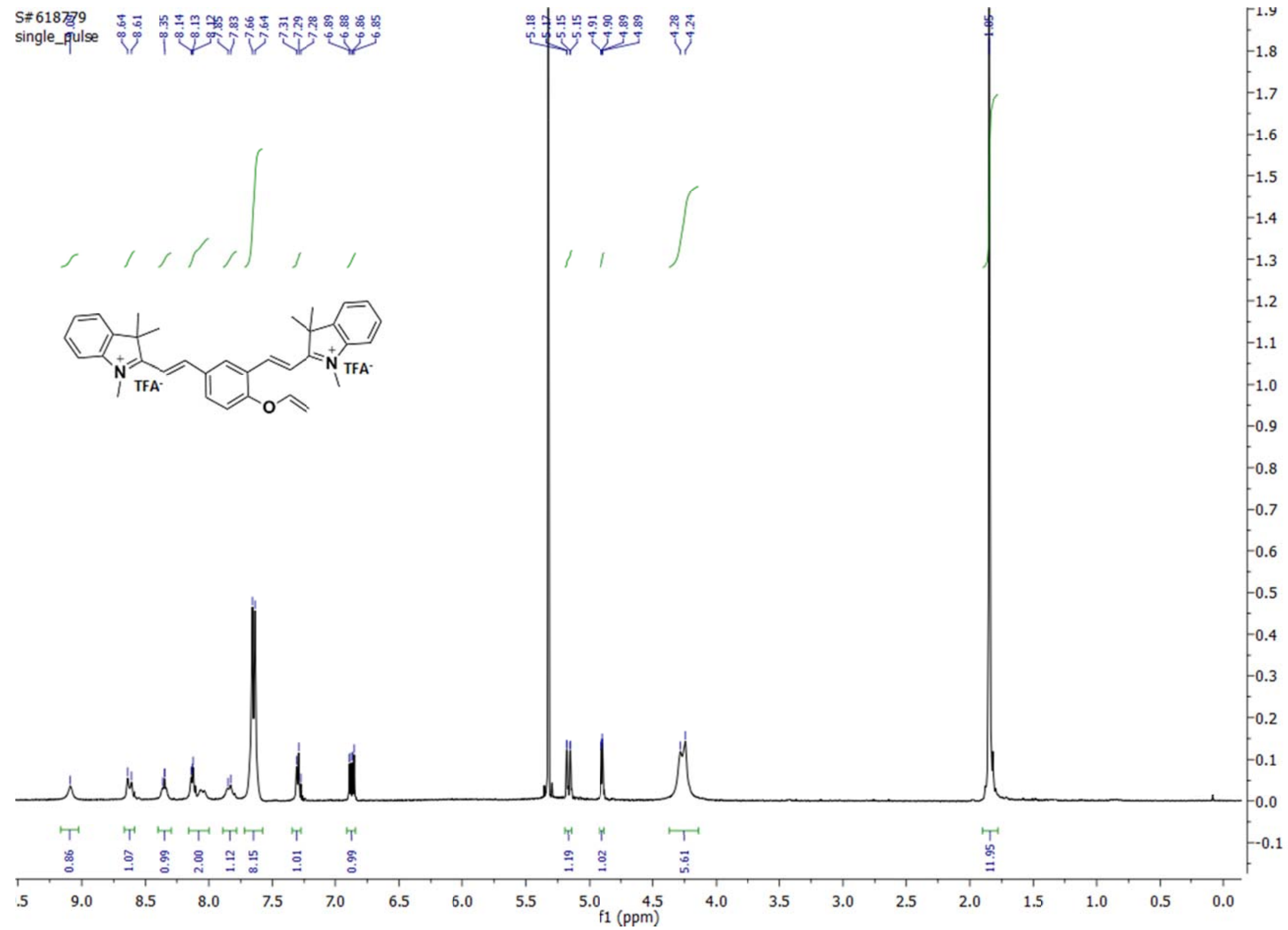



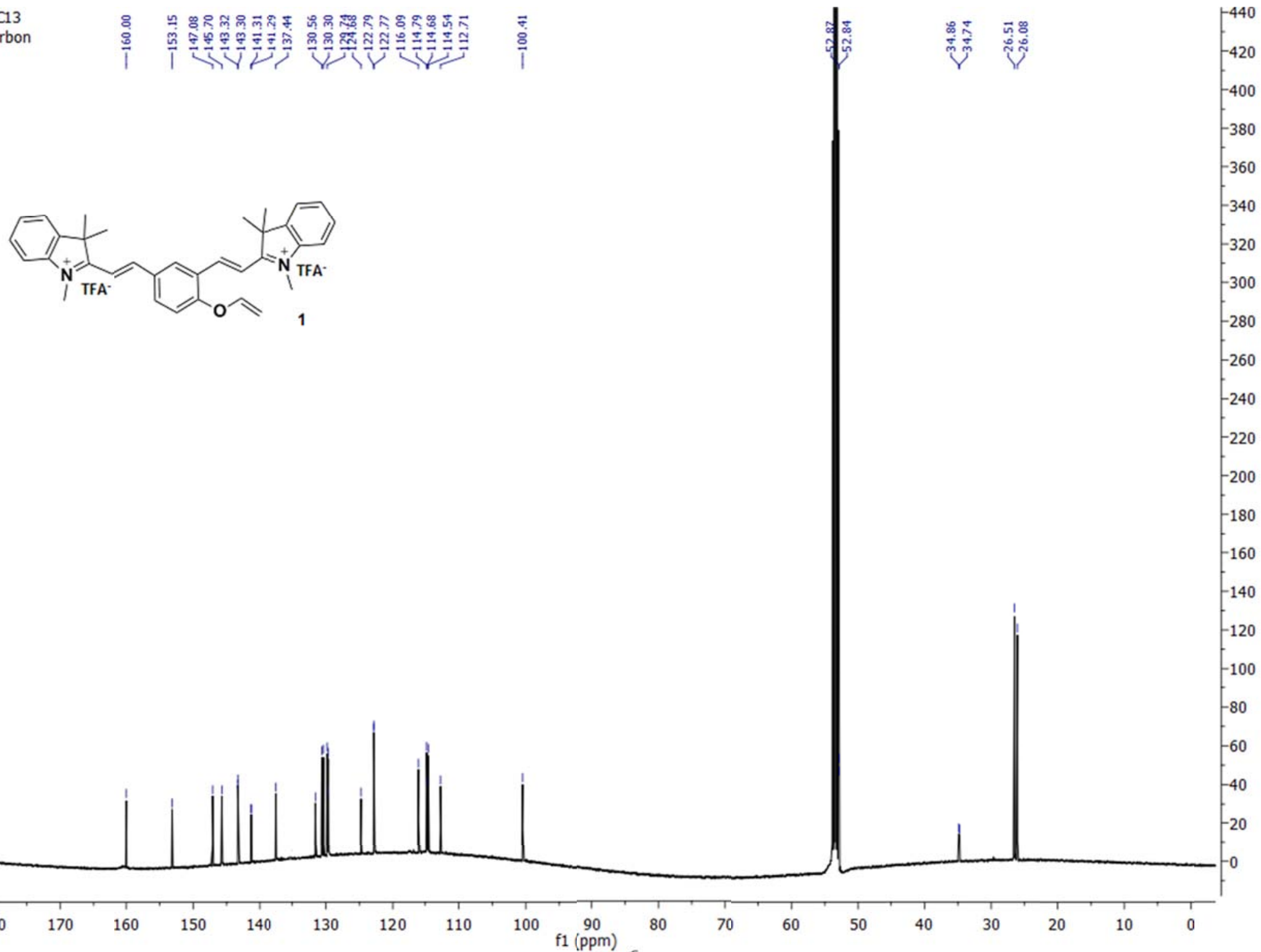


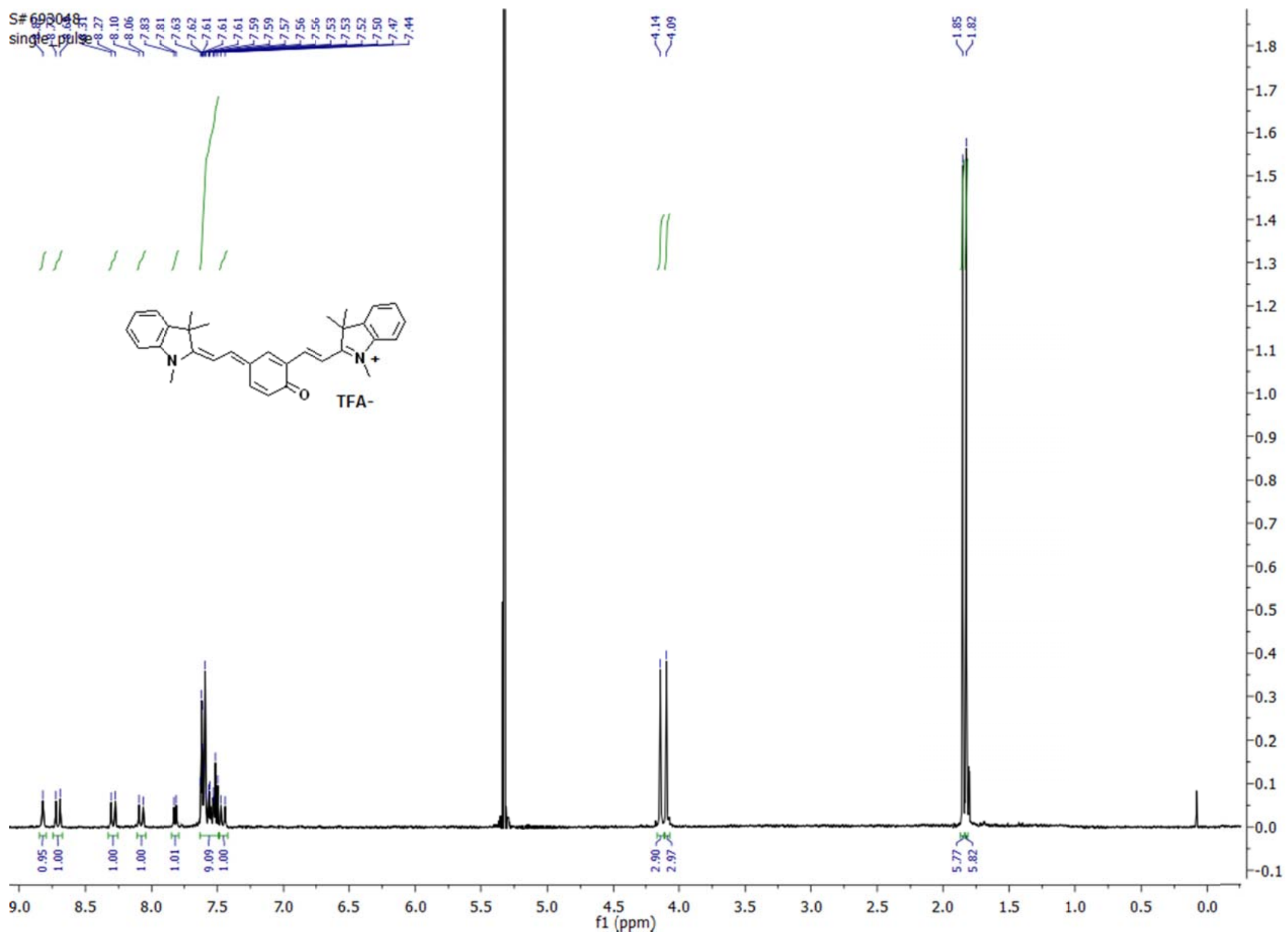




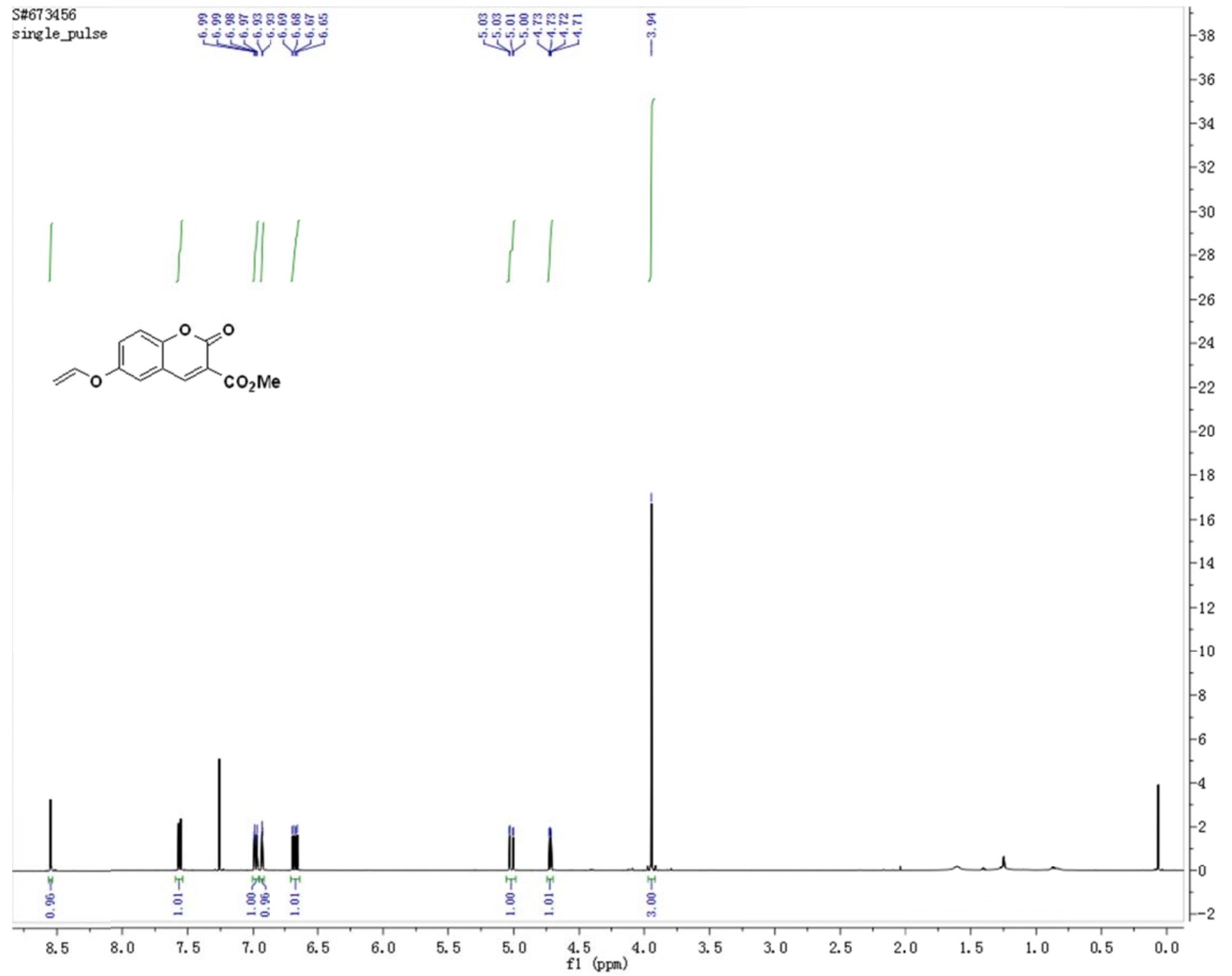




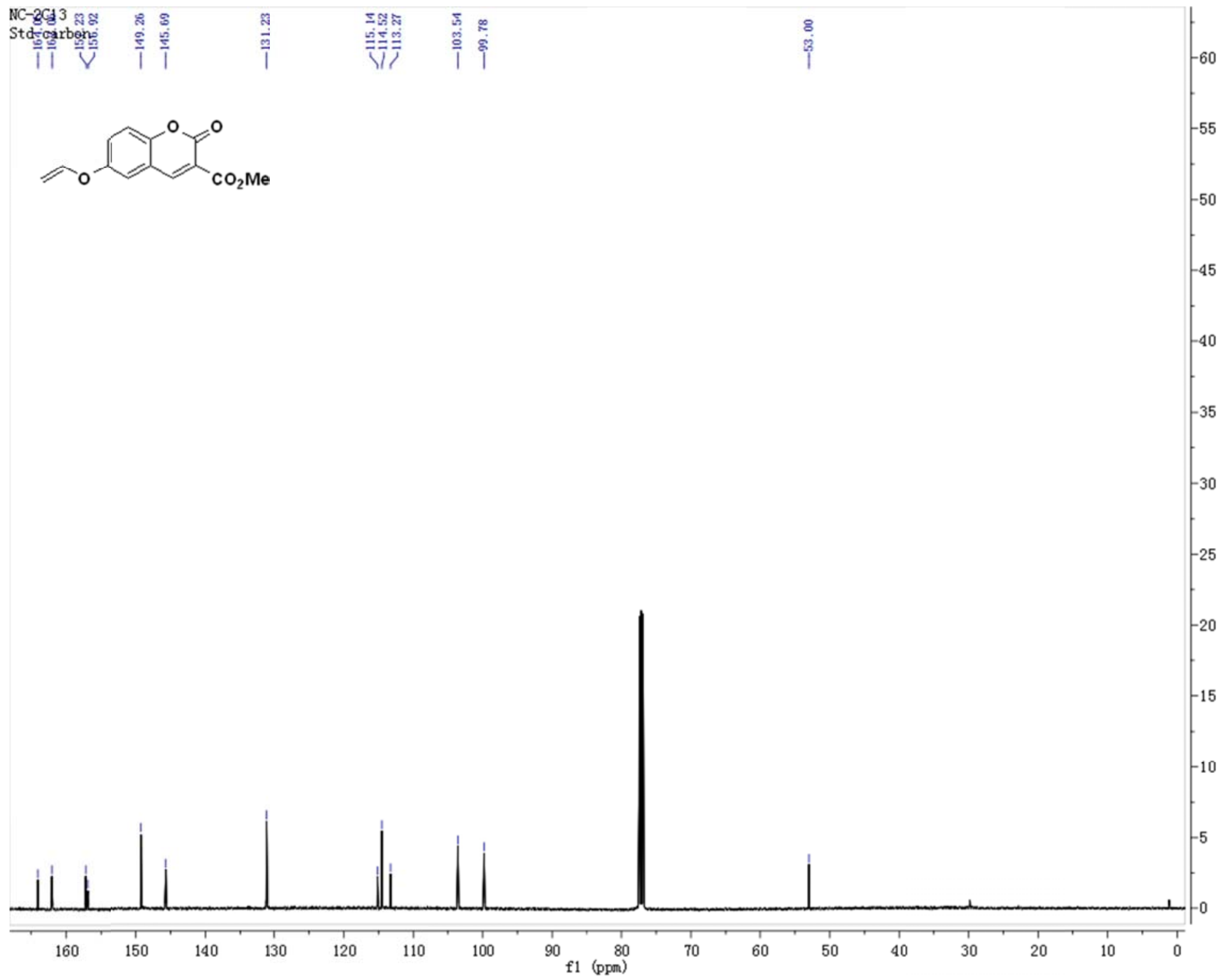




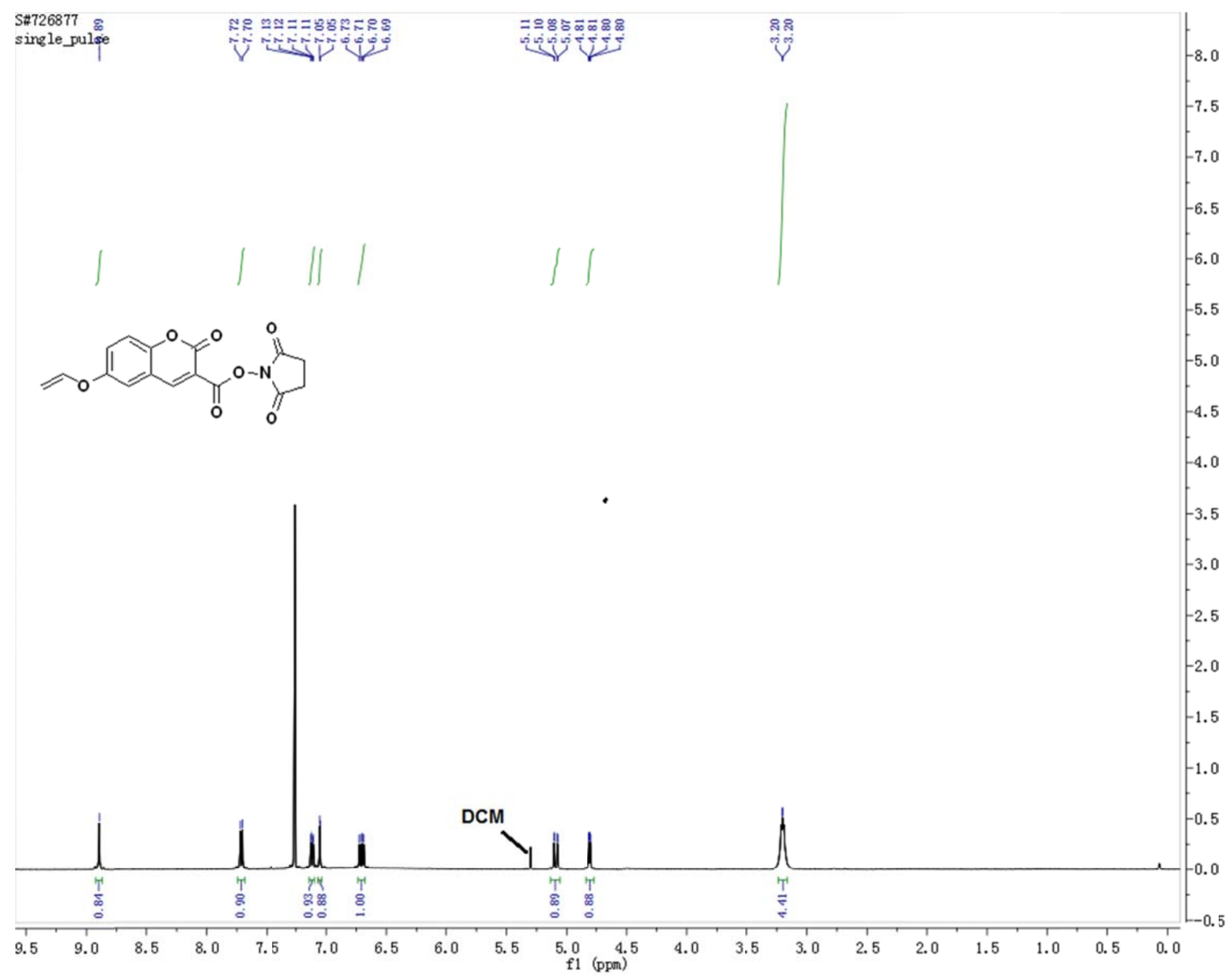




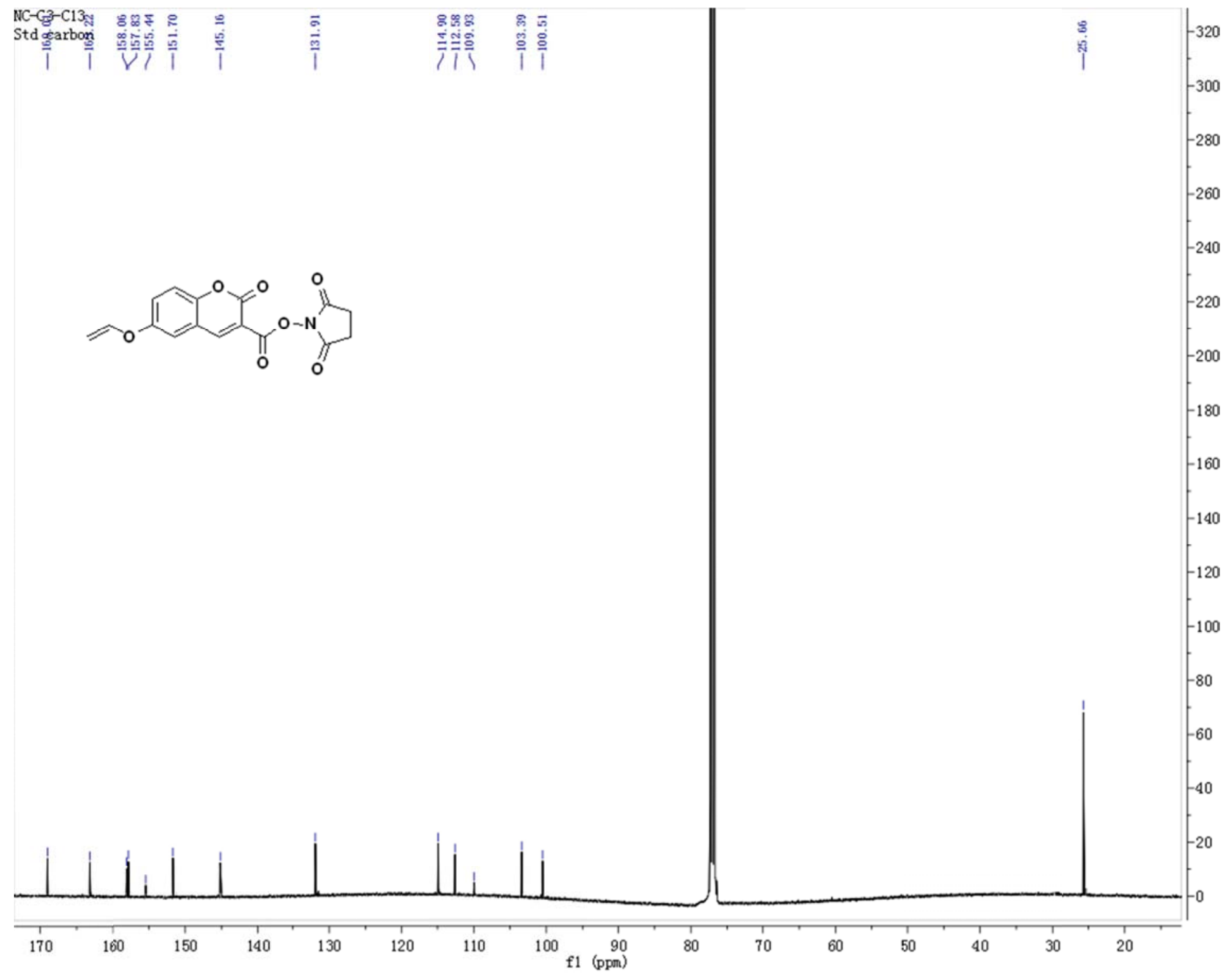




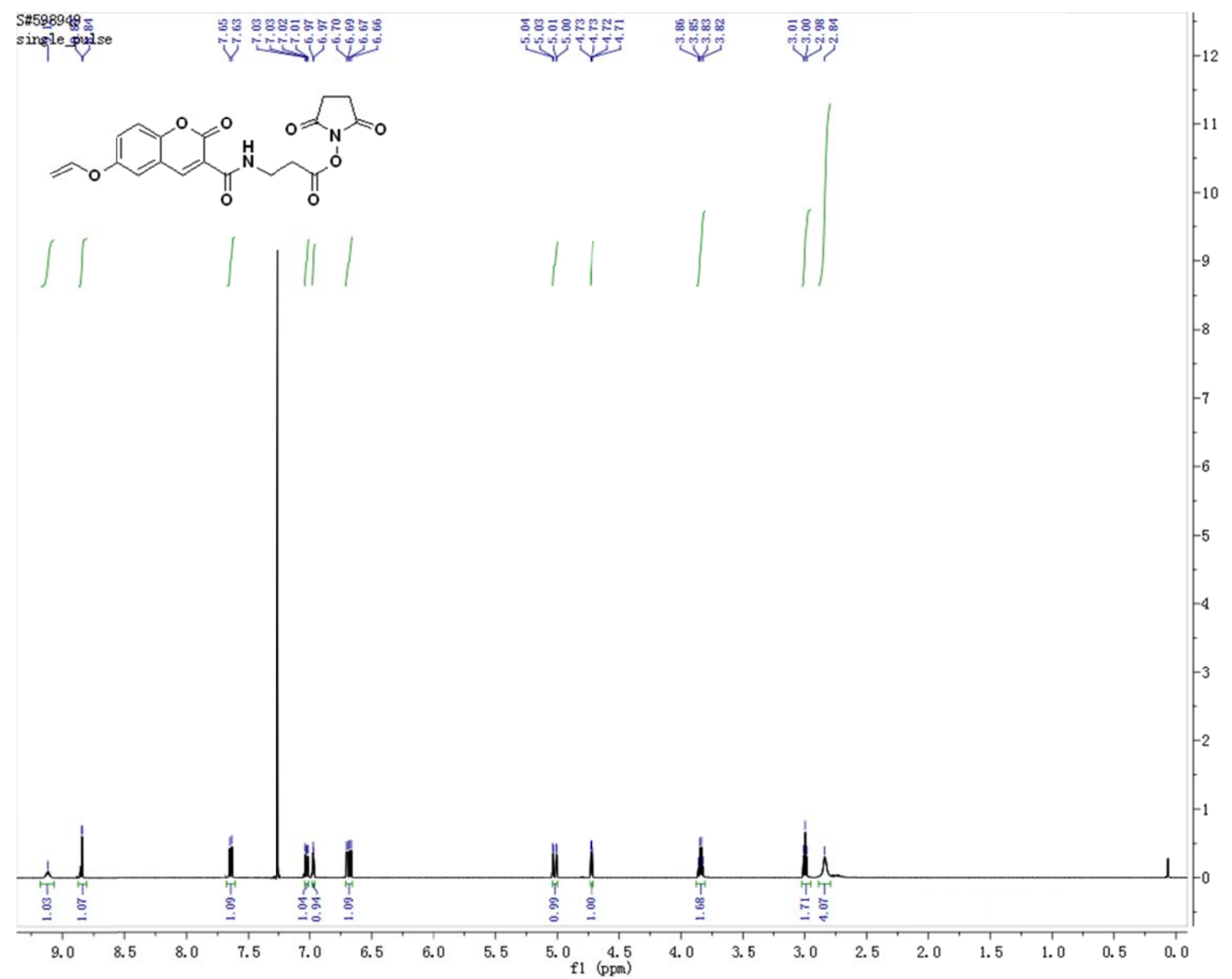




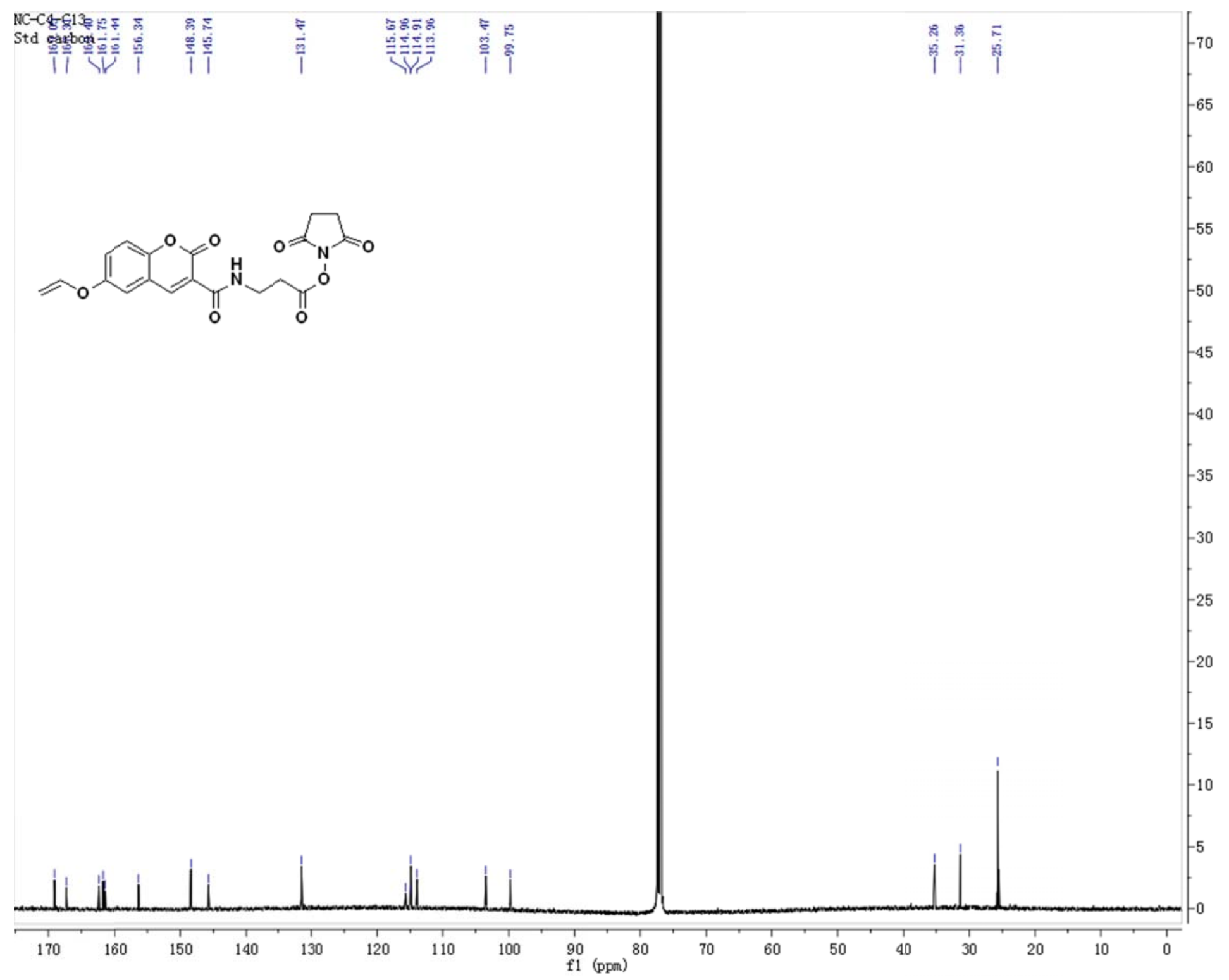




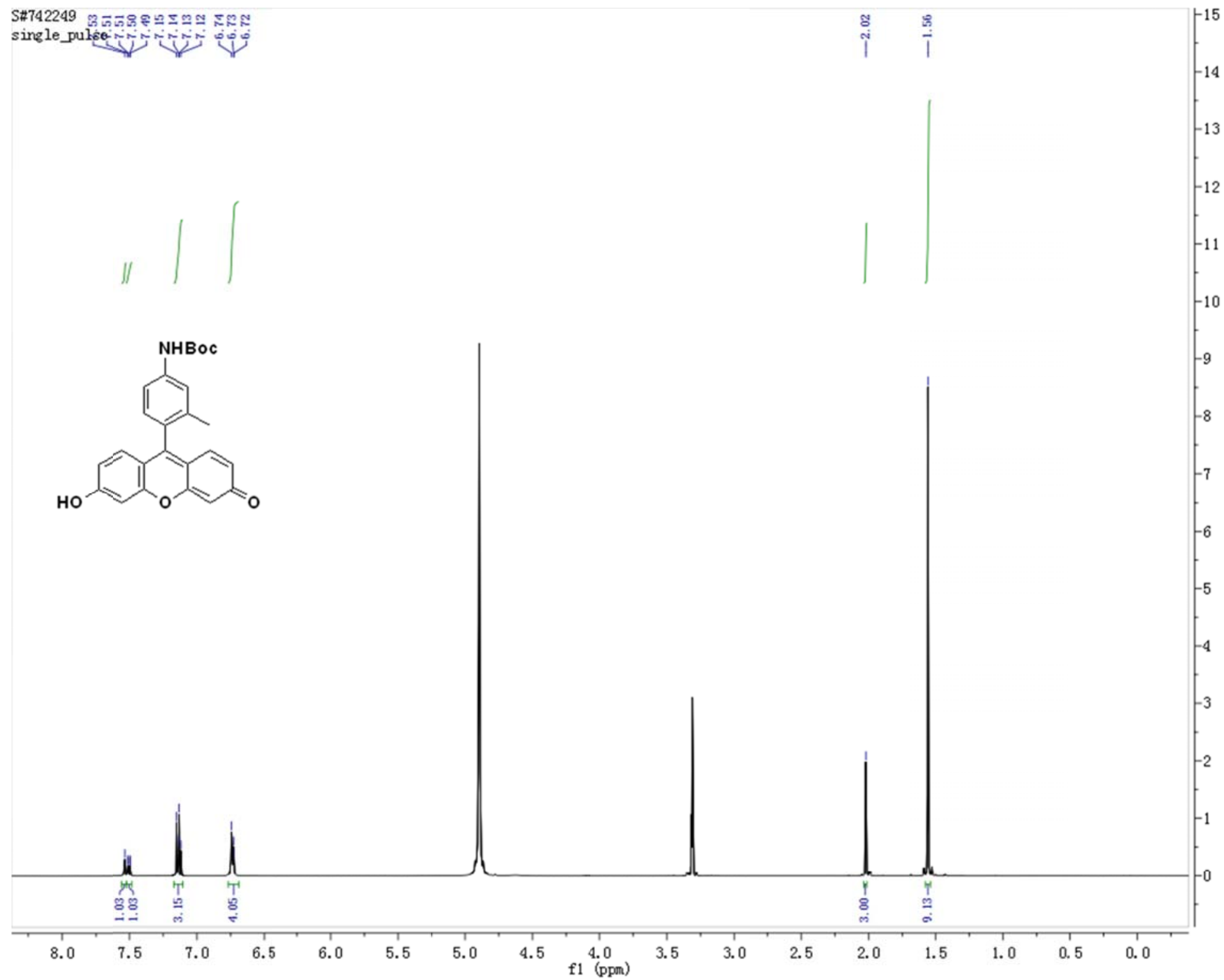




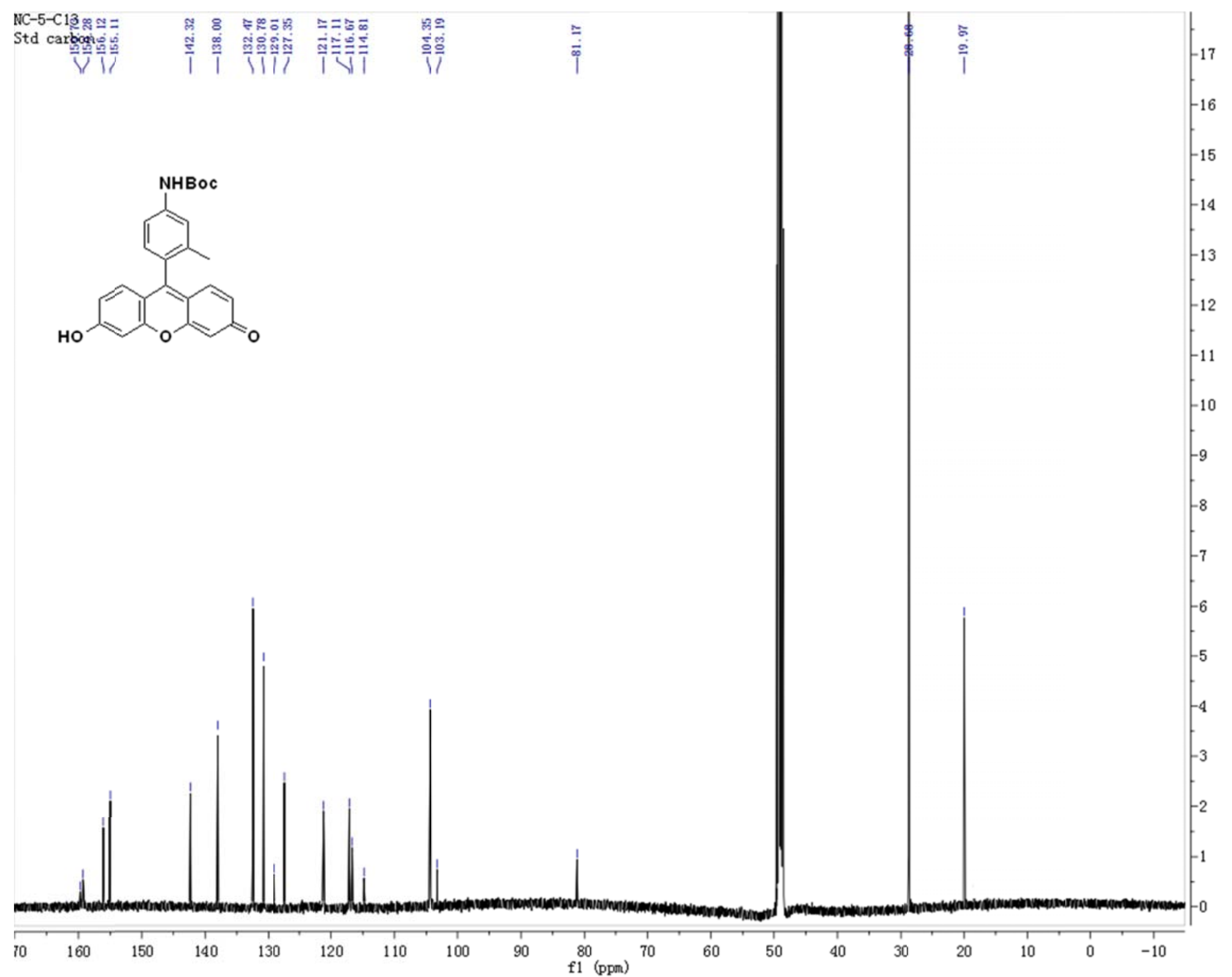




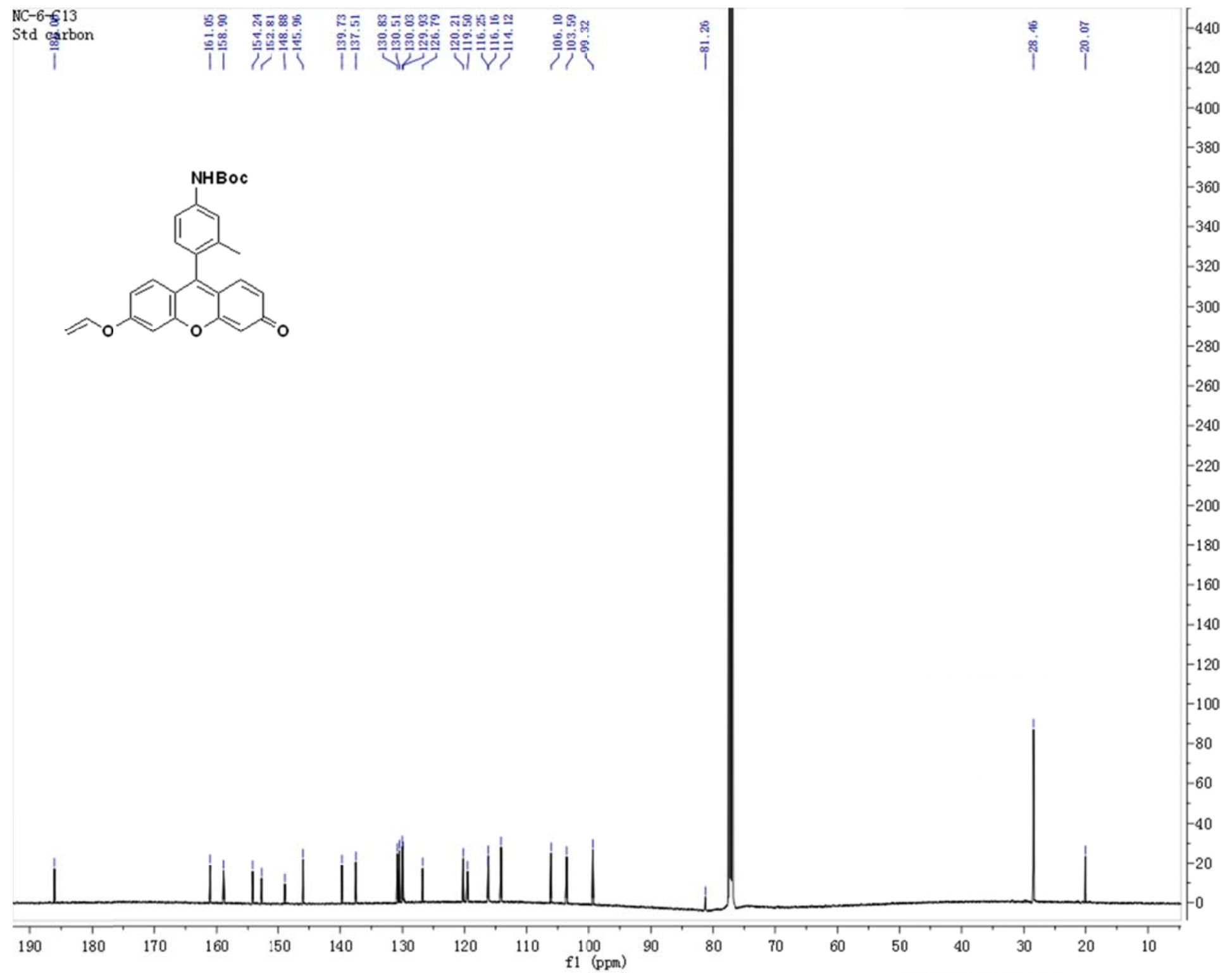




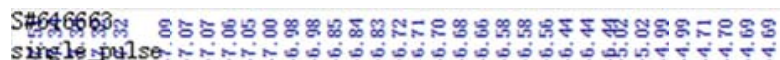

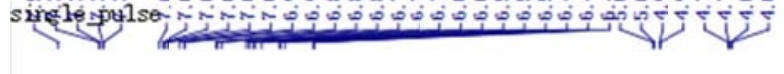

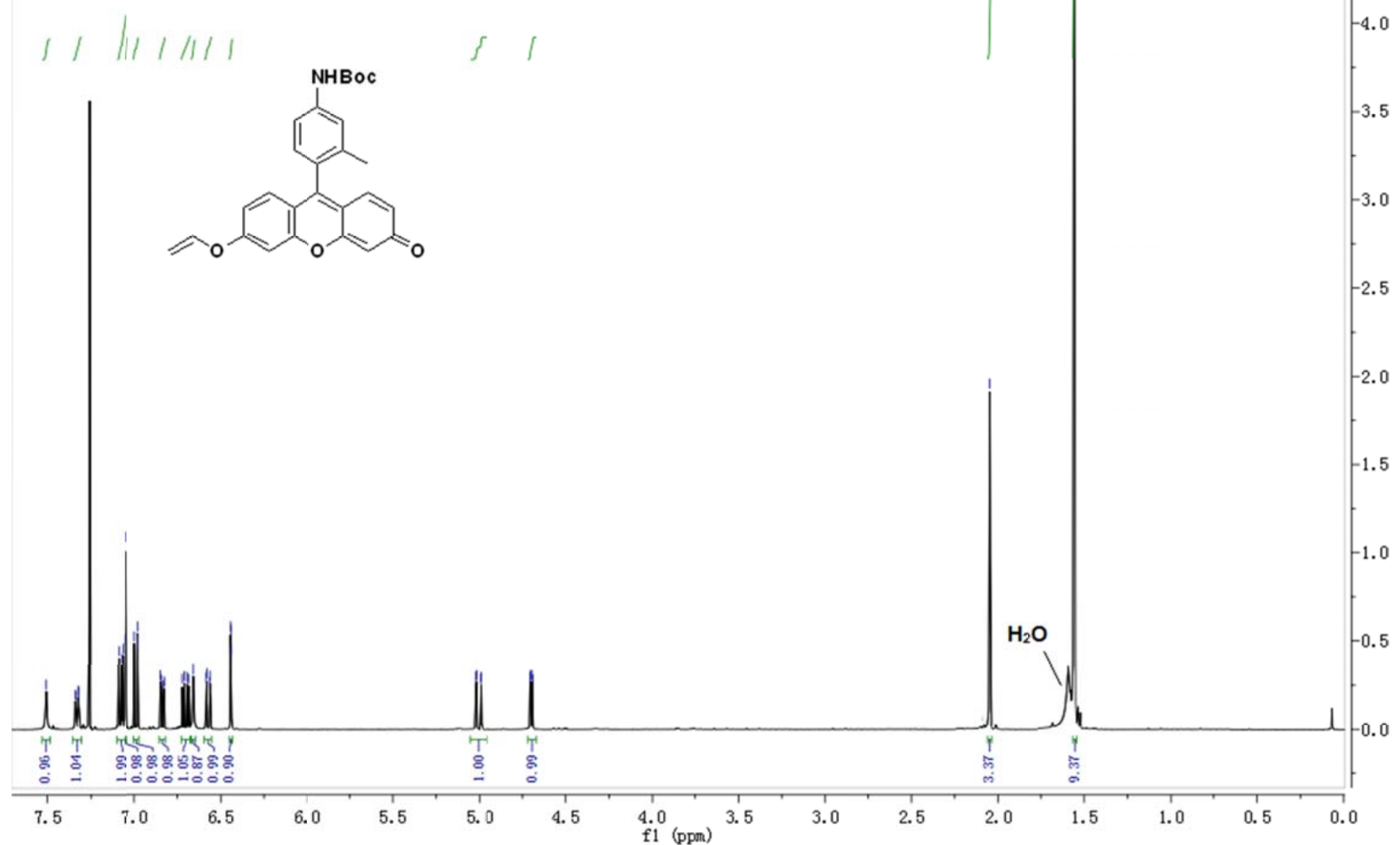




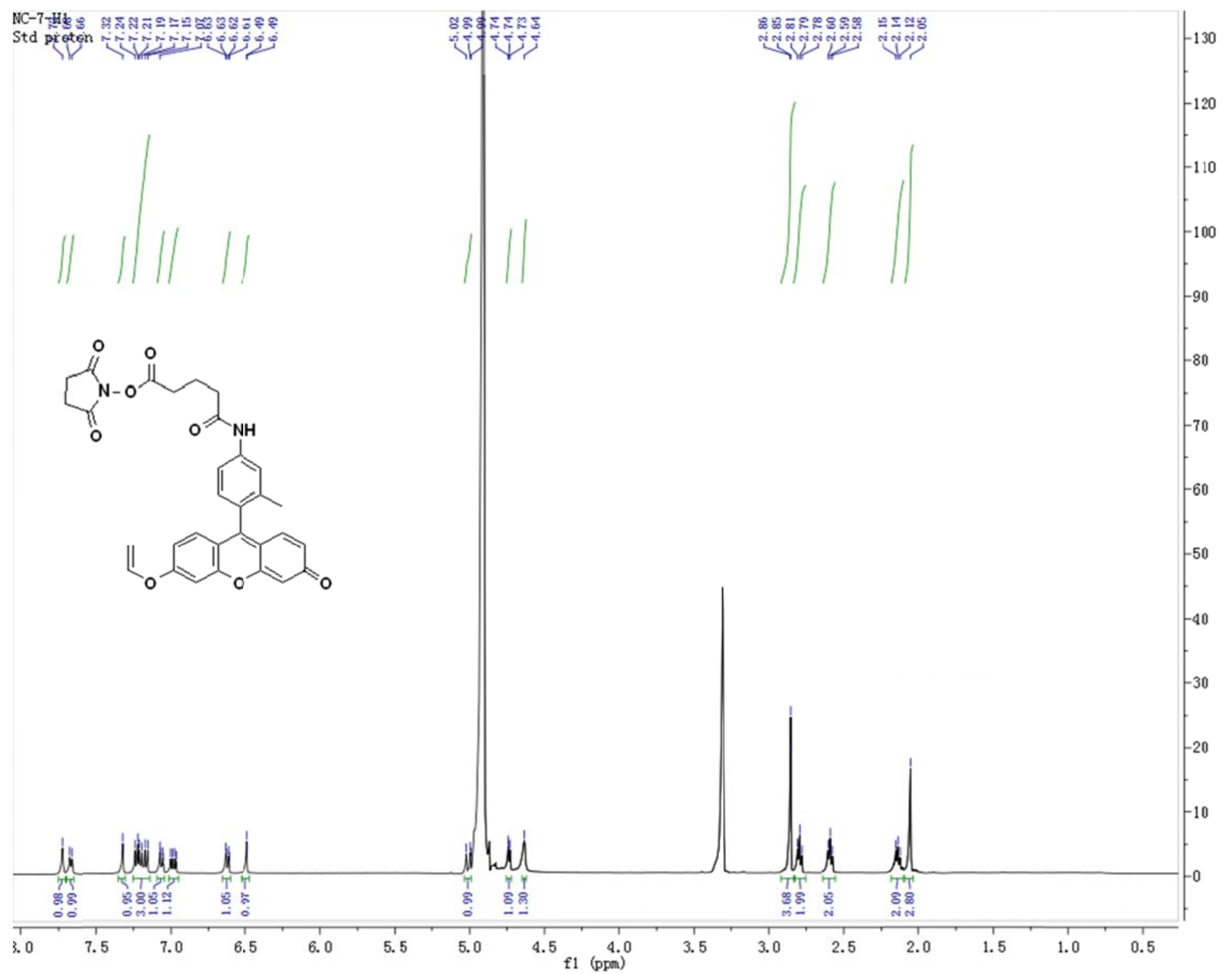




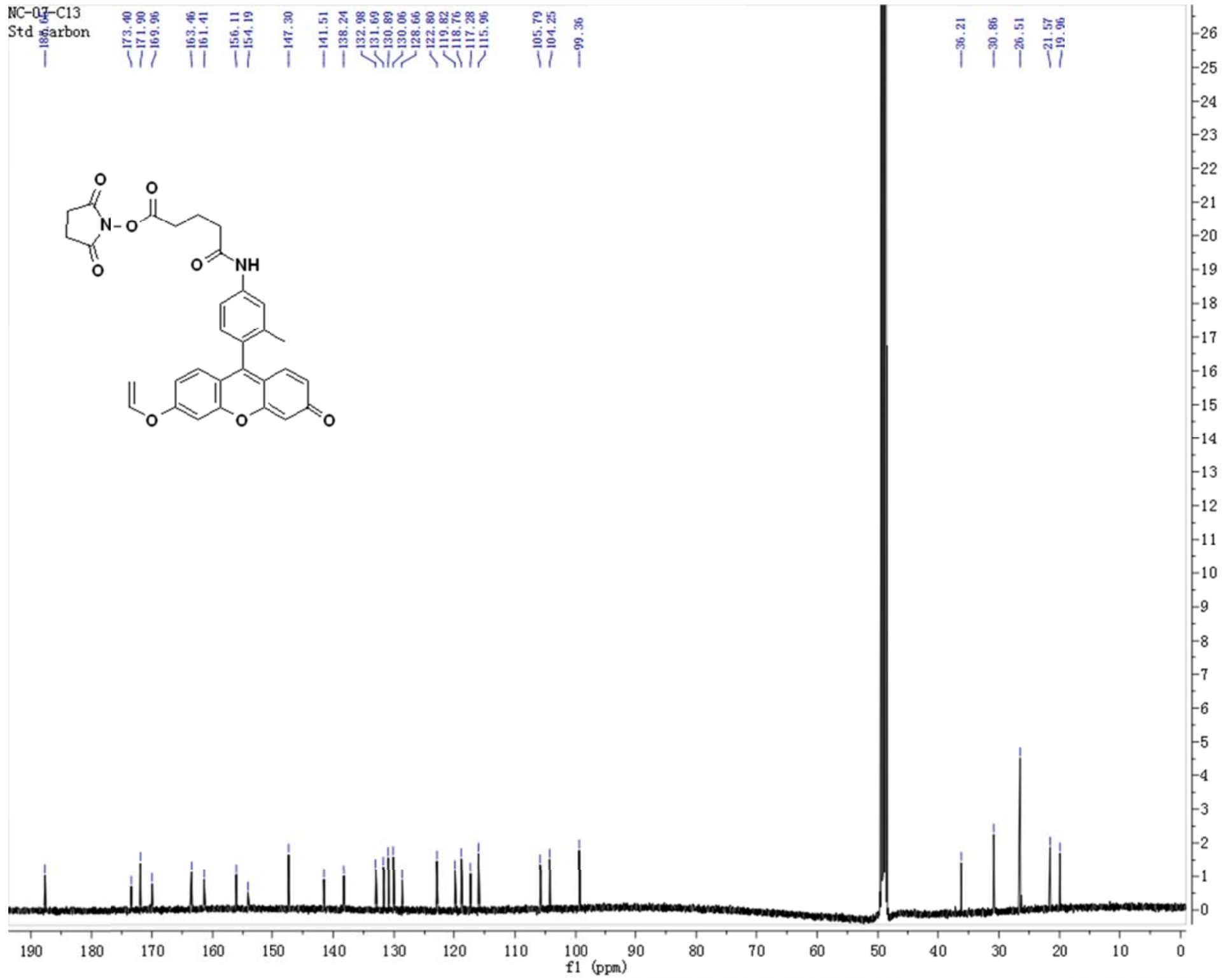




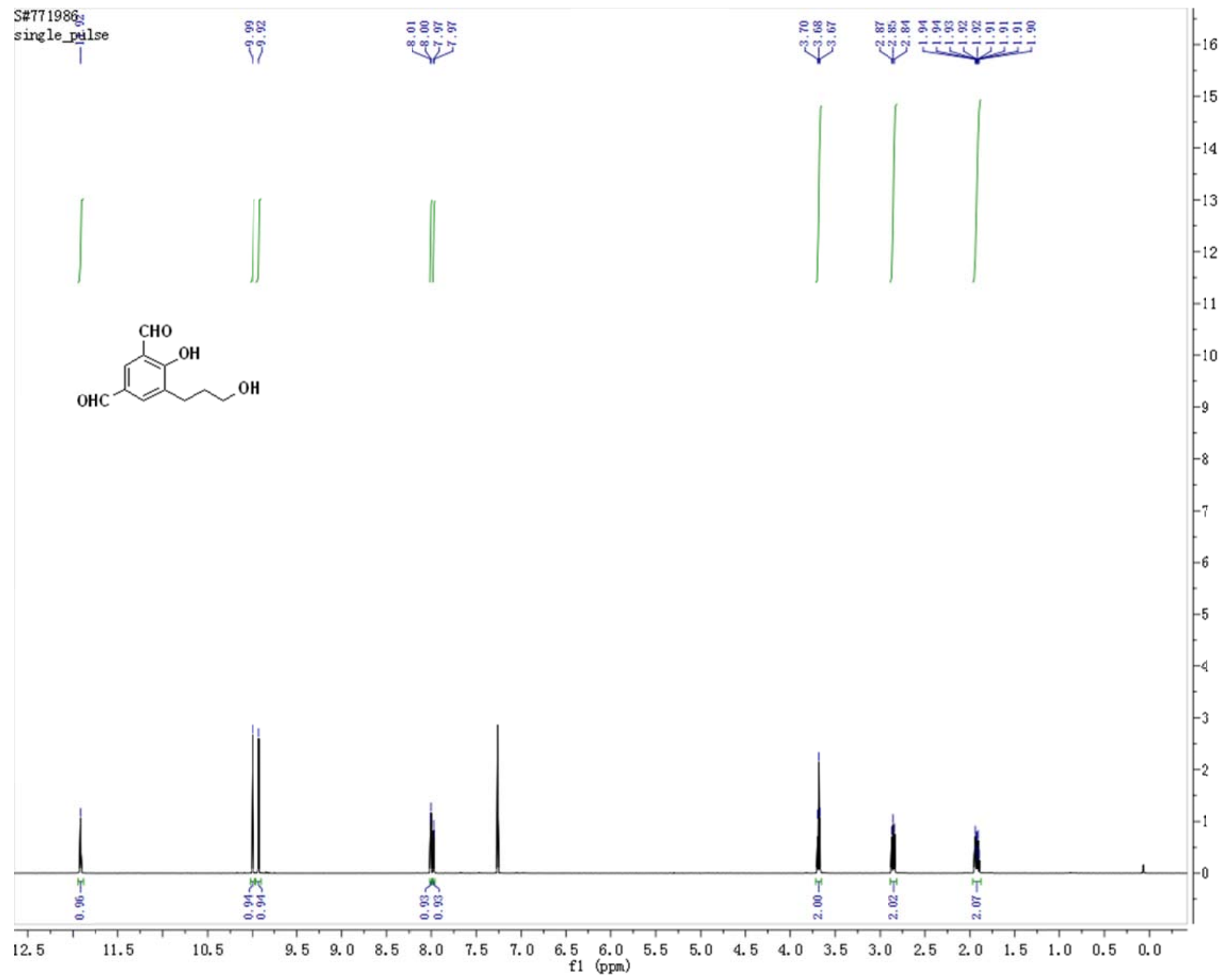




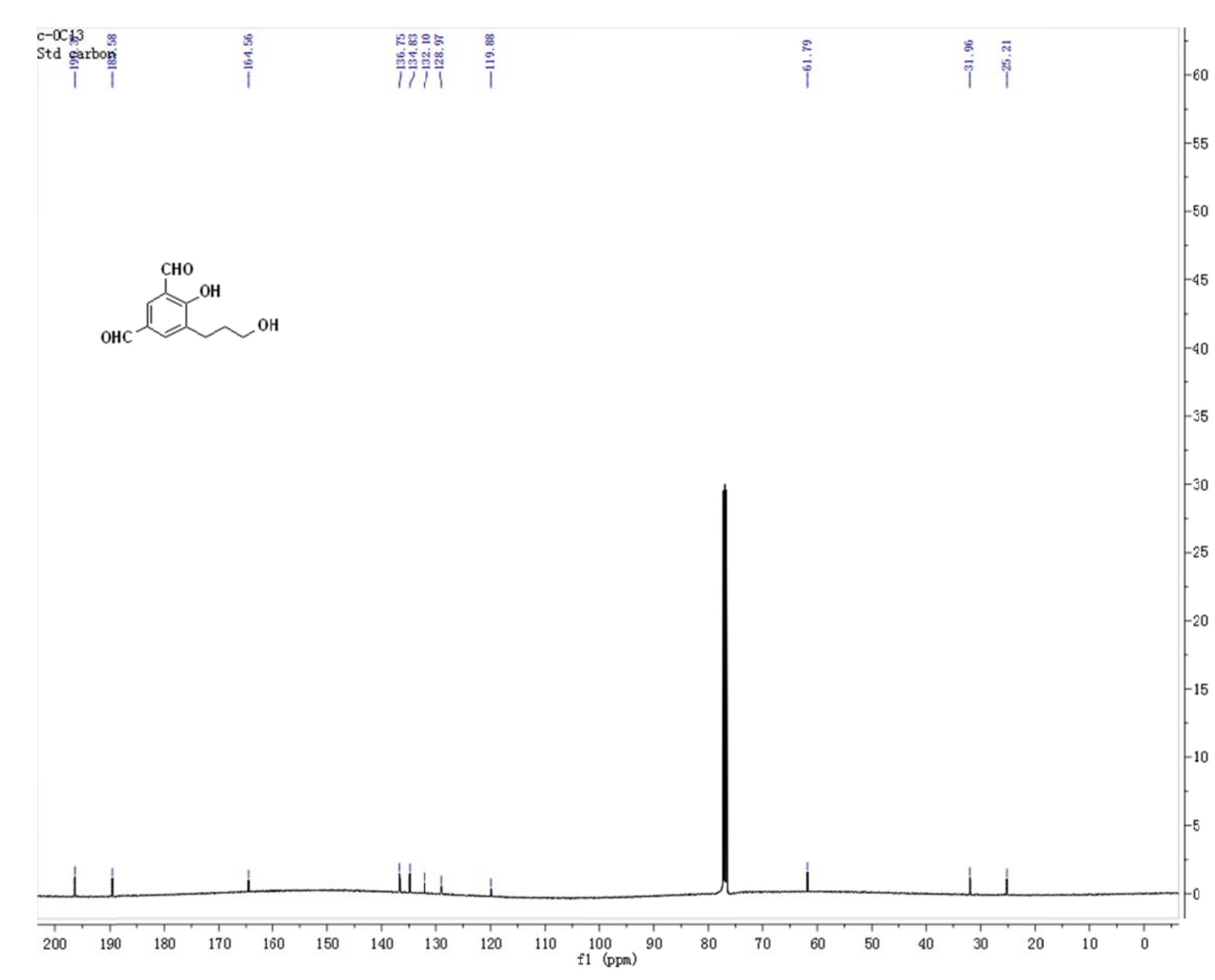




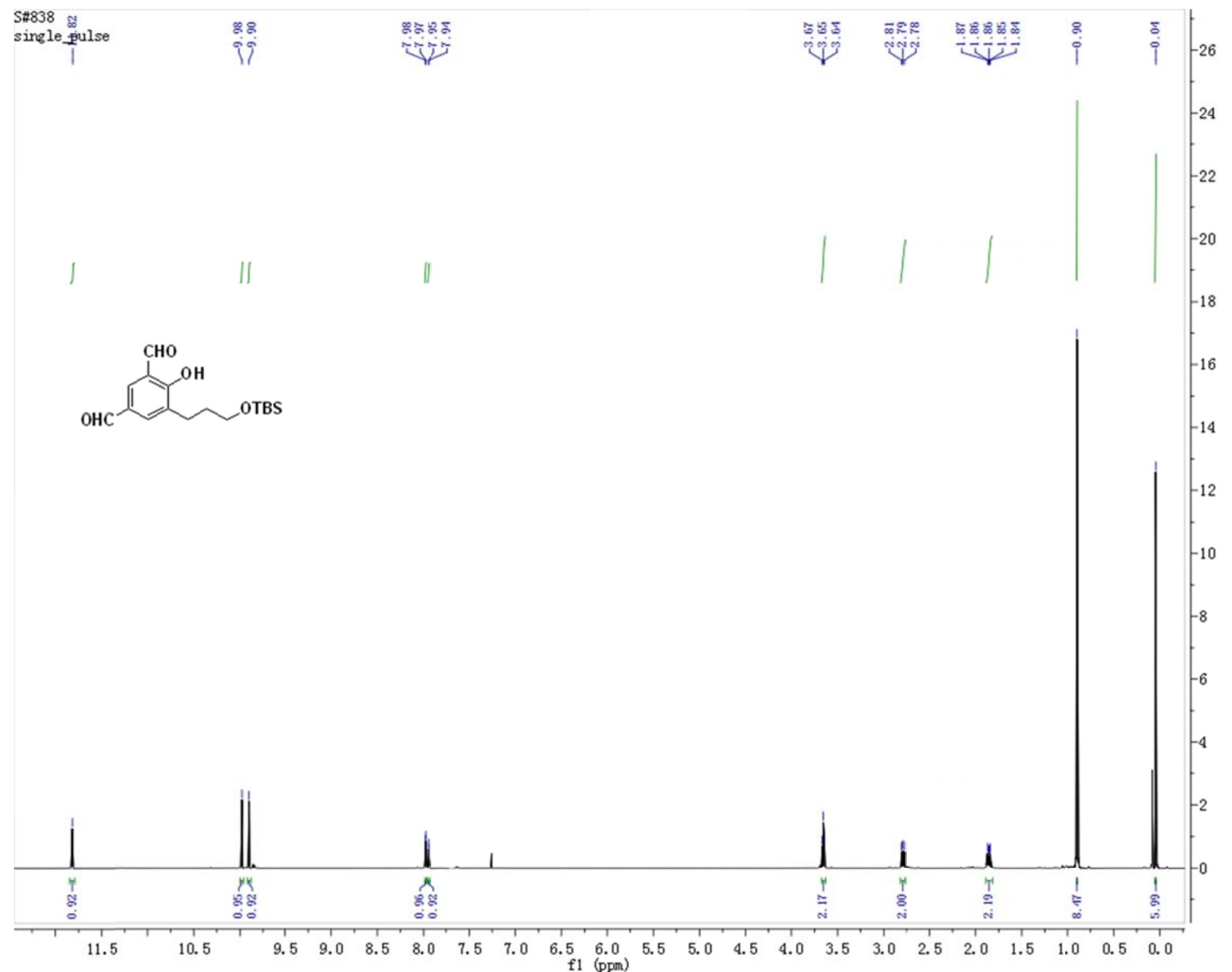




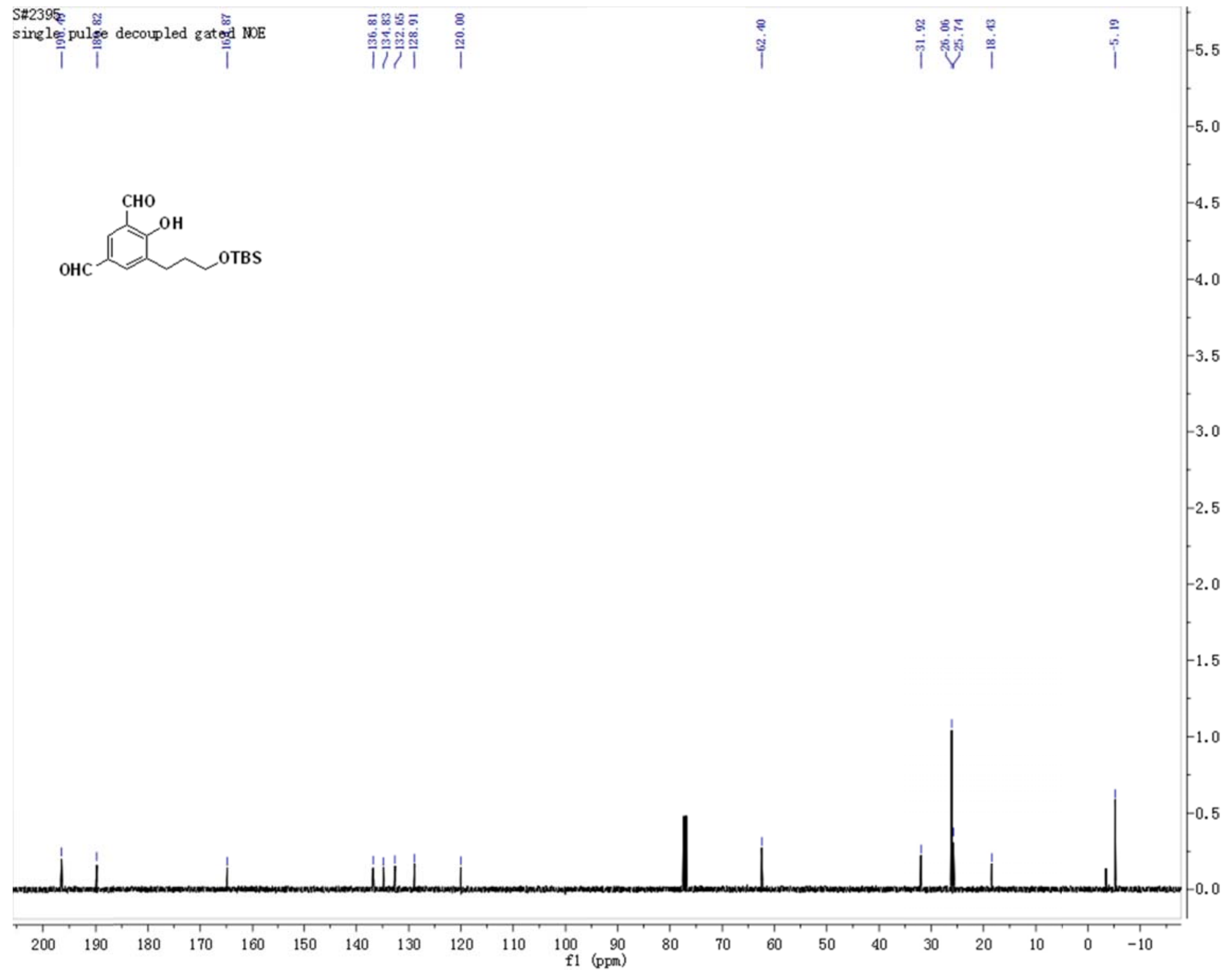




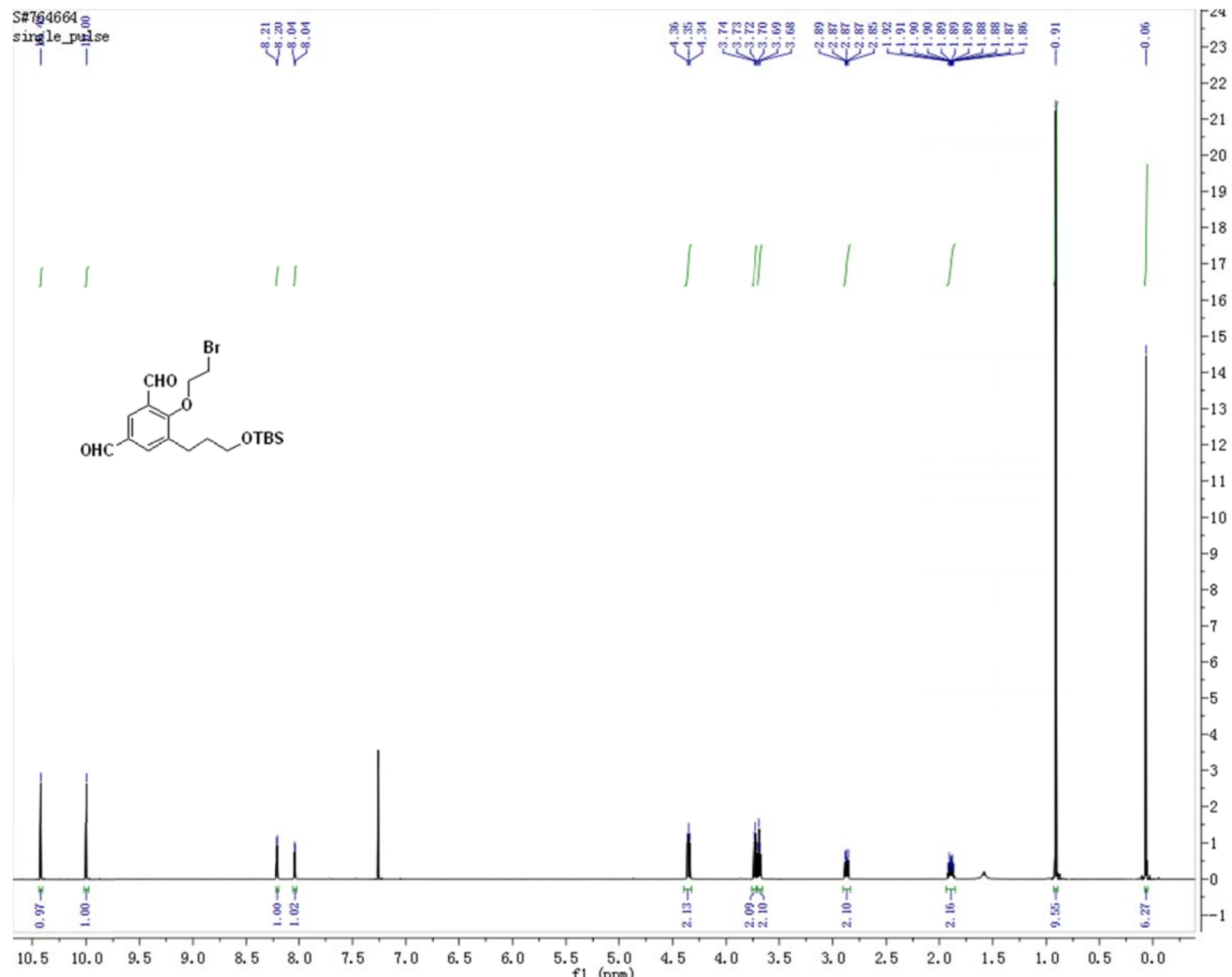




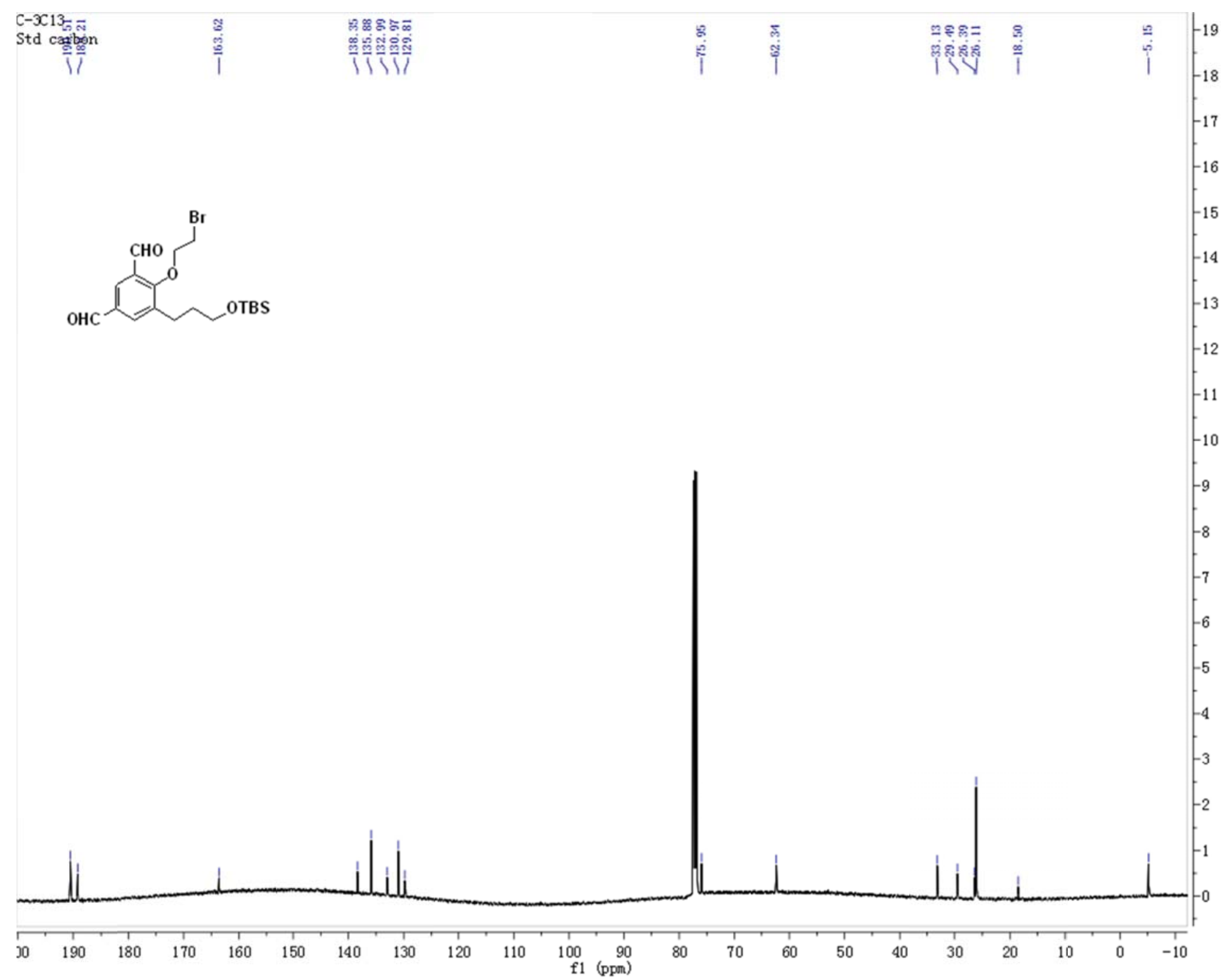




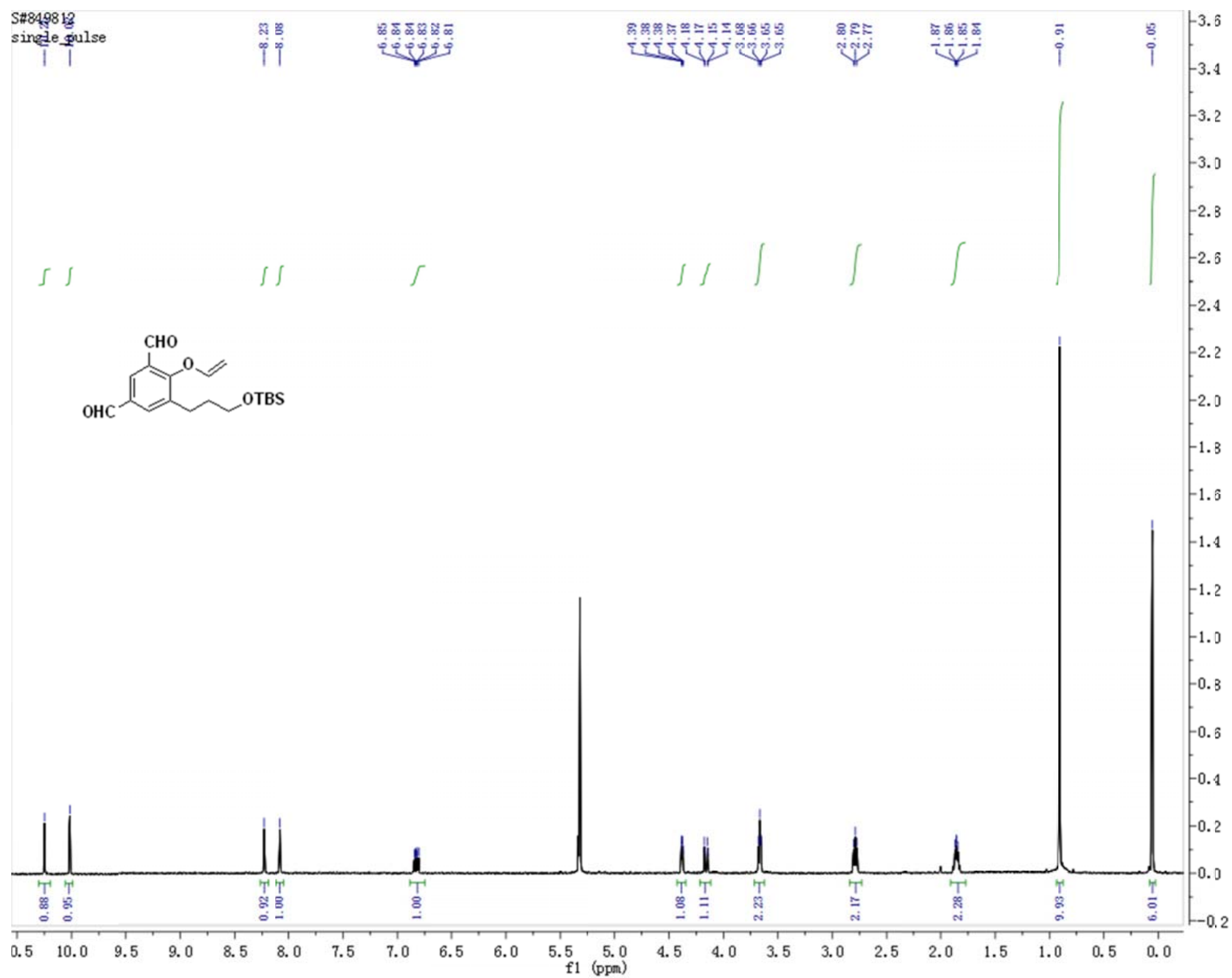




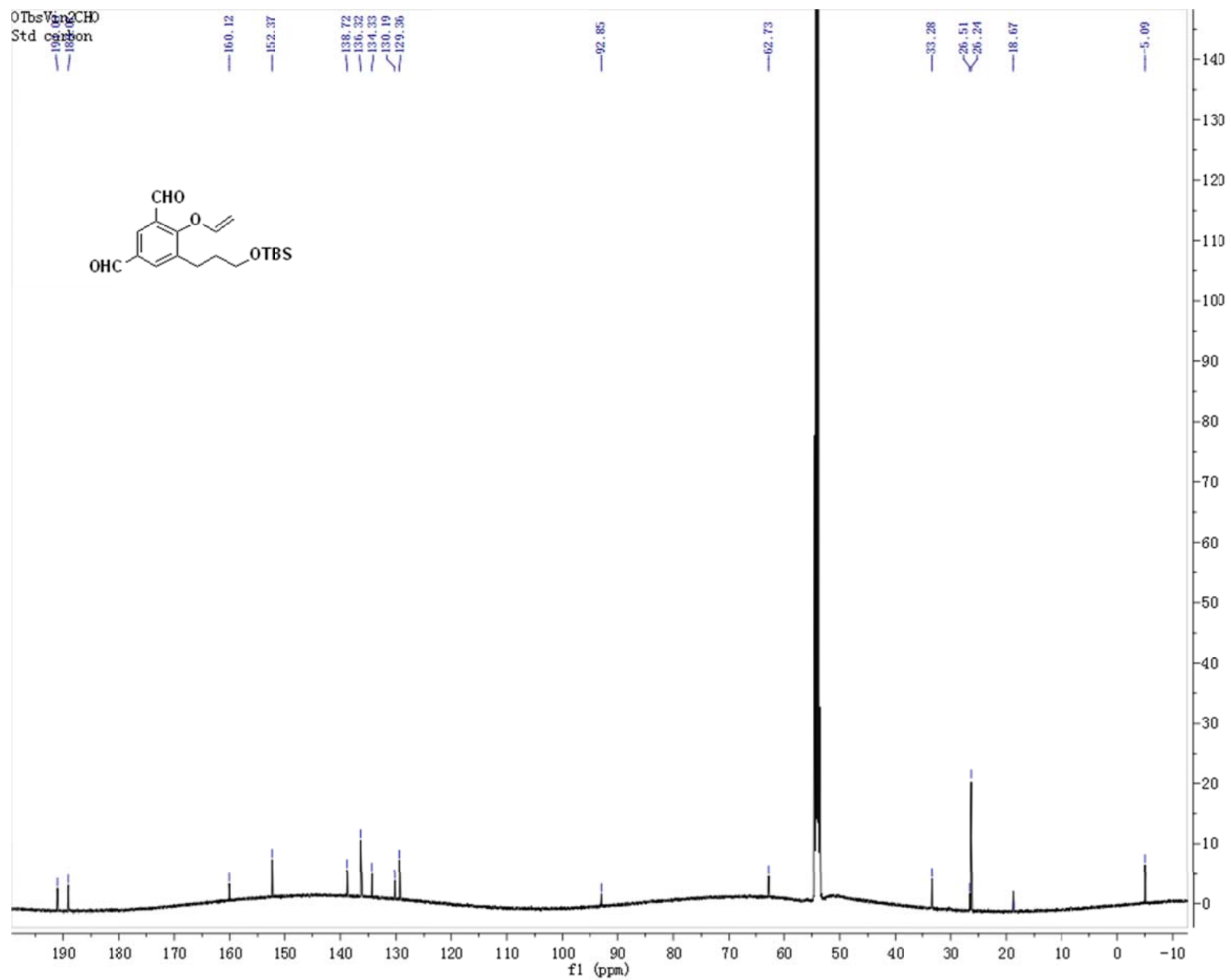




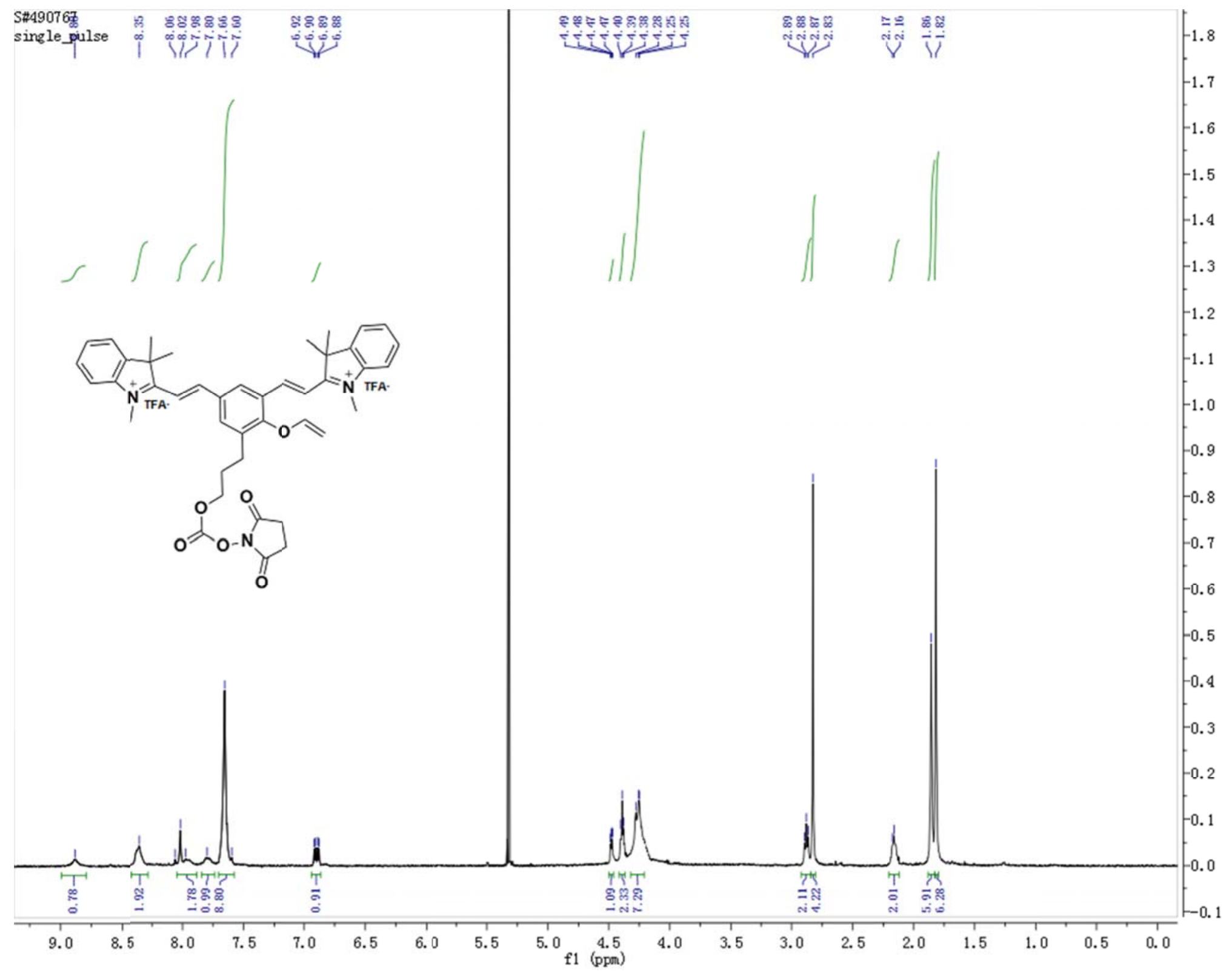




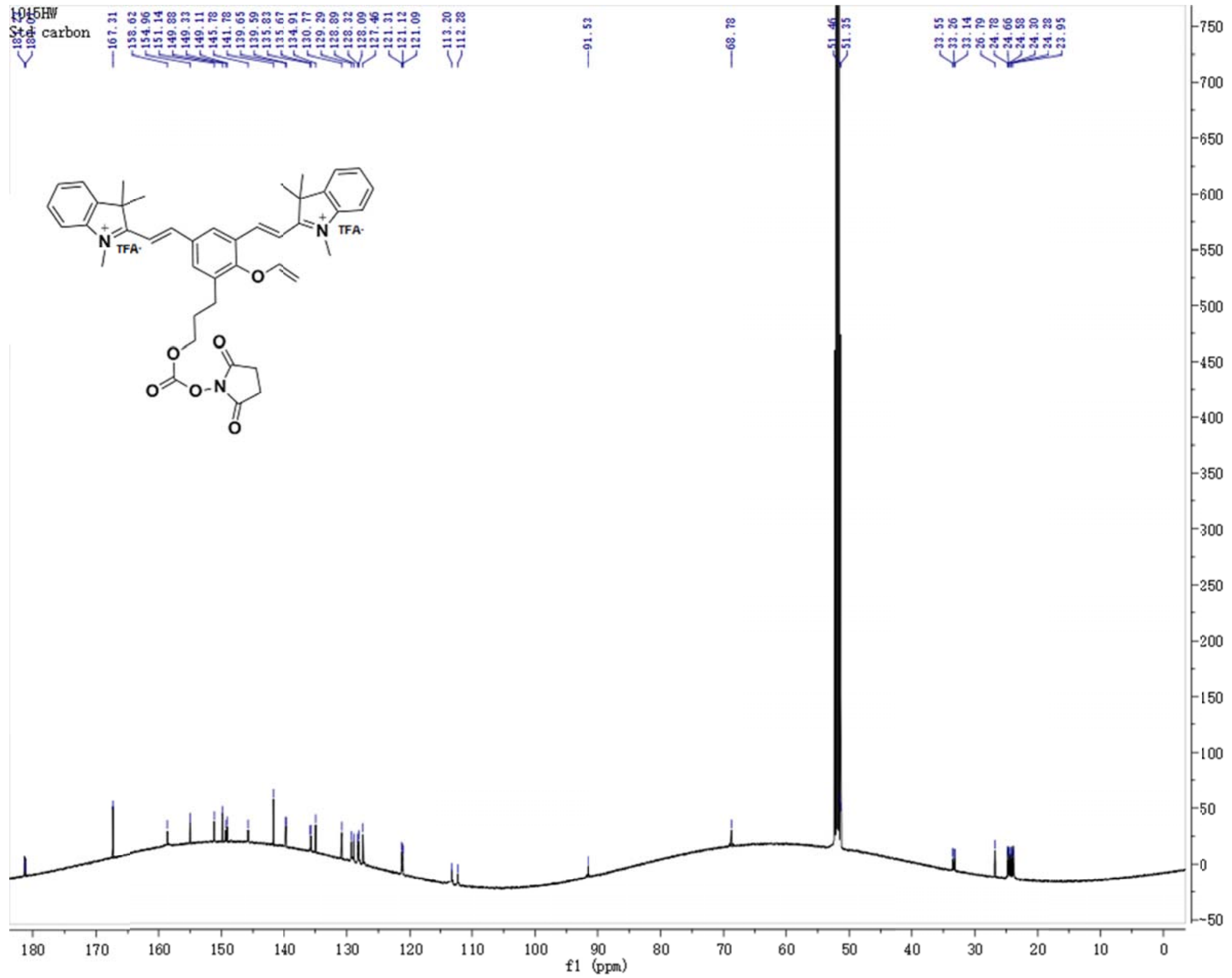

